University of Rhode Island

DigitalCommons@URI

Open Access Dissertations

1977

\title{
An Investigation of a Simulated Spatial Technique as a Measure of Interpersonal Distancing Behavior
}

Max C. Alovisetti

University of Rhode Island

Follow this and additional works at: https://digitalcommons.uri.edu/oa_diss

\section{Recommended Citation}

Alovisetti, Max C., "An Investigation of a Simulated Spatial Technique as a Measure of Interpersonal Distancing Behavior" (1977). Open Access Dissertations. Paper 640.

https://digitalcommons.uri.edu/oa_diss/640

This Dissertation is brought to you for free and open access by DigitalCommons@URI. It has been accepted for inclusion in Open Access Dissertations by an authorized administrator of DigitalCommons@URI. For more information, please contact digitalcommons-group@uri.edu. 


\section{AN INVESTIGA.TION OF A SIMULATED \\ SPATIA.L TECHNIQUE A.S A \\ MEASURE OF INTERPERSONAL \\ DISTANCING BEHAVIOR}

BY

MAX C. ALOVISETTI

A DISSERTATION SUBMITTED IN PARTIAI FULFILINENT OF THE REQUIRENENTS FOR THE DEGREE OF DOCTOR OF PHILOSOPHY

IN

PSYCHOLOGY

UNIVERSITY OF RHODE ISIAND

1.977 


\section{DOCTOR OF PHILOSOPHY DISSERTATION \\ OF}

MAX C. ALOVISETTI

Approved :

Dissertation Committee

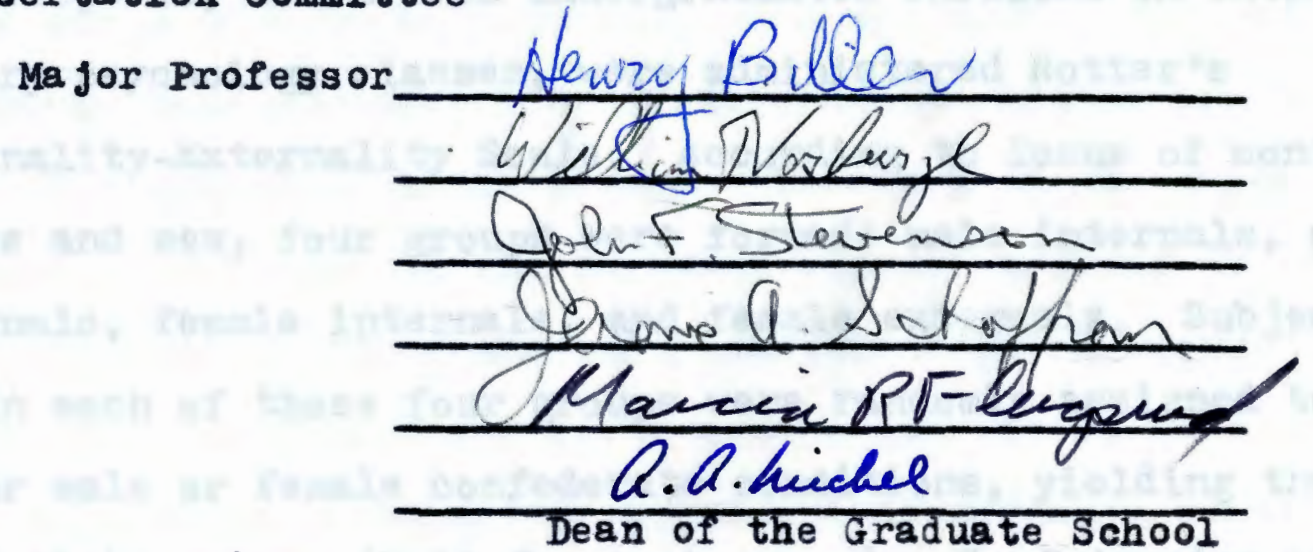

UNIVERSITY OF RHODE ISLAND

1977 


\section{ABSTRACT}

Due to ease of administration, many studies in the area of interpersonal distancing behavior have used simulated spatial measurement techniques. These have generally included manipulations of inanimate representations of people. They have often been assumed to be equivalent to behavioral measures of interpersonal distancing. The present investigation's major objectives were to determine the following:

(1) extent to which a simulated spatial measure of interpersonal distancing is related to actual behavior; (2) whether interpersonal distancing can be understood in terms of a social learning model; (3) whether personality variables are related to a simulated spatial measure of interpersonal distancing; and (4) effects of sex differences and body orientation on interpersonal distancing.

Subjects, drawn from undergraduates enrolled in introductory psychology classes, were administered Rotter's Internality-Externality Scale. According to locus of control scores and sex, four groups were formed male internals, male externals, female internals, and female externals. Subjects within each of those four groups were randomly assigned to either male or female confederate conditions, yielding the final eight groups ( $N=10$ for each group). Confederates were chosen so as to match as closely as possible the age and general appearance of the subject pool. All subjects were administered the Personal Research Form and were individually given two 
experimental tasks: (1) the simulated spatial measure in which they were asked to place pairs of felt figures onto a board; (2) the behavioral measures in which unobtrusive measurements were taken of the distance they placed themselves from confederates at side and frontal body orientations. For subjects given same sex felt figures, on the simulated spatial measure, confederates in the behavioral measures were also of the same sex as the subjects. For subjects given mixed sex felt figures, the confederates were of the opposite sex.

The results indicated that there is no significant relationship between the simulated and behavioral measures of interpersonal distancing. The findings also provide only partial support for the view that interpersonal distancing may be understood in terms of a social learning model. On the behavioral measure, subjects with an internal locus of control reflected needs related to a desire for interpersonal closeness, while subjects with an external locus of control did not. Internals demonstrated closer interpersonal distancing on the simulated measure than externals. However, on the behavioral measure, internals did not maintain closer distance to others than externals. There was only limited evidence supporting the hypothesis that subjects' responses on the simulated measure were related to personality variables. Distancing at the frontal-body orientation was significantly closer on both the simulated and behavioral measures than for the side-body orientation. On both the simulated and behavioral measures 
there were no statistically significant differences in interpersonal distancing between male and female subjects nor between male and female confederates. Mixed sex felt-figure pairs were placed closer together than same sex pairs. However, there was no significant interaction of sex of subject by sex of confederate on the behavioral measure. Future research and applied implications are discussed. 


\section{ACKNOW LEDGENENTS}

I would like to express sincere appreciation to each member of my dissertation committee: Dr. Henry Biller, Hajor Professor, Dr. William Vosburgh, Dr. John Stevenson, Dr. Jerome Schaffran, and Dr. Marcia Flugsrud. Their support and guidance were invaluable throughout the preparation of this research. Special thanks go to Dr. Joseph weaver who provided the initial inspiration for this research and to Dr. Vosburgh for the support, advice and friendship he provided throughout my graduate career. In addition, thanks are expressed to Dr. Peter Nerenda and Dr. Wayne Velicer for their valuable assistance with the design and statistical analysis.

The friendship and support of my fellow students were of immeasureable importance. My special thanks go to Liza, Ann, Dolf, Tom and Alan for their caring and encouragement during many difficult times.

Lastly, without the unswerving support and love of Nary and my parents this work would not have been possible. It is to them that this work is dedicated. 


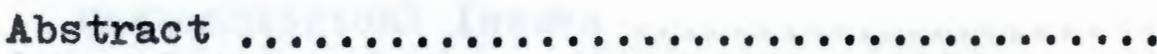
Acknowledgements List of Tables

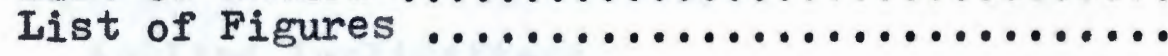

$\ldots \ldots \ldots \ldots \ldots \ldots \ldots \ldots$

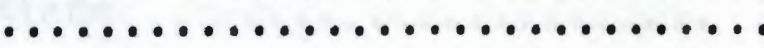

Literature Review

Relationship Between Simulated and Behavioral Measures

Theoretical Aspects of Interpersonal ... Distancing

Personality Correlates .............. Sex Differences ...................

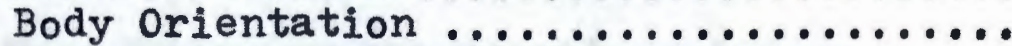
Derivation of Hypotheses ............ Hypotheses and Predictions

II METHOD

Subjects

Confederates

Personality Measures

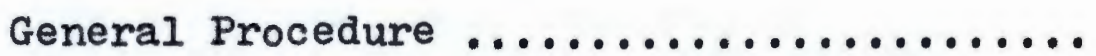

Measures of Interpersonal Distancing ......

Post-Experimental Questionnaire .........

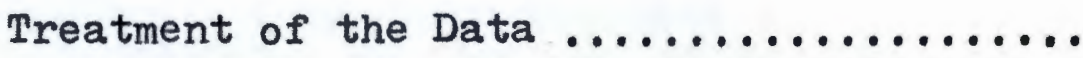

Intercorrelations Among All Variables .....

Simulated Interpersonal Distance Scores ...

Behavioral Interpersonal Distance Scores ..

Overall Implications, Problems and Limitations 
Chapter

Page

Methodological Issues ............

Future Directions ................

Applied Implications ..............

Bibliography $\ldots \ldots \ldots \ldots \ldots \ldots \ldots \ldots \ldots \ldots$

Appendices

A. Tables ......................

B. Raw Data

C. Subject Biographical Data Sheet

D. Post-Experimental Questionnaire

E. Word List $\ldots \ldots \ldots \ldots \ldots \ldots \ldots \ldots$ 


\section{LIST OF TABLES}

Table

Page

1 Mean Age in Months, Standard Deviations ....... Groups

Means and Standard of Confederates

Deviations of Rating
on Five Attributes by

Two Raters

Intercorrelations Among Measures of

Interpersonal Distancing, Personality

Variables and Subjects 'Ratings of

Confederate Characteristics For All

Subjects $(N=80)$

4

Intercorrelations Among Measures of .

Interpersonal Distancing, Personality

Variables and Subjects' Ratings of

Confederate Characteristics For Male

Subjects $(N=40)$

Intercorrelations Among Measures of Interpersonal Distancing. Personality

Variables and Subjects' Ratings of

Confederate Characteristics For Female

Subjects $(N=40)$

Intercorrelations Among Measures of

Interpersonal Distancing. Personality

Variables and Subjects' Ratings of

Confederate Characteristics For

External Subjects $(\mathrm{N}=40)$

Intercorrelations Among Measures of

Interpersonal Distancing, Personality

Variables and Subjects ' Ratings of

Confederate Characteristics For

Internal Subjects $(\mathrm{N}=40)$

Summary Table of Analysis of Variance of Simulated Spatial Measure 
Table

Page

11 Intercorrelations Among the 29 Variables ..... 97 For All Subjects $(\mathrm{N}=80)$

12 Intercorrelations Among the 29 Variables ..... 100 For Male Subjects $(\mathrm{N}=40)$

13 Intercorrelations Among the 29 Variables .... 103 For Female Subjects $(\mathrm{N}=40)$

14 Intercorrelations Among the 28 Variables ..... 106 For Internal Subjects $(N=40)$

15 Intercorrelations Among the 28 Variables .... 109 For External Subjects $(\mathrm{N}=40)$ 
Figure

$\underline{\text { Page }}$

1 Felt Figures

2 Schematic Representation of Treatment Conditions

3 Interaction of Sex of Subject by Sex

71 of Confederate at Each Level of Body Orientation and Locus of Control

4 Interaction of Locus of Control by Sex of Confederate at Each Level of Body Orientation and Sex of Subject 


\section{Chapter 1}

\section{INTRODUCTION}

While there appears to be an increasing interest in people's interpersonal distancing behavior, its determinants, correlates and measurement, much of the data in this area remains inconsistent and ambiguous. Lett, Clark and Altman (1969) reviewed the major findings in this area and found that "very few relationships are well established" (p. 4). One major factor contributing to the inconsistent findings in this area, according to Evans and Howard (1973), is the absence of an accurate, reliable measure. While actual behavioral measures would seem to be most desirable, the attendant difficulties of an in-vivo technique has led to the development of various simulated measures which are easily administered and facilitate data collection. Many of these simulated measures, involving manipulations of inanimate representations of people, are variants of Kuethe's (1962a) felt-figure placement technique. Kuethes investigations in the area of interpersonal distancing had led him to hypothesize that people possess social schemas which can be assessed by his felt-figure technique. "When a person indicates that two objects belong together he has employed some schema or plan. If these objects are people or people symbols, the schema employed may be considered, by definition, a social schema" (Kuethe, 1962a, p. 31). 
In Kuethe's measurement technique, subjects are asked to place sets of felt figures on a felt board anywhere they wish. Kuethe found that subjects made organized responses by grouping certain sets of figures. For example, subjects consistently grouped human figures together to a greater extent than non-human figures; men grouped male and female felt-figure pairs to a greater extent than two female figures. There was also a significant tendency to place a child figure closer to a female than a male figure. From the consistent grouping found, Kuethe concluded that there are common social schemas (e.g. people belonging together). He believes that responses differing from these common social schemas are indicative of "disturbances in normal social thinking" (, 38$)$.

Various investigators have used the felt-figure technique and variants of it as a measure of psychological distance, which has generally been defined as the desire for or perception of interpersonal closeness (e.g. Weinstein, 1965; Fischer, 1967; Tolor \& Orange, 1969). To a more limited extent, this measurement technique has also been used as a measure of interpersonal distancing behavior, with the assumption of it being equivalent to actual interpersonal distancing (e.g. Iittle, 1965, Meisel \& Guardo, 1969; Pedersen, 1973c). The commonly used term of personal space was first suggested by Sommer (1959) for the phenomenon of interpersonal distancing. He defined personal space as "an area with invisible boundaries surrounding a person's body into which intruders may not come" (1969, p. 26). Another often used 
term is that of proxemics coined by Hall (1966) for the study of man's use of space. For the purposes of this study the generic term of interpersonal distancing behavior will be used and viewed as encompassing the more specific terms of proxemics, personal space and social schemas.

The main focus of the present investigation will includes (1) determination of the extent to which a simulated spatial technique, which is essentially a refinement of Kuethe's measure, is directly comparable to actual interpersonal distancing behavior; (2) determination of whether interpersonal distancing behavior can be understood in terms of a social learning model; (3) determination of whether personality variables are related to a simulated spatial measure of interpersonal distancing; and (4) an examination of sex differences and effects of body orientation in interpersonal distancing.

\section{Literature Review}

Relationship Between Simulated and Behavioral Measures

Research involving interpersonal distancing behavior has tended to treat the variety of measurement techniques used as being equivalent. Yet the evidence as to their comparability remains equirocal. Most of the simulated measures are variants of Kuethe's (1962a) techniques for assessing social schemas. It essentially involves manipulating distance between inanimate representations of human figures. Several investigations have provided at least indirect evidence that 
simulated measurement techniques and "real life" behavior are in some manner related. Kuethe and Weingartner (1964) report that homosexual males when asked to place male and female figures on a felt field often did not show the normal schemata of man-woman pairings. Homosexual males also tended to place two male figures closer together than man-woman figure pairs. Guardo (1969) had sixth-grade boys and girls trace a cutout silhouette figure, representing themselves in relation to pre-printed figures in a booklet. These preprinted figures were described by the experimenter as having various kinds of relationships to the children (e.g. friend, acquaintance, stranger, liked very much, etc.). The figures were scaled 1-inch to the foot. When the distances between the traced and pre-printed figures were converted according to the scale, the distances were found to a large extent to be comparable to Hall's (1964) distance zones which are based on observations of natural interactions.

Kleck, Buck, Coller, London, Pfeiffer and Vukcevic (1968) explored the distance male college students placed between figures representing various categories of stigmatized persons (e.g. ex-mental patient, epileptic, amputee, etc.) and a figure representing themselves. The figure representing "self" was found to be placed significantly further from figures represented as stigmatized than from figures described positively (good friend and liked professor). To determine whether behavior in the figure placement task reflected distancing behavior in an actual interaction, Kleck et. al (1968) 
completed a second experiment. Actual distance subject maintained between himself and an experimenter who had previously been described as epileptic was recorded. Results were similar to that reported on the figure placement task. Subjects maintained greater distance from the experimenter described as having epilepsy than to the "normal" experimenter. Levinger and Gunnar (1967) have reported that students who closely paired figural representations of themselves and that of a professor tended to sit in front of the classroom while those who placed greater distance between the representations tended to sit to the rear of the classroom. Tolor (1975) found that the distances subjects place between "self" symbols and symbols representing such social stimuli as policemen, boss, mother, friend, etc. were reported by the subjects as corresponding to their actual behavior. Thus, in this study the subjects' use of representational space was at least perceived by them as being equivalent to actual behavior.

There have been a series of studies which have more directly compared the relationship between simulated and actual measures of interpersonal distancing. Unfortunately, the results are far from conclusive due to differences in experimental conditions and measures used. In a study with college students, Little (1965) found a very high correlation ( $\underline{r}=.77)$ between the students placement of photographs of male and female silhouettes in various settings, and their placement of actresses recreating scenes from the silhouette task. This 
is the highest reported correlation in the literature between a simulated and behavioral measure of interpersonal distancing. However, this appears to be an artifact of the measures used in the study. The behavioral measure is so similar to Little's simulated/projective measure that the subjects may have in essence been performing the same task. The only difference between the two tasks seems to be the use of live actresses instead of silhouettes.

Gottheil, Corey, and Paredes (1968) photographed through a two-way mirror a seated subject and experimenter. The subject's physical distance (nose to nose) from the experimenter was measured from the photographs. Subjects were asked to place cylindrical magnets representing "father", "mother", "best male friend", "God", and "interviewer" in relation to a magnet representing "self" according to how close the subject felt towards them. The physical distance from the experimenter and the distance between the "self" and "experimenter" magnet were moderately correlated.

Haase and Markey (1973) investigated the relationship between four measures of interpersonal distancing. Each subject was administered four measures in a single testing session. The measures were as follows: (1) Photographed observations. Each subject observed five slides of a male and female at different seated distances. Subjects rank ordered their preferred interaction distances. (2) Live observation. Each subject observed a male and female actor at different standing distances from each other. Subjects 
again rank ordered their preferred interaction distances. (3) In vivo participation. Subjects were asked to approach the experimenter from a distance of 15 feet until they were at a distance comfortable for a conversation. (4) Felt board placement. Subjects placed a same sex felt figure on a felt board in relation to an opposite sex figure already on the board. They were instructed to place the same sex figure as if a conversation was to be carried on with the other figure. The in vivo measurement was viewed as the behavioral criterion measure. The live observation, felt board placement, photograph observation were all found to be moderately correlated with the criterion measure.

Pedersen (1973b) used a simulated measure in which subjects were instructed to place a profile representing another person "as close as is comfortable for you in most situations" to a profile representing "self." The profiles were drawn facing left, front, right, and one with a top view. Two behavioral measures were taken. The awareness measure involved subject approaching, being approached and both subject and experimenter approaching each other as close as possible without feeling uncomfortable. In the "unawareness" behavioral measure subjects were asked to bring two chairs to the center of a room facing each other and to be seated. Measurement was taken of the distance from the front of one chair to the other. In the situation where the simulated task orientation was most similar to the awareness behavioral measure, the measures were moderately correlated. The simulated measure 
was not predictive of the "unawareness" behavioral measure. In contrast to the above findings, Dosey and Meisels (1969) and Love and Aiello (1976) found no significant relationship between simulated and behavioral measures. Dosey and Meisels (1969) compared three measures of personal space in an investigation exploring the effect of stress on personal space. The measure included: (1) distance subject maintained from another subject when asked to approach him or her; (2) distance subject placed a silhouette, representing himself, in relation to a printed silhouette of the opposite sex; (3) choice of either a near or far seat from the experimenter. The intercorrelations among these three measures were very light, and it was concluded that there was little consistency in these measures. However, it should be noted that the simulated task measured personal space of the sides while the behavioral measure, where a subject approached another, measured frontal personal space. It may be that the simulated and behavioral measures were not related since they were measuring personal space at different body orientations.

Love and Aiello (1976) examined the relationship between three projective distance measures (approach distance, doll placement, felt figure placement) and observed interaction distance. Female undergraduates serving as subjects were first told that this study was investigating the process of conversations. Two unacquainted subjects at a time were then asked to converse about recent films. While they were con- 
versing the observer recorded their interaction distance and body orientation. The projective measures were subsequently administered with subjects specifically asked to replicate their interpersonal distancing behavior during the conversation task. None of the projective measures were found to be significantly related to actual observed distancing behavior. There is some evidence to indicate that there are sex differences in the extent to which simulated and behavioral measures are related. Pedersen (1973a) related the dimension of sensation seeking to simulated and behavioral measures of personal space. The behavioral measure consisted of having an unfamiliar person approach the subject until the subject indicated that he would begin to feel uncomfortable if the person approached any closer. For females, the Disinhibition subscale, which consisted of items that expressed a hedonistic playboy philosophy, significantly correlated with personal space on a simulated measure but did not relate to the females' behavioral personal space. Males with a playboy philosophy did not consistently differentiate their placements on either the simulated or behavioral measure. The Boredom Susceptibility subscale did correlate significantly with the simulated measure for males but not for females. For females there was no significant relationship between the overall simulated measure score and the behavioral measure. However, when personal space was measured sideways for females, the simulated and behavioral measures were significantly related. The simulated frontal personal space of males was not significantly related to 
behavioral frontal space. But for males the overall average scores on the simulated and behavioral measures were significantly related.

Tolor and LeBlanc (1974) related Kuethe's felt-figure technique with several measures of expressed desire for interpersonal association (A Desire for Psychological Distance Scale and the Autonomy, Affiliation and Nurturance scales from the Edwards Personal Preference Scales) and several behavioral measures of interpersonal distancing. The behavioral measures included seating distance (choice of one of four chairs which were at varying distances from a female experimenter) and approach distance (subjects instructed to approach male experimenter to point where most comfortable). The investigators reported that for male subjects, Kuethe's free placement of felt figures was significantly related to approach distance and first trial free placement significantly related to chair selection. Although these correlations were quite low, the investigators concluded that for males "free placement performance corresponds roughly to the actual movement through space in an interpersonal context." For females, on the other hand, free placements significantly correlated with Desire for Psychological Distance and need for autonomy. Thus, it was stated that for females Kuethe's free placement technique was a poor predictor of actual social behavior but did reflect "need for social involvement." Tolor and LeBlanc also reported intercorrelations with Kuethe's reconstruction technique, where subjects were asked to reconstruct a placement 
of two figures, $20.29 \mathrm{~cm}$ apart, that had been viewed for five seconds. They concluded that for males reconstruction reflects social needs, while for females it reflects actual social behavior. However, the reported test-retest correlations for the reconstruction technique was an extremely low .13 making such conclusions unwarranted. Obviously their conclusions regarding the meaning of free placements are also highly suspect because of the low, though significant correlations they report.

Theoretical Aspects of Interpersonal Distancing

Lett, Clark and Altman (1969) have observed thats

Unique propositions seem to proliferate in a topsy-like fashion with individual investigations using wildly disparate methods, subjects and settings and generally new isolated facts which are not replicated or tested for generality... Most of the findings appear to be atheoretical and of the single "I wonder what will happen" variety (p. 37).

While it is true that the vast majority of studies have been lacking any theoretical basis to their investigations, there have been some limited attempts to provide a conceptual framework to this general area. The two major theoretical approaches are Argyle and Dean's (1965) affiliative conflict theory and a social learning model as set forth by Duke and Nowicki (1972).

Argyle and Dean's Affiliative-Conflict Theory, Argyle and Dean (1965) investigated the determinants of eye-contact in social interactions. They proposed an affiliative-conflict theory of eye contact. Their theory is of relevance to the 
area of interpersonal distancing since they proposed that the determinants of physical closeness between two people are similar to those of eye contact. They postulate that there are both approach and avoidance forces behind eye contact. Approach forces include the necessity for feedback and affiliative needs. Avoidance forces include fear of revealing inner states, being seen and of seeing the rejecting responses of others. If there are approach and avoidance forces, then Argyle and Dean believe that Miller's (1944) conflict theory would be applicable in this area. From Miller's analysis, it would be expected that there should be an equilibrium level of eye contact for people coming into contact with another person. If eye contact rises above the equilibrium point, it will be anxiety arousing. other behaviors, such as physical closeness, amount of smiling, intimacy of conversation, etc.. also have an equilibrium point. As the frequency of these behaviors increases, affiliation needs are also increasingly satisfied. However, after a certain point an increase in these behaviors results in anxiety. They suggest that an equilibrium develops for "Intimacy" which is a joint function of eye-contact, physical proximity, intimacy of topic, amount of smiling, etc. They deduced that if one of the aspects of intimacy changes, then in order to maintain the equilibrium point, one or more of the other components will move in the reverse direction. If this is not possible and equilibrium cannot be restored, then avoidance forces will predominate in the situation of too much 
intimacy, in the situation of not enough intimacy, a person will feel a lack of affiliative satisfaction.

From this theoretical formulation Argyle and Dean derived 12 empirical deductions. They cite Exline's (1963) study as confirming one of these deductions. Exline found that eye contact increased when the intimacy level of a conversation decreased. Argyle and Dean (1965) also reported results that support their deduction that interpersonal distance between individuals will be greater with eye contact than without and that with less interpersonal distance, eye contact will decrease.

Goldberg, Kiesler and Collins (1969) attempted to replicate Argyle and Dean's (1965) study. They reported that subjects spent less time gazing at the interviewer's eyes when seated at $21 / 2$ feet than when seated 6 feet from them. This finding supports Argyle and Dean's theory. However, Goldberg et. al (1969) also state that their finding can only be viewed as a demonstration that interaction distance influences behavior.

It is not a test of any theoretical interpretation of the data and it does not enable one to sort among various theoretical ideas which could account for the data in terms of underlying variables. Argyle and Dean's theory of "intimacy" "it should be noted, accounts for these data only by redescribing them in terms of the construct of "intimacy." The theory is not a testable statement of underlying variables ( $p .52)$.

Goldberg et. al's critique appears to be well founded and when viewed with the only partial support Argyle and Dean's theory has received ( 3 out of 12 deductions from the theory have been supported by research findings), its usefulness as a major 
theoretical framework for understanding interpersonal distancing remains questionable.

Social Learning Model, Duke and Nowicki (1972) have interpreted interpersonal distancing within a social learning framework as developed by Rotter (Rotter, 1954; Rotter, Chance \& Phares, 1972). While their arguments in support of their position are impressive, the lack of empirical supporting evidence, as will be subsequently detailed, is a major problem with their presentation. Their stated reasons for the choice of social learning theory include: (1) Social behavior is learned and follows rules; (2) Studies have indicated that locus of control, which is a major facet of social-learning theory, mediates interpersonal distance (Tolor, Brannigan \& Murphy, 1970; Tolor \& Jalowiec, 1968); and (3) Interpersonal distance is a joint function of the situational context in which the behavior occurs and an individual's previous history of reinforcement in relation to others.

These factors of situational context and history of reinforcement are integral aspects of social learning theory.

There are four classes of variables in social learning theory: behaviors, expectancies, reinforcements and psychological situations. In its most basic form, the general formula for behavior is that the potential for a behavior to occur in any specific psychological situation is a function of the expectancy that the behavior will lead to a particular reinforcement in that situation and the value of that reinforcement (Rotter, 1975, p. 57).

Expectancies are determined by reinforcement histories. Positive reinforcements in a situation would strengthen the expectancy that positive reinforcements will again occur in 
that particular situation. This specific expectancy generalizes to similar situations. Therefore, expectancies in any situation are a result of specific experiences in that situation and also of experiences in other similar situations. The importance of generalized versus specific expectancy is a function of the amount of experience in a particular situation. The importance of generalized expectancy increases as situations are more novel and decreases in situations where an individual's experiences in it increases. Situations are viewed as a complex set of stimuli which elicit expectancies.

A major outgrowth of social learning theory is the measurement of generalized expectancies. This has been referred to as internal versus external control of reinforcement or locus of control. Rotter (1966) defines this concept as follows:

When a reinforcement is perceived by the subject as following some action of his own, but not being entirely contingent upon his action, then, in our culture it is typically perceived as the result of luck, chance, fate, as under the control of powerful others, or as unpredictable because of the great complexity of forces surrounding him. When the event is interpreted in this way by an individual, we have labeled this a belief in external control. If the person perceives that the event is contingent upon his own behavior or his own relatively permanent characteristics, we have termed this a belief in internal control ( $p .1)$.

From these basic assumptions Duke and Nowicki (1972) have postulated that locus of control has a mediational role in interpersonal distancing behavior. Since externals generally perceive a lack of personal control in novel situations, then they should prefer to maintain greater distance from others than internals. 
Duke and Nowicki developed several experiments designed to test a priori predictions based on social learning theory. It was predicted that in situations where a subject would interact with a stranger, generalized expectancy would determine interpersonal distance. In situations where a person interacts with someone whom specific expectancies are available, then interpersonal distance would not be mediated by locus of control orientation. Specifically, it was predicted that for strangers, internals will distance less than externals and locus of control scores would be significantly correlated with interpersonal distance; for people with whom there is actual past experience, locus of control should not differentiate nor correlate with distancing behavior. The results reported from two experiments using a simulated measure of interpersonal distance that the authors developed (Comfortable Interpersonal Distance Scale) supported all the above predictions. Duke and Nowicki (1972) had also previously reported correlations of as high as .84 between the Comfortable Interpersonal Distance Scale and actual approach distances. Thus, the findings reported on the mediating role of locus of control is viewed as reflecting a real-life relationship. However, the extraordinarily high correlation reported between the simulated measure and actual interpersonal distancing are somewhat suspect since it is so atypical and based on an unpublished manuscript.

Duke and Nowicki's citing of previous research (Tolor, Brannigan \& Murphy, 1970; Tolor and Jalowiec, 1968) as supporting 
their view is quite misleading. In Tolor, Brannigan and Murphy's (1970) study, using a simulated measure, it was in fact reported that for males there was no relationship between interpersonal distance and locus of control orientation. For females, internals placed themselves closer to a stimulus figure representing "sister" than externals. But this finding is contrary to Duke and Nowicki's hypothesis that generalized expectancy would not be a factor in determining interpersonal distance with stimuli with whom there is past experience as there obviously is with a "sister". Even more astounding is that Tolor and Jalowiec (1968) report a non-significant relationship between body boundary (personal space) and internal versus external expectancy.

other investigations using simulated measures have provided only partial support for the hypothesized role of locus of control in interpersonal distancing behavior. Brannigan and Tolor (1971) used a simulated measure consisting of seven concepts (sister, stranger, father, brother, neighbor, best friend, mother) and presented two concepts paired at a time in all possible combinations. Each pairing was printed on a single sheet of paper. The subjects were instructed to place an " $X$ " in one of five spaces between the two concepts, depending on the degree of closeness felt. For females there was a significant relationship between distance placed between self and parental distance and internality. The relationship for males approached significance. 
Duke and Mullens (1973) report that locus of control scores were significantly correlated with interpersonal distance (using a simulated measure) for a schizophrenic and non-schizophrenic patient group, but not for a normal group. Tolor (1975) reported that locus of control was not related to interpersonal distance for females. However, males placement of "self" symbols in relation to "mother" figures on a sheet of paper was significantly related to externality. Externally-oriented men placed themselves farther from "mother" than male internals.

\section{Personality Correlates}

Results from investigations relating interpersonal distance to personality variables have been ambiguous in their findings. Lett, Clark and Altman (1969) concluded that it has been well established that personality abnormality is associated with large interpersonal distancing behavior. Horowitz, Duff and Stratton (1964) and Duke and Mullens (1973) both report that schizophrenics maintain greater distance from others than do non-schizophrenic groups. Using Kuethe's social schema technique, Weinstein (1965) found that emotionally-disturbed boys placed human figures further apart than geometric figures, significantly more often than did normal boys. Fisher (1967) reported that normal boys arranged human figures more closely together than did disturbed boys. Similarly, Gerber (1973) found that disturbed boys placed dolls representing themselves and "mother" at greater distances than normal boys. 
Yet there are also studies which did not find this relationship between psychopathology and interpersonal distance. For example, Duhamel and Jarmon (1971) found no difference between emotionally-disturbed boys and their siblings in the placement of "mother" and "son" figures. Tolor (1968) and Tolor, Warren and Weinick (1971) report no difference in distance placement of figures for normal and disturbed children. Gerber and Kaswan (1971) report that youngsters with learning difficulties did not place dolls representing family members at greater distances than their "normal" siblings. Tolor (1971), in contrast to Duke and Mullens (1973) and Horowitz, Duff, and Stratton's (1964) findings, report that schizophrenics placed human figures closer together than normal adults.

Investigations of specific personality dimensions have also reported contradictory findings. Leipold (1963) found that introverted and anxious undergraduates sat further away from the experimenter than extroverted undergraduates with a lower anxiety level. Males high on the Heterosexual Scale, from the Edwards Personal Schedule, were found by Harnett, Bailey and Gibson (1970) to allow females to approach closer than males low in this scale. Bailey, Harnett and Gibson (1972) also report that the distancing of male subjects was significantly correlated with heterosexual interest; however, this occurred only under the condition of a male approaching the subjects. For females, anxiety was significantly correlated with distancing when approaching or being approached by a male. 
Frankel and Barrett (1971) report that individuals high on a scale of authoritarianism and low in self-esteem maintained the largest interpersonal distance from others. Tipton, Nailey and Obenshain (1975) found that "traditional" women placed greater distance between themselves and males than did "feminists." The investigators point out that various studies have shown "feminists" to exceed "traditional" women in autonomy, aggression, dominance and self-confidence.

In contrast to the above findings, various investigators have reported no relationship between personality variables and interpersonal distancing behavior. Dosey and Meisels (1969) related body image boundary and anxiety, as assessed by the Rorschach, to three measures of spatial behavior. The measurement techniques included two behavioral measures and a variant of Kuethe's (1962a) felt-figure placement measure. They report no significant relationship between anxiety, body image boundary and any of the measures of spatial behavior. Similar negative findings have been reported by Meisels and Canter (1970) with introversion and schizophrenic tendency. Boorem and Flowers (1972) found the relationship between a behavioral measure of personal space and self-reported anxiety to be quite low. Church (1975) reports no significant correlation between actual distancing behavior and several personality measures, including social desirability (as measured by the Marlow-Crowne) and three factors of self-esteem (evaluation concern, self-regard and interaction anxiety). 
Sex Differences

Effect of Sex of Subject. There is a substantial body of research using both simulated and behavioral measures indicating that males and females differ in their overall interpersonal distancing behavior. Lett, Clark and Altman (1969), in their review article on interpersonal distance, state that it appears "moderately well established" that females in general maintain less interpersonal distance from others than males. Yet Maccoby and Jacklin (1974) in their extensive review on sex differences state that there is no conclusive evidence which would indicate that there is a general tendency for girls to be "proximity seekers". At least in this one area of possible sex differences, Maccoby and Jacklin reviewed a very limited sample of the literature on interpersonal distancing. Sommer (1967), for example, notes that sex differences in distancing behavior have often been found. He suggests that in our culture females tolerate others at a closer distance than males. The fact is supported, according to Sommer, by the general observation of women holding hands and kissing each other, which is relatively rare among males in our culture.

One aspect of Guardo's (1969) study explored where elementary school subjects would place a cutout silhouette figure which was to represent themselves in relation to a pre-printed figure on a page. In a schoolyard setting, the experimenter described different degrees of acquaintance, liking or threat and then asked, "Where would you be standing?". 
The average age of the 60 subjects was 11 years, 7 months. Guardo reports that girls place significantly less distance between the figures in situations described as with a "best friend" and "someone you like very much." However, girls had significantly greater distance between the figures in a situation with "someone you're afraid of." These results were explained in terms of sex appropriate behavior.

Pedersen ( $1973 \mathrm{c}$ ), using a simulated measure of personal space, asked 132 children in grades one through six to place a movable profile which was to represent themselves from another profile representing another person "as close as possible so that the subjects still felt comfortable." The profiles represented a man, woman, boy and a girl. He reports that across all grade levels and stimulus persons, girls placed the profile representing themselves significantly closer to the other profile than boys did. Pedersen stated that his findings indicate that females have smaller personal space zones than males and that this sex difference emerges during the years they are in elementary school.

Interpersonal distance in White's (1975) study was measured by the "horizontal nose to nose distance between two seated speakers." A subject and a confederate were asked to seat themselves and to discuss the counseling program at the college. The confederate would place his chair in a predetermined position thus allowing the subject to place his chair at a distance of his choice from the confederate. The actual measurement was taken by determining chair to chair 
distance and adding one of three correction factors, depending upon whether the subject was leaning forward, sitting upright or leaning back. For this sample of 80 college freshmen the sex of the subject was an important factor in interpersonal distancing. Female subjects sat closer to the confederate than the males, regardless of the sex of the confederate. Effect of Sex of Confederate. Several studies using behavioral measures have indicated that regardless of sex of subject, people maintain less distance from females than males. Horowitz, Duff and Stratton (1964) found that both male and female adults maintained greater interpersonal distance at "body buffer zones" as they called it, when approaching men than women. Lomranz, Shapira, Choresh and Gilat (1975) investigated the personal space of 3-, 5-, and 7-year old children as they approached both boys and girls in their own age range. Each child entered a room where another child was already seated on a bench and drawing, and was told to sit next to the seated child. It was reported that for all ages both boys' and girls' personal space zones were smaller when they approached girls than boys.

Similarly, Eberts and Lepper (1975) found when measuring the distances that preschool children approached an experimenter seated at a table, that they more closely approached the female than the male experimenters. There was no effect for sex of subject nor a sex of subject by sex of experimenter interaction. These findings were explained by the investigators as resulting from both boys and girls at this early age receiving more 
nurturance and intimate contact from female than male adult figures.

Barrios, Corbitt, Estes and Topping (1976) examined the effect that social stigma has on interpersonal distancing as well as the effect of sex of the interacting persons. Using chosen seated distance as the measure of interpersonal distance, they reported that both males and females chose to sit closer to the female confederates than the male confederates. Interaction of Sex of Subject by Sex of Confederate, The findings from studies using simulated measure of interpersonal distance provide evidence that opposite sex pairs maintain smaller distances between themselves than same sex pairs. The series of studies by Kuethe and associates have consistently found that, when subjects are instructed to place felt cutouts of human figures anywhere they wish on a board, malefemale felt-figure pairings were placed closer together than same sex pairings (Kuethe, 1962a; 1964, 1964a; Kuethe \& Stricker, 1963; Kuethe \& Weingartner, 1964).

Meisels and Guardo (1969) instructed subjects in grades three to ten to trace a manipulable cutout figure representing themselves to a series of preprinted figures. They report a consistent developmental pattern of children in the later grades, beginning about grade six, of having overall smaller personal space zones. There is also a shift to closer distance being maintained with the opposite sex. Tolor and Salfia (1971) asked 160 male college students to place either two male or one female silhouette figure anywhere they wished on a felt 
board. The figures were described as having either positive or negative attributes (e.g. high intelligence, low intelligence). Male-female figure pairs were placed significantly closer together than same sex figures when given a positive set.

In contrast, studies using behavioral measures have generally not supported the above findings of smaller interpersonal distances being maintained by mixed sex pairs. Hartnett, Bailey and Gibson (1970) measured personal space by having introductory psychology students approach and be approached by the experimenter until they wanted to stop or wanted the experimenter to stop approaching them. Female subjects allowed what Hartnett et. al called "greater personal space invasion" by both male and female experimenters than did the male subjects. There was no evidence of sex of subject by sex of experimenter interaction effect on personal space. Eberts and Lepper's (1975) investigation of the personal space of preschool children, discussed previously, also did not provide any indication of mixed sex pairs (in this study, child-adult pairs) differing in their personal space zones from same sex pairs.

Dosey and Meisel (1969) report that female college students moved closer to same sex persons than opposite sex persons when under "stress". Stress was induced by subjects having their physical attractiveness questioned. On the other hand, males used approximately the same distance in approaching a same or opposite sex person. The investigators felt that 
this result was due to the cultural norm of females being more reserved with opposite sex strangers than same sex strangers. It may be that this cultural norm becomes prepotent only in actual interpersonal behavior, not simulated measures.

This finding though was not supported by Bailey, Hartnett, and Gibson (1972). They also used a behavioral measure of interpersonal distance under a stress condition, with stress being brought about by suggesting the possibility of physical violence. In this situation, females' distancing was not affected by sex of another person, while males approached most closely opposite sex persons. The differences between the studies appears due to the differing types of stress induced and their probable differential impact depending on sex of subject.

The inclusion of "stress" as a variable in these studies certainly makes it more difficult to determine sex differences in interpersonal distancing. In Dosey and Meisel's (1969) and Bailey, Hartnett and Gibson's (1972) studies, the effect of "stress" on interpersonal distancing differed while Meisels and Canter (1970) found no effect of stress on distancing. It is apparent that the often expressed view that mixed sex pairs have smaller personal space zones than do same sex pairs, have not been clearly demonstrated in studies using behavioral measures. This may be due to confounding variables included in such studies as well as methodological weakness which will be more fully discussed later. 
Body Orientation

There is convincing evidence from many investigations using behavioral measures that body orientation (i.e. degree communicator's body is turned in the direction of the person he is addressing) is a major factor influencing interpersonal distancing. In one of the earliest studies incorporating this variable, Sommer (1959) asked male and female subjects to sit down at a table and discuss a topic with an already seated confederate. Females preferred sitting alongside a female confederate significantly more than the male subjects or than either sex with male confederates. Males tended to sit opposite both male and female confederates. Subsequently, Sommer (1967) in a general review article on spatial arrangements of people stated that "side-by-side seating, which is generally considered to be the most intimate of all seating arrangements for people already acquainted, is comparatively rare among males if they are given the opportunity to sit across from one another" (p. 149).

Horowitz, Duff and stratton (1964) instructed subjects to simply walk towards either a male or female experimenter. The subject approached the "object person" at eight different angles of approaches. When the subject stopped moving forward, at his or her accord, the distance between the subject's feet and the object person was noted. The investigators report that while females more closely approached others in a frontal orientation (i.e. face to face) than sideways, males more closely approached others sideways than frontally. This 
difference was found regardless of the sex of the person being approached.

Mehrabian (1969) reviewed the research findings on the effects of posture and gesture in the communication of affect. Generally, the findings indicate that for females the least direct orientation occurs in situations where the person being addressed is intensely disliked, the most direct orientation for neutral persons and moderately direct orientation where the person being addressed is intensely liked. The only consistent finding for males is that when a person being addressed is intensely liked, a less direct body orientation tends to occur.

In Pellergrini and Empey's (1970) study, a confederate was already seated in a room when the subject was brought in and told he was to describe himself to this other person. The subject was then told "pull up a chair and go ahead whenever you're ready." While there was a general tendency for all subjects to turn away from a face-to-face orientation, the closer they sat to the confederate, female subjects to a significantly greater extent, sat further away from a face-toface orientation than males.

Patterson, Mullens and Romano (1971) attempted to examine responses to personal space intrusions. The investigation took place in a university library with subjects targeted as one seated alone at a table. A female intruder sat either adjacent, across from, two seats or three seats adjacent to the subject. Dependent measures recorded were length of time 
subject remained seated, number of glances directed to the intruder, leaning and blocking responses. Blocking responses were defined as those "which would serve to lessen the presence of the intruder," such as placing elbow or hand between himself and the intruder. There was no effect of sex of subject on any of the dependent measures; however, females demonstrated more blocking than males at the closest adjacent positions while males showed more blocking than females in the face-to-face position.

In a similar study, Fisher and Byrne (1975) examined sex differences in response to spatial intrusions in both adjacent and across seated positions. A major methodological improvement from Patterson et. al's (1971) study was the use of both male and female confederates in initiating spatial intrusions. Sex differences reported were related to the spatial relationship with the "invader." Males felt more negatively toward the "invaders" who sat across from them than did females. But when the "invaders" sat adjacent to the subjects, females felt more negatively towards them than males. Males were also found to erect more barriers (e.g. books, personal effects) in the across position while females more often erected adjacent barriers. Contrary to prediction, the sex of the "invader" did not have a differential effect on any of the dependent measures. The lack of a sex of "invader" effect was felt to be a result of the asocial library setting of the study. Since the library generally has a work orientation, the sexual identity of someone approaching a person 
may not be relevant. The investigators suggest that in a more social situation, sex of an "invader" would be significant.

Bryne, Baskett, and Hodges (1971) provide further evidence that a side-by-side as compared to a frontal seating orientation have different meaning for males than females. Differences in attraction, defined as likeability and desirability as a work partner as measured by a paper and pencil test, were related to distancing in a side-by-side seating situation for females; for males it was related to choice of a face-toface seat versus a non-facing seat.

One of the few studies using both a simulated and behavioral measure of personal space and incorporating spatial orientation as a variable was that of Pedersen (1973a). Subjects were asked to place a gum-backed profile representing another person, in relation to a profile, representing the subject as close as would be comfortable for the subject. These were to be placed on a line radiating from the profile at nine different angles. The behavioral measure involved approaching the subject until the subject said that it was as close as the person could approach and still feel comfortable. The experimenter approached the subject at nine different angles. For all subjects, regardless of sex, both simulated and behavioral measures of personal space were most different between front and side orientations. For males, in the simulated task, there was no relationship between the personal space maintained between other males and females in a face-toface orientation. 
It is by no means certain how exactly body orientation influences interpersonal distancing for males and females. However, the evidence appears sufficiently convincing to conclude that it is a variable which must be taken into account. Investigations which either do not include body orientation as a variable or control for its possible influences would appear to be of limited value.

\section{Derivation of Hypotheses}

Locus of control has been hypothesized as having a mediational role in interpersonal distancing behavior (Duke and Nowicki, 1972). Duke and Nowicki have reported some limited evidence, using a simulated measure, that internals and externals differ in their interpersonal distancing behavior. Subjects with an external locus of control, due to their generalized expectancy of lack of personal control, should maintain greater distance from others than internals. The present study attempted to determine whether this difference in interpersonal distancing occurs in actual behavior.

Previous studies (Pedersen, 1973a; Tolor and LeBlanc, 1974) have suggested that for female college students certain personality variables, which seem relevant to choice of interpersonal distance from others (e.g. need for affiliation), are related to simulated but not behavioral measures of interpersonal distancing. There is also evidence that during the college years, women tend to have an external locus of control (Maccoby and Jacklin, 1974). These findings led the present 
investigator to view a simulated measure of interpersonal distancing as essentially being a projective technique.

By the simulated measure being a relatively unstructured task, it permits an individual a wide variety of possible placements. Thus, the individual's placement choice may reflect some fundamental aspects of his psychological functioning, namely, needs or wish to associate with others. However, an individual's locus of control would determine the extent to which a need, desire or wish for closeness to others is reflected in actual behavior. Internals should show more initiative and effort to attain their goals than externals. Internals should also generally adopt behaviors which facilitate personal control over their environment. Thus, internals ' interpersonal distancing should not only be smaller but also reflect to a greater extent their needs relating to proximity to others than externals. Externals, while maintaining greater interpersonal distance from others in actual behavior, may. still have high needs to associate with others and therefore place felt-figure cutouts close together. By maintaining a greater congruence between their needs and wishes and actual behavior, the relationship between a simulated and behavioral measure of interpersonal distancing should be greater for internals than externals.

The various simulated and behavioral measures of interpersonal distancing have generally been inadequate. This has contributed to the inconsistency in findings as to the comparability of simulated and behavioral measures. For example, 
many of the behavioral measures used require verbal report of discomfort when a subject approached or was approached by another person (e.g. Horowitz, Duff \& Stratton, 1964; Hartnett, Bailey \& Gibson, 1970, Pedersen, 1973a). However, there is evidence that subject awareness that interpersonal distancing behavior is being measured alters his spatial behavior (Eberts, 1972). There is also evidence that eye contact (Argyle and Dean, 1965; Goldberg, Kiesler and Collins, 1969), body orientation (e.g. Horowitz, Duff \& Stratton, 1964; Bryne, Baskett \& Hodges, 1971; Fisher and Byrne, 1975), sex of subject (e.g. Sommer, 1967; Pedersen, 1973c; Guardo, 1969) and sex of confederate (e.g. White, 1975; Eberts and Lepper, 1975. Barrios, Corbitt, Estes \& Topping, 1976) may also influence interpersonal distancing.

None of the previously reported investigations attempting to determine the relationship between simulated and behavioral measures of interpersonal distancing has controlled for all of these possible interacting factors. Only by taking into account eye contact, body orientation, sex of subject, sex confederate and controlling for subject awareness that spatial behavior is being measured, in both simulated and behavioral measures, can the extent of their relationship be determined. In the present study, all the above factors were taken into account in order that a more valid indication of the extent a simulated and behavioral measure of interpersonal distancing are comparable would be determined. 
This study also attempted to investigate and clarify some of the inconsistent and contradictory findings in this area. Previous studies have generally used either a simulated or behavioral measure with often differing results depending on the measure employed. By correcting some of the major methodological weaknesses of previous investigations and using both a simulated and behavioral measure, it was believed that a clearer understanding of interpersonal distancing behavior would result.

Hypotheses and Predictions

The central hypotheses of this study are:

(1) Responses on the simulated measure of interpersonal distancing are related to personality variables.

(2) Locus of control mediates the extent that personality variables are related to the behavioral measure of interpersonal distancing.

(3) Locus of control determines the extent that the simulated and behavioral measure of interpersonal distancing are comparable.

(4). Locus of control has a mediational role in determining individuals' interpersonal distancing behavior. Specifically, the following predictions are proposed:

(1) Needs for affiliation, autonomy and dominance will be related to responses on the simulated measure of interpersonal distancing.

(2) Subjects with an internal locus of control will reflect needs for affiliation, autonomy and dominance to a greater 
extent on the behavioral measure of interpersonal distancing than subjects with an external locus of control.

(3) The simulated and behavioral measure of interpersonal distancing will be related to a greater extent for subjects with an internal locus of control than for subjects with an external locus of control.

(4) Subjects with an internal locus of control will demonstrate closer interpersonal distancing behavior on both the simulated and behavioral measure than subjects with an external locus of control.

In view of the somewhat exploratory nature of this study, the following suppositions are presented in a non-specific formats

(5) Distancing on both the simulated and behavioral measures will differ between side and frontal orientations.

(6) Sex of subject and sex of confederate will differentially affect interpersonal distancing on both the simulated and behavioral measures.

(7) Sex of subject will interact with sex of confederate to differentially affect interpersonal distancing on the simulated and behavioral measure. 


\section{Chapter II}

METHOD

Subjects

Subjects were American-born, Caucasian young adults drawn from undergraduate students enrolled in introductory psychology classes at the University of Rhode Island. Their class standing was as follows: freshmen, 55\%; sophomores, $35 \%$; juniors, $5 \%$ seniors, $5 \%$. In accordance with established policy for students, all those participating in the study received extra credit in their course. Of the total number of students present on the days the experimenter met with the recitation classes, all but one participated in the first phase of the study, providing an initial subject pool of 84 males and 157 females, for a total of 241 students. All 241 students were administered Rotter's Internality-Externality Scale. From the subject pool there was a selection of 20 male and 20 female "internals" with the lowest scores and 20 male and 20 female "externals" with the highest scores. of the initial 80 individuals subsequently contacted, four chose not to participate and were replaced by random selection from the highest and lowest scoring individuals on the I-E scale.

According to locus of control scores and sex, four groups were formed, male internals, male externals, female externals, and female internals. Subjects within each of those four groups were randomly assigned to either male or female confederate conditions, yielding the final groups $(N=10$ for each group). 
The groups were male-internal-male, male-internal-female, male-external-male, male-external-female, female-internal-male, female-internal-female, female-external-male, and femaleexternal-female. The mean age in months and I-E scores for each of the experimental groups are presented in Table 1. There were no significant differences in I-E scores or age among the four groups with an internal locus of control nor among the four groups with an external locus of control. However, there was a significant difference between the male-externalmale and the female-external-female group.

The total mean I-E score of 11.77 for the initial subject pool of 241 students appears representative of the present college population. While the mean I-E scores reported by Rotter (1966) of various populations ranged from 5.48 to 10.00 , mean scores have increasingly been reported to have moved in the external direction (Schneider, 1971).

\section{Confederates}

A total of ten undergraduate psychology majors originally volunteered to participate as confederates in this study. Undergraduates were chosen so that the confederates would be similar in age and general appearance of the subject pool. In order to control for possible confounding effects of confederate variability, the final choice of two male and two female confederates was done on the basis of an observermatching procedure. The potential confederates were rated by two observers on five 5-point scales. Taking into account the need for two males and two females, the four most similar individuals were chosen as confederates. Interrater reliability 


\section{Table 1}

Mean Age in Months, Standard Deviations and I-E Scores for Each of the Experimental Groups

\begin{tabular}{|c|c|c|c|c|}
\hline $\begin{array}{l}\text { Sex of } \\
\text { Subject }\end{array}$ & $\begin{array}{l}\text { Iocus of } \\
\text { Control }\end{array}$ & $\begin{array}{c}\text { Sex of } \\
\text { Confederate }\end{array}$ & Age & $I-E$ \\
\hline Male & $\begin{array}{l}\text { Internals } \\
\mathrm{SD}\end{array}$ & Female & $\begin{array}{l}232.8 \\
12.89\end{array}$ & $\begin{array}{l}5.2 \\
2.04\end{array}$ \\
\hline Male & $\begin{array}{l}\text { Internals } \\
\text { SD }\end{array}$ & Male & $\begin{array}{r}236.4 \\
16.04\end{array}$ & $\begin{array}{l}5.1 \\
2.4\end{array}$ \\
\hline Male & $\begin{array}{l}\text { Externals } \\
\text { SD }\end{array}$ & Female & $\begin{array}{c}232.8 \\
18.06\end{array}$ & $\begin{array}{r}15.4 \\
2.41\end{array}$ \\
\hline Male & $\begin{array}{l}\text { Externals } \\
\text { SD }\end{array}$ & Male & $\begin{array}{c}237.8 \\
17.58\end{array}$ & $\begin{array}{c}14.5 \\
1.58\end{array}$ \\
\hline Females & $\begin{array}{l}\text { Internals } \\
\text { SD }\end{array}$ & Female & $\begin{array}{c}230.4 \\
14.75\end{array}$ & $\begin{array}{l}5.8 \\
2.04\end{array}$ \\
\hline Female & $\begin{array}{l}\text { Internals } \\
\text { SD }\end{array}$ & Male & $\begin{array}{r}234.0 \\
40.49\end{array}$ & $\begin{array}{l}5.7 \\
2.45\end{array}$ \\
\hline Female & $\begin{array}{l}\text { Externals } \\
\text { SD }\end{array}$ & Female & $\begin{array}{c}223.2 \\
16.19\end{array}$ & $\begin{array}{c}16.4 \\
2.01\end{array}$ \\
\hline Female & Externals & Male & $\begin{array}{l}225.6 \\
14.75\end{array}$ & $\begin{array}{c}16.3 \\
1.82\end{array}$ \\
\hline TOTAL & SD & & $\begin{array}{r}232.0 \\
21.84\end{array}$ & $\begin{array}{r}10.55 \\
5.55\end{array}$ \\
\hline
\end{tabular}




\section{Table 2}

Means and Standard Deviation of Rating of Confederates on Five Attributes by Two Raters

Size Strength Aggressivity Bearing Attractiveness

Males

$13(.0) \quad 3(.0)$

$3(.0)$

$2.66(.57)$

$3(.0)$

$23(.0) \quad 3(.0)$

$3.33(.57)$

$2.66(.57)$

$3(.0)$

Females

$\begin{array}{llllll}12.66(.57) & 3(.0) & 3(.0) & 2.33(.57) & 2.33(.57) \\ 2 & 3(.0) & 3(.0) & 3(.0) & 2.66(.57) & 2.66(.57)\end{array}$


was found to be .89. The attributes rated included: (1) size (small-large); (2) strength (weak-strong): (3) aggressiveness (passive-aggressive); (4) bearing (friendly-unfriendly); and (5) attractiveness (attractive-unattractive) (see Appendix A for rating sheet). Table 2 presents the means and standard deviations of the ratings for each of the confederates chosen. Each confederate served in each experimental condition an equal number of times. This was done in order to balance any extraneous effects due to differences in the behavior or characteristics of the confederates.

\section{Personality Measures}

Rotter Internal-External Control Scale (I-E Scale), The Rotter I-E scale is a 29-item, forced choice test, in which a subject must choose one statement from a pair of alternatives he more strongly believes to be true. The items are concerned with the expectation of reinforcement being controlled by one's own action or luck, fate or simply by it not being in one's control. For example, a typical item is the following: (a) I have often found that what is going to happen will happen: (b) Trusting to fate has never turned out as well for me as making a decision to take a definite course of action. Another typical item is the following: (a) Many times I feel that I have little influence over the things that happen to me; (b) It is impossible for me to believe that chance or luck plays an important role in my life. The test score is the total number of external choices made. In the examples above (a) is the external choice. The higher the score, the greater the presumed subject's belief in external control. 
Included in the 29 items are six filler items which are aimed at disguising the purpose of the test. A typical filler item would be: (a) Children get into trouble because their parents punish them too much; (b) The trouble with most children nowadays is that their parents are too easy on them.

Rotter (1966) reports test-retest reliabilities after a one-month period ranging from .60 to .83, after a two-month period test-retest reliabilities are markedly lower, ranging from .49 to .61 . Good discriminant validity is indicated by low relationships between the I-E and such variables as intelligence, adjustment, need for approval and social desirability. However, Rotter does caution that testing conditions can influence the extent social desirability affects the I-E scale. This would be a problem in situations where it would be to a subject's advantage to portray himself in a most favorable manner. There are at this time well over 600 published studies investigating some aspect of internal versus external control (Rotter, 1975). Comprehensive reviews of these studies are supportive of the construct validity of this instrument with the internality-externality concept operating in many different situations (Joe, 1971; Lefcourt, 1966; Phares, 1976; Rotter, 1966, 1975).

Personality Research Form (PRF). The Personality Research Form is a self-report personality inventory designed by Jackson (1967) for use within the normal population range. The PRF is available in several different formats. Form $A$, which was used in this study, consists of 300 items divided 
into 15 scales of 20 items each. The following 14 scales are personality variables based on Murray's need system: achievement, affiliation, aggression, autonomy, dominance, endurance, exhibition, harm avoidance, impulsivity, nurturance, order, play, social recognition, understanding. There is also a "validity" scale aimed at detecting non-purposeful or careless responding.

The scales have been designed to be bi-polar with half of the items expressed in terms of one pole, the other half in terms of the other pole. A description of a high scorer for each of the traits is presented in the manual. For example, a subject who scores high on the achievement scale is described as "aspires to accomplish difficult tasks; maintains high standards and is willing to work toward distant goals; responds positively to competition; willing to put forth effort to attain excellence."

Norms are based on samples of over 1,000 male and female students from 30 colleges and universities. Data supporting the reliability and validity of this instrument appear to be superior to many of the other available personality tests. Anastasi (1972) reports that "technically the PRF appears to be exemplary" (p. 298). Two aspects of reliability are reported--estimates of homogeneity and stability of scores over time. A median $\mathrm{K}-\mathrm{R}_{20}$ coefficient of .78 , and an odd-even median reliability of .81 is reported. Test-retest reliabilities reported for one group of college students after a one-week interval ranged from .77 to .90 . 
Both convergent and discriminant validation of the PRF scales have been reported. A series of validation studies involved relating the $P R F$ scales to peer ratings and self ratings. For one study the median correlation with peer ratings was .52 and .56 for self ratings. 0ther studies summarized in the manual report validity coefficients of similar magnitudes. The intercorrelations of PRF scores, self ratings and peer ratings of 202 college students were subjected to a multi-method factor analysis. The PRF scales were found to load the appropriate factors that emerged, thus providing important evidence for both convergent and discriminant validity.

\section{General Procedure}

As previously described, the I-E scale was administered in the introductory psychology recitation sections. The following intructions were read aloud: "I am investigating the relationship certain personality characteristics have on performing learning tasks. There are three phases to this study; the first phase you will complete today. Within the next two weeks, I will randomly select and contact by phone a limited number of you to complete the other two phases of the study. The second phase will require approximately 50 minutes to complete and the last phase approximately 10 minutes."

The instructions for the I-E were the standard ones provided by Rotter (1966). Subjects were subsequently contacted 
by phone and scheduled in groups of six to complete the PRF. Instructions for the PRF were the standard ones provided by Jackson (1967). While the subjects were completing the PRF, the experimenter took them one at a time to another room to administer the simulated spatial measure. Approximately two weeks later all subjects were again contacted by phone and scheduled individually to complete phase three which included the behavioral measures and the post-experimental interview. It should be noted that the procedures described above which necessarily involved the use of deception were approved by the Department of Psychology's ethics committee.

Measures of Interpersonal Distancing

Simulated Spatial Measure, This measure of interpersonal distancing is essentially a variant of Kuethe's (1962a) free placement technique for measuring social schemas. The apparatus constructed for this measure consisted of a three-foot wide $(.9144 \mathrm{~m})$ by five-foot long $(1.524 \mathrm{~m})$ quarter-inch $(.635 \mathrm{~cm})$ board. Four pieces of green felt, the size of the board, were attached to the top of the board by four metal rings. On each piece of felt a white tape, one-half inch $(1.27 \mathrm{~cm})$ in width, was placed horizontally in the middle of the board, stretching from one edge to the other. Human figures in frontal and side orientations as shown in Figure 1 were cut out of red felt. The height of the figures were as follows: male $=6$ inches $(15.24 \mathrm{~cm})$, female $=53 / 4$ inches $(14.6 \mathrm{~cm})$. Both the male and female figures in the frontal orientations were two inches $(5.08 \mathrm{~cm})$ at their widest points. In the side 

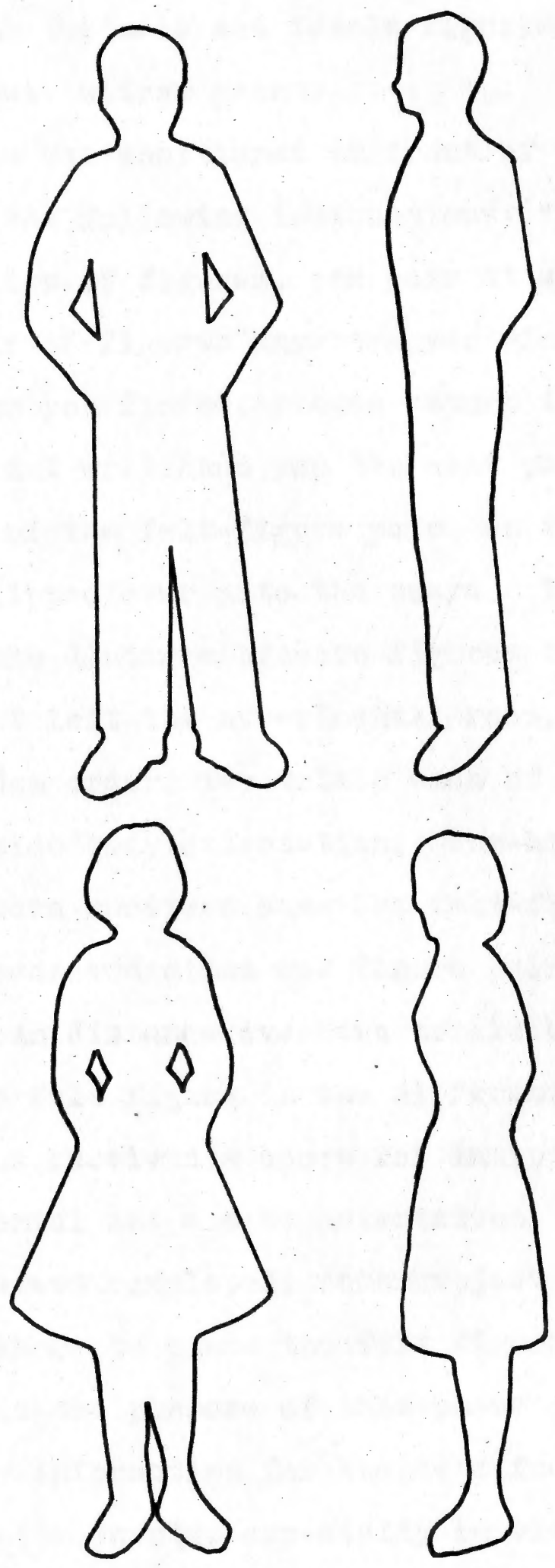

FIGURE 1. Felt Figures

45 
orientations both the male and female figures were $1 \frac{1}{4}$ inches $(3.175 \mathrm{~cm})$ at their widest points.

Each subject was positioned in front of the felt-covered board and given the following instructions: "I am going to hand you four pairs of figures, one pair at a time. You are to place the pair of figures anywhere you wish standing on the white line. When you finish, please return to where you are standing now, and I will hand you the next pair of figures." After placement of the felt-figure pairs on the board, another felt piece is flipped over onto the board. This allowed measurement of the distance between figures to be completed after the subject left the experimental room. Each subject received in random order, two trials each of felt-figure pairs in frontal and side body orientation. One-half of the male and female subjects received same sex felt-figure pairs while the other half received mixed sex figure pairs. The subject's score was the mean distance over two trials between the midlines of each felt figure in the different body orientations. Each subject thus received a score for manipulation of felt figures in a frontal and a side orientation. When the experimental procedure was completed, each subject was asked (1) How did you decide where to place the felt figures? and (2) What did you think was the purpose of this phase of the study?. Reliability information for Kuethe's free placement techniques is quite scanty, especially in view of the large number of studies using this technique or a variant of it. Tolor and LeBlanc $(1974)$ report a test-retest reliability of 
.75 after a two-week interval. In view of the substantial differences between the present measure and Tolor and LeBlanc's variant of Kuethe's technique, a reliability study using a separate sample was completed. Subjects were randomly choosen from the initial subject pool of 241 students who had not been selected to complete all phases of the study. Out of a remaining pool of 161 subjects, 45 subjects were contacted by phone and agreed to participate in this reliability study. Subjects were informed that they would be required to attend two experimental sessions one month apart. Administration of this measure at each session required approximately five minutes. Subjects were presented with two trials of same sex figures in frontal and side orientation. Following a one-month interval subjects participating in Session I were contacted by phone and scheduled individually for Session II. Subjects were individually debriefed at the completion of Session II. However, six subjects could not be contacted by phone and apparently no longer attended classes. Four subjects refused any further participation in the study and three subjects, while agreeing to attend Session II, were not present when scheduled and inspite of repeated attempts could no longer be contacted. Thus, the reliability study is based on a final sample of 20 females and 12 males for a total sample of 32 subjects. Test-retest reliability with a one-month internal for the frontal orientation figures produced an $\underline{\underline{r}}$ of $.69(\underline{p}<.01)$ while the side orientation produced an $\underline{r}$ of $.81(p<.01)$. 
Behavioral Measure--Side Orientation. An attempt was made to develop an unobtrusive measure of how subjects distance themselves from strangers. Measures were taken in a room $17 \frac{1}{2}$ feet $(5.3 \mathrm{~m})$ by 15 feet $(4.6 \mathrm{~m})$ and empty with the exception of a bench 15 feet $(4.6 \mathrm{~m})$ long at one end of the room. Behind the bench was a two-way mirror stretching across the entire wall. In an adjacent room it was possible by way of the two-way mirror to observe where subjects seated themselves. A tape marked off in centimeters was placed across the entire length of the two-way mirror.

Each subject was met by the experimenter outside what was called the "waiting room" and given the following instructions: "I would like you to fill out this biographical data sheet in the waiting room. I will return in a few minutes to bring you to another room where we will complete the last phase of this study. One of my assistants is in this room working on some papers related to the experiment."

For subjects who were given same sex felt figures on the simulated spatial measure, the confederate seated in the waiting room was also of the same sex as the subject. For those subjects given mixed sex felt figures, the confederate was of the opposite sex. Thus, the behavioral measure paralleled as closely as possible the simulated spatial measure.

The confederate was seated one-foot from the end of the bench (measured from the mid-line of his or her torso to the edge). When the subject entered the room the confederate was instructed to smile, glance at the subject, and then to 
resume "marking" papers. The confederate avoided eye contact with the subject while he or she was seating themselves. Once seated, any questions the subject asked the confederate were answered directly, but conversation was discouraged. Since the only available seat in the room for the subject was the bench, it thus provided the choice of sitting close or far from the confederate. The experimenter in the adjacent room was able to measure directly the interpersonal distance by drawing an imaginary line from the mid-point of the torso of the subject and the confederate to the tape measure.

The reliability of the measurements was pretested by having a person role play a subject and sit in ten different side positions in relation to a confederate. The experimenter and another person, independently recorded the observed distances through the two-way mirror by use of the tape measure. A correlation of .99 was obtained between the recorded observations of independent observers.

Behavioral Measure--Frontal Orientation. This measure was developed by the experimenter to provide an unobtrusive measure of subjects distancing behavior from a stranger when in a face-to-face frontal body orientation. A confederate is already seated in a chair placed in a predetermined position. For subjects who were given same sex felt figures on the simulated measure, the confederate was also of the same sex as the subject. For those subjects given mixed sex felt figures, the confederate was of the opposite sex. The confederate was instructed to sit upright with his feet flat 
on the ground between the legs of the chair. Both the confederate's chair and the one the subjects used were armless wooden chairs normally found in school settings. The "experimental room" was $113 / 4$ feet $(3.6 \mathrm{~m})$ by $91 / 4$ feet $(2.8 \mathrm{~m})$. The floor of this room was composed of tiles 12 inches $(30.48 \mathrm{~cm})$ square. It was therefore quite easy to place markings on the floor in $1 \frac{1}{2}$-inch $(3.81 \mathrm{~cm})$ intervals. While these markings were clear enough for the experimenter to use in estimating subject distance, they were sufficiently camouflaged so that the subjects were not aware of them. Besides the chair the confederate was sitting in, the only other chair in the room was placed in a far corner.

Each subject was brought by the experimenter from the "waiting room" to the doorway of the "experimental room" and told: "For the next phase of this study, please pull up a chair in front of and facing (confederate's name) and sit down." If the subject asked how far should he place the chair, the experimenter responded "wherever you wish." The subject thus had to retrieve the only available chair in the room and place it some distance from the confederate. The confederate was instructed to glance up to the subject when he or she entered the room, smile, and then resume "marking" papers. The confederate avoided eye contact with the subject while he or she was placing their chair. In order to prevent subject awareness that distance measurement was the variable of interest, once the subject was seated the following instructions were given. "I am going to hand you a list of word pairs 
which you are to attempt to memorize in one minute. When I say time is up, hand the list over to (confederate's name). When I say begin, try to recite, in any order, the word pairs. (Confederate's name) will prompt you if you forget a word. You are to go through the list as many times as necessary until you successfully recite it without prompting" (see Appendix for word list). While the subject was memorizing the word list the interpersonal distance from the experimenter was determined by estimating the horizontal distance between the front legs of the subject and confederate's chair through the use of the floor markings.

The reliability of these estimates was pretested by having an individual role play the subject and place his chair at different distances from the confederate. After several practice sessions, it was possible to accurately estimate distances in approximately five to ten seconds. The experimenter and a confederate taking measurements of 20 different placements of a volunteer role playing the subject obtained a correlation of .99 between estimates of distance and actual distance taken by a tape measure within $1 / 2$-inch $(1.27 \mathrm{~cm})$.

\section{Post-Experimental Questionnaire}

When subjects completed the memory task, they were asked to complete a questionnaire (see Appendix D). It included rating both confederates that they had met on the attributes of size, strength, aggressivity, bearing and attractiveness. 
The experimenter stressed the necessity for the subject to give honest ratings and promised that the confederates would not see their ratings. They were also asked the question, "What did you think this experiment was all about?" Upon completing the questionnaire they were partially debriefed. They were not informed at this time that behavioral measures of interpersonal distancing had been taken. Appointments were scheduled when subjects could look at their scores and receive a complete debriefing.

\section{Treatment of the Data}

The data collected by both the simulated and behavioral measures of interpersonal distancing were analyzed by a $2 \times 2 \times 2 \times 2$ analysis of variance with repeated measures on the last variable. The factors used in the design were of sex of subject, locus of control (internals and externals), sex of confederate or felt figure, and body orientation (side and frontal). The schematic representation of the experimental design is presented in Figure 2. The level of significance was established at .05.

In order to determine the relationships among the measures of interpersonal distancing, personality variables and subjects ' ratings of confederate characteristics, a series of Pearson-Product moment correlations were computed, The linearity of the relationships were pretested by inspecting scatter diagrams of the scores. 


\begin{tabular}{|c|c|c|c|}
\hline \multicolumn{1}{c}{$\begin{array}{c}\text { SIDE - BODY } \\
\text { ORIENTATION }\end{array}$ FRONTAL-BODY } \\
ORIENTATION
\end{tabular}

FIGURE 2. Schematic Representation of Treatment Conditions 


\section{Chapter III}

\section{RESULTS}

This chapter of the dissertation will deal with the presentation of the results. The chapter has been divided into three sections. The first section presents the intercorrelations among all the variables in the study. The second and third sections present the analysis of the simulated and behavioral interpersonal distance scores respectively. It should be noted that the attempt to develop an unobtrusive behavioral measure of interpersonal distancing was highly effective according to the subjects' responses to the postexperimental questionnaire. Each subject was requested to describe what they thought was the purpose of the experiment. Nearly all the subjects stated that they had no idea. None stated that the purpose of the study dealt with interpersonal distancing behavior.

\section{Intercorrelations Among All Variables}

A series of correlational analyses were computed between the measures of interpersonal distancing, personality variables and subjects' ratings of confederates. The following abbreviated correlational matrix tables were constructed. Table 3 for all subjects $(n=80)$, Table 4 for males $(n=40)$, Table 5 for females $(n=40)$, Table 6 for externals $(n=40)$, and Table $?$ for internals $(n=40)$ (see Appendix for complete correlational matrix tables). 
Table 3

Intercorrelations Among Measures of Interpersonal Distancing, Personality Variables and

Subjects' Ratings of Confederate Characteristics For All Subjects $(\mathrm{N}=80)$

\begin{tabular}{|c|c|c|c|c|}
\hline & 1 & 2 & 3 & 4 \\
\hline 1 & - & & & \\
\hline 2 & .03 & - & & \\
\hline 3 & .03 & -.09 & - & \\
\hline 4 & -.01 & $.25^{*}$ & .01 & - \\
\hline 5 & -.14 & .01 & .08 &.- .14 \\
\hline 6 & -.18 & .16 & -.08 & -.01 \\
\hline 7 & .09 & -.19 & .03 & -.04 \\
\hline 8 & .14 & .08 & .01 & .12 \\
\hline 9 & .12 & .02 & .00 & -.07 \\
\hline 10 & -.09 & .14 & -.06 & -.07 \\
\hline 11 & .09 & .08 & .03 & -.16 \\
\hline 12 & -.08 & .02 & -.09 & -.11 \\
\hline 13 & $.37^{* *}$ & .11 & -.09 & $.23^{*}$ \\
\hline 14 & -.15 & .04 & -.09 & .04 \\
\hline 15 & -.19 & -.12 & .06 & -.16 \\
\hline 16 & .02 & .12 & -.02 & .08 \\
\hline 17 & .14 & -.12 & -.07 & $-.26^{*}$ \\
\hline 18 & -.08 & .08 & .02 & -.06 \\
\hline 19 & $.26^{*}$ & .12 & .02 & $.25^{*}$ \\
\hline 20 & .01 & $-.32^{* * *}$ & .11 & -.05 \\
\hline
\end{tabular}

(Continued to the next page) 


$\begin{array}{lrrrr}21 & .01 & -.01 & .21 & -.07 \\ 22 & -.31^{* *} & -.02 & .04 & .06 \\ 23 & -.18 & .01 & .05 & -.07 \\ 24 & .03 & -.06 & -.08 & .04 \\ 25 & -.03 & .07 & .08 & -.01 \\ 26 & -.03 & .06 & .24 & -.05 \\ 27 & -.07 & -.03 & .17 & -.00 \\ 28 & -.01 & .01 & .01 & -.01 \\ 29 & -.04 & -.05 & -.010 & -.07\end{array}$

** ${ }^{*}<<<.01$

Code 1. Behavioral Side Distance; 2. Simulated Side Distance; 3. Behavioral Frontal Distance; 4. Simulated Frontal Distance; 5. Achievement; 6. Affiliation; 7. Aggression; 8. Autonomy; 9. Dominance; 10. Endurance; 11. Exhibition; 12. Harm Avoidance; 13. Impulsivity: 14. Nurturance; 15. Order; 16. Play; 17. Social Recognition; 18. Understanding; 19. Locus of Control; 20. Side Confederate Attractiveness; 21. Side Confederate Size; 22. Side Confederate Strength; 23. Side Confederate Aggressiveness; 24. Side Confederate Bearing; 25. Frontal Confederate Attractiveness; 26. Frontal Confederate Size; 27. Frontal Confederate Strength; 28. Frontal Confederate Aggressiveness; 29. Frontal Confederate Bearing. 


\section{Table 4}

Intercorrelations Among Measures of Interpersonal Distancing, Personality Variables and

Subjects' Ratings of Confederate Characteristics For Male Subjects $(\mathrm{N}=40)$

\begin{tabular}{|c|c|c|c|c|}
\hline & 1 & 2 & 3 & 4 \\
\hline 1 & - & & & \\
\hline 2 & .05 & - & & \\
\hline 3 & .06 & .00 & - & \\
\hline 4 & -.01 & .16 & .14 & - \\
\hline 5 & -.06 & -.01 & .11 & -.03 \\
\hline 6 & .09 & .21 & -.05 & -.12 \\
\hline 7 & -.20 & -.26 & -.13 & -.01 \\
\hline 8 & .09 & .06 & -.06 & .18 \\
\hline 9 & .07 & .01 & -.16 & -.18 \\
\hline 10 & .07 & .17 &.- .11 & .01 \\
\hline 11 & -.04 & .16 & -.02 & -.27 \\
\hline 12 & .10 & .12 & -.02 & -.21 \\
\hline 13 & $.40^{*}$ & .11 & -.05 & .17 \\
\hline 14 & .08 & .00 & -.20 & .06 \\
\hline 15 & -.21 & -.12 & .00 & -.24 \\
\hline 16 & -.00 & .11 & .00 & -.24 \\
\hline 17 & -.17 & -.08 & -.11 & $-.35^{*}$ \\
\hline 18 & .01 & .08 & -.02 & -.25 \\
\hline 19 & .26 & .14 & .03 & $.34^{*}$ \\
\hline 20 &.- .11 & $-.50^{* *}$ & .04 & -.18 \\
\hline
\end{tabular}




\begin{tabular}{lrrrr}
21 & .07 & .00 & .09 & .02 \\
22 & -.030 & .18 & -.02 & .27 \\
23 & $-.38^{*}$ & $.38^{*}$ & -.09 & -.06 \\
24 & .02 & -.23 & -.22 & -.09 \\
25 & -.06 & .10 & -.00 & -.31 \\
26 & .01 & -.06 & .23 & -.02 \\
27 & -.25 & -.02 & .23 & .03 \\
28 & -.04 & -.11 & .05 & -.07 \\
29 & -.07 & -.11 & -.028 & -.015 \\
\hline
\end{tabular}

${ }_{* *}^{*} \mathrm{p}<.05$

Code 1. Behavioral Side Distance; 2. Simulated Side Distance; 3. Behavioral Frontal Distance; 4. Simulated Frontal Distance; 5. Achievement; 6. Affiliation; 7. Aggression; 8. Autonomy: 9. Dominance; 10. Endurance; 11. Exhibition; 12. Harm Avoidance; 13. Impulsivity; 14. Nurturance; 15. Order; 16. Play: 17. Social Recognition; 18. Understanding; 19. Locus of Control; 20. Side Confederate Attractiveness; 21. Side Confederate Size; 22. Side Confederate Strength; 23. Side Confederate Aggressiveness; 24. Side Confederate Bearing; 25. Frontal Confederate Attractiveness; 26. Frontal Confederate Size; 27. Frontal Confederate Strength; 28. Frontal Confederate Aggressiveness; 29. Frontal Confederate Bearing. 


\section{Table 5}

Intercorrelations Among Measures of Interpersonal Distancing, Personality Variables and

Subjects' Ratings of Confederate Characteristics For Female Subjects $(\mathrm{N}=40)$

\begin{tabular}{|c|c|c|c|c|}
\hline & 1 & 2 & 3 & 4 \\
\hline 1 & - & & & \\
\hline 2 & -.01 & - & & \\
\hline 3 & .00 & -.27 & - & \\
\hline 4 & .00 & $.41^{* *}$ & -.09 & - \\
\hline 5 & -.20 & .02 & .04 & -.19 \\
\hline 6 & $-.38^{*}$ & .11 & -.10 & .04 \\
\hline 7 & $.34^{*}$ & -.09 & .06 & -.05 \\
\hline 8 & .16 & .08 & .02 & .12 \\
\hline 9 & .13 & .01 & .09 & -.01 \\
\hline 10 & -.28 & .10 & -.03 & -.13 \\
\hline 11 & .19 & -.04 & .07 & -.09 \\
\hline 12 & -.19 & -.09 & -.12 & -.09 \\
\hline 13 & $.36 *$ & .14 & -.12 & .28 \\
\hline 14 & $-.32^{*}$ & .13 & .04 & .02 \\
\hline 15 & -.17 & -.12 & .15 & -.12 \\
\hline 16 & .05 & .15 & .12 & $.36^{*}$ \\
\hline 17 & .11 & -.20 & -.04 & -.20 \\
\hline 18 & -.17 & .09 & .03 & .06 \\
\hline 19 & .26 & .11 & .02 & .20 \\
\hline 20 & .16 & .08 & .20 & .08 \\
\hline
\end{tabular}




$\begin{array}{lrrrr}21 & -.05 & -.04 & .29 & -.12 \\ 22 & -.03 * & -.32^{*} & .28 & -.07 \\ 23 & -.02 & -.28 & .18 & -.07 \\ 24 & .04 & .17 & .04 & .12 \\ 25 & -.01 & .03 & .15 & .09 \\ 26 & -.06 & -.08 & .26 & -.08 \\ 27 & -.08 & .05 & .12 & -.03 \\ 28 & .04 & .24 & -.03 & .03 \\ 29 & .07 & .03 & .01 & -.01\end{array}$

$\begin{array}{rl}* & * 05 \\ * * \mathrm{p} & <.01\end{array}$

Code 1. Behavioral Side Distance; 2. Simulated Side Distance; 3. Behavioral Frontal Distance; 4. Simulated Frontal Distance; 5. Achievement; 6. Affiliation; 7. Aggression; 8. Autonomy; 9. Dominance; 10. Endurance; 11. Exhibition; 12. Harm Avoidance; 13. Impulsivity; 14. Nurturance; 15. Order; 16. Play; 17. Social Recognition; 18. Understanding; 19. Locus of Control; 20. Side Confederate Attractiveness; 21. Side Confederate Size; 22. Side Confederate Strength; 23. Side Confederate Aggressiveness; 24. Side Confederate Bearing; 25. Frontal Confederate Attractiveness; 26. Frontal Confederate Size; 27. Frontal Confederate Strength; 28. Frontal Confederate Aggressiveness; 29. Frontal Confederate Bearing. 
Table 6

Intercorrelations Among Measures of Interpersonal

Distancing, Personality Variables, and

Subjects' Ratings of Confederate Characteristics For External Subjects $(\mathrm{N}=40)$

\begin{tabular}{|c|c|c|c|c|}
\hline & 1 & 2 & 3 & 4 \\
\hline 1 & - & & & \\
\hline 2 & .04 & - & & \\
\hline 3 & .06 & -.04 & - & \\
\hline 4 & .02 & .19 & -.07 & - \\
\hline 5 & -.14 & .13 & .13 & .04 \\
\hline 6 & .11 & .21 & -.26 & -.12 \\
\hline 7 & -.05 & -.27 & -.15 & .05 \\
\hline 8 & -.12 & .15 & .00 & $.42^{* *}$ \\
\hline 9 & -.08 & .14 & -.28 & .10 \\
\hline 10 & -.04 & .20 & .08 & -.00 \\
\hline 11 & .03 & .05 & -.14 & -.15 \\
\hline 12 & -.06 & .08 & -.16 & $-.35^{*}$ \\
\hline 13 & $.37^{*}$ & .21 & -.12 & $.32 *$ \\
\hline 14 & .03 & -.04 & -.09 & .04 \\
\hline 15 & -.10 & -.11 & .22 & -.26 \\
\hline 16 & .22 & .07 & -.04 & .07 \\
\hline 17 & -.10 & .03 & -.24 & $-.50^{* *}$ \\
\hline 18 & -.02 & .19 & .09 & .14 \\
\hline 19 & -.11 & $-.54^{* *}$ & .11 & -.11 \\
\hline 20 & -.06 & .00 & .12 & -.28 \\
\hline
\end{tabular}




$\begin{array}{lrrrr}21 & -.40^{*} & .03 & -.05 & -.07 \\ 22 & -.10 & .10 & .12 & -.09 \\ 23 & -.03 & -.14 & -.11 & .21 \\ 24 & -.05 & .20 & .02 & -.16 \\ 25 & -.07 & -.08 & .45^{*} & -.11 \\ 26 & -.14 & -.10 & .40^{*} & -.06 \\ 27 & -.20 & -.08 & .26 & .03 \\ 28 & -.05 & -.05 & -.04 & -.14\end{array}$

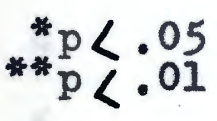

Code 1. Behavioral Side Distance; 2. Simulated Side Distance; 3. Behavioral Frontal Distance; 4. Simulated Frontal Distance; 5. Achievement; 6. Affiliation; 7. Aggression; 8. Autonomy; 9. Dominance; 10. Endurance; 11. Exhibition; 12. Harm Avoidance; 13. Impulsivity; 14. Nurturance; 15. Order; 16. Play; 17. Social Recognition: 18. Understanding; 19. Side Confederate Attractiveness: 20. Side Confederate Size; 2i. Side Confederate Strength; 22. Side Confederate Aggressiveness; 23. Side Confederate Bearing; 24. Frontal Confederate Attractiveness; 25. Frontal Confederate Size; 26. Frontal Confederate Strength; 27. Frontal Confederate Aggressiveness; 28. Frontal Confederate Bearing. 
Table 7

Intercorrelations Among Measures of Interpersonal Distancing, Personality Variables and

Subjects' Ratings of Confederate Characteristics For Internal Subjects $(\mathrm{N}=40)$

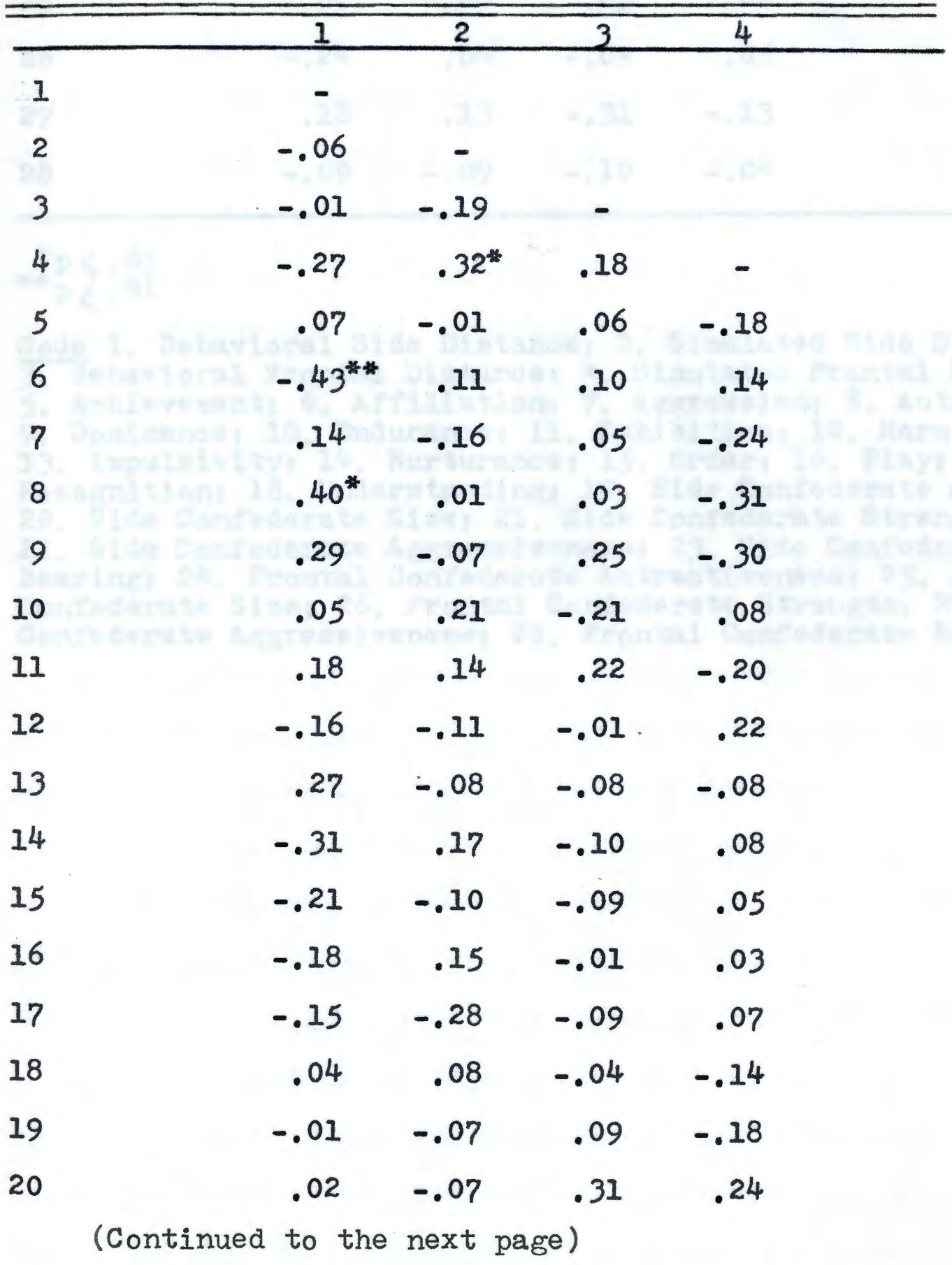




\begin{tabular}{rrrrr}
21 & $-.32^{*}$ & -.11 & .11 & .21 \\
22 & -.22 & .15 & -.02 & .00 \\
23 & .10 & .05 & -.05 & -.24 \\
24 & -.04 & -.12 & .15 & .02 \\
25 & .00 & -.06 & .03 & .04 \\
26 & -.24 & .04 & -.09 & .05 \\
27 & .18 & .13 & -.31 & -.13 \\
28 & -.09 & -.09 & -.019 & -.04 \\
\hline
\end{tabular}

$\begin{aligned} * \mathrm{p} & <.05 \\ * \mathrm{p} & <.01\end{aligned}$

Code 1. Behavioral Side Distance, 2. Simulated Side Distance; 3. Behavioral Frontal Distance; 4. Simulated Frontal Distance; 5. Achievement; 6. Affiliation; 7. Aggression; 8. Autonomy: 9. Dominance; 10. Endurance; 11. Exhibition; 12. Harm Avoidance; 13. Impulsivity; 14. Nurturance; 15. Order; 16. Play: 17. Social Recognition; 18. Understanding; 19. Side Confederate Attractiveness 20. Side Confederate Size; 21. Side Confederate Strength; 22. Side Confederate Aggressiveness; 23. Side Confederate Bearing; 24. Frontal Confederate Attractiveness; 25. Frontal Confederate Size; 26. Frontal Confederate Strength; 27. Frontal Confederate Aggressiveness; 28. Frontal Confederate Bearing. 
The simulated measure of interpersonal distance was found to be significantly related to various personality variables. For all subjects the simulated measure at the frontal orientation was significantly related to Impulsivity $(\underline{r}=.23)$, Externality $(\underline{r}=.25)$, and negatively related to Social Recognition $(\underline{r}=-.26)$. Similarly, for males the simulated measure at the frontal orientation was significantly related to externality ( $\underline{r}=.34)$ and negatively correlated with Social Recognition $(\underline{r}=-.35)$, while for females it was significantly related to Play $(\underline{r}=.36)$. For the externals the simulated measure at the frontal orientation was significantly related to Autonomy $(\underline{r}=.42)$, Impulsivity $(\underline{r}=.32)$, and negatively related to Harm Avoidance $(\underline{r}=-.35)$ and Social Recognition $(\underline{r}=-.50)$. For internals the simulated measures were significantly correlated $(\underline{r}=.32)$ but they were not significantly related to the personality variables.

The behavioral measures of interpersonal distance were also significantly correlated with various personality factors. The strongest relationship between the behavioral measures and personality variables are seen in Table 7 for the internals. The behavioral measure at the side orientation, for subjects with an internal locus of control, was negatively correlated with Affiliation $(\underline{r}=-.43)$ and positively correlated with Autonomy $(\underline{r}=.40)$. In contrast, as seen in Table 6 for subjects with an external locus of control, the behavioral measure at the side orientation was significantly related only to Impulsivity $(\underline{r}=.37)$. Table 3 indicates that for all subjects the behavioral measure of side 
orientation was significantly correlated with Impulsivity $(\underline{r}=.37)$ and externality $(\underline{r}=.26)$. Table 4 indicates that for males this measure was also correlated with Impulsivity $(\underline{r}=.40)$. For females, as shown in Table 5, the behavioral measure for side orientation was negatively related to Affiliation ( $\underline{\underline{m}}=-.38)$ and positively related to aggression $(\underline{r}=.34)$ as well as Impulsivity $(r=.36)$.

An examination of Tables 3 to 7 indicates that there is no significant relationship between the simulated and behavioral measures of interpersonal distancing. However, the simulated measure at the side and frontal orientation were significantly correlated for all subjects $(\underline{r}=.25)$, for internals $(\underline{r}=.32)$. and for females $(\underline{r}=.41)$.

Other significant relationships of interest to this study shown in Table 3 for all subjects is that of the behavioral measure at the side orientation and subject's perception of confederate's strength $(\underline{r}=-.31)$, and that of the behavioral measure at the frontal orientation and subject's perception of confederate's size $(\underline{r}=.24)$. For males, the behavioral measure at the side orientation was negatively related to perception of confederates' aggressiveness $(\underline{r}=-.38)$ while for females it was negatively related to their perception of confederates' strength $(\underline{r}=-.33)$. Table 6 indicates that for externals the behavioral measure at the side orientation was negatively related to perception of confederates' strength $(\underline{r}=-.40)$, while the behavioral measure at the frontal orientation was related to perception of confederates size $(\underline{r}=.48)$ and also that of confederate strength $(\underline{r}=.39)$. 
Finally, for internals the behavioral measure at the side orientation was negatively related to subjects perception of confederate strength $(\underline{r}=-.32)$.

\section{Simulated Interpersonal Distance Scores}

The data collected by means of the simulated measure were analyzed by a $2 \times 2 \times 2 \times 2$ analysis of variance with repeated measures on the last variable. The analysis contained the following factors: sex of felt figure, locus of control of subjects (internals and externals), sex of the other felt figure and body orientation (side and frontal). As a preliminary procedure, Hartley's F max test (Winer, 1972) was applied to the data and indicated extreme violation of the homogeneity of variance assumption $(F \max (16.9)=75.04$, $\underline{p}(.01)$. A logarithmic transformation of the data was thus performed. The data was again tested using a Hartley's F max test and no violation of the homogeneity of variance assumption was found $(F \max (16,9)=12.25, \underline{p}>.01)$. The summary of the analysis of variance of the transformed simulated interpersonal distance scores is presented in Table 8.

As can be seen in Table 8 , significant differences were found for locus of control $(F(1,72)=4.59, p<.05)$ and orientation $(F(1,72)=33.61, p<.01)$ in terms of distance between the felt figures. The mean distance scores (transformed) for internals and externals were .99 and 1.11 respectively. The mean distance score (transformed) for side and frontal body orientation were 1.176 and .923 respectively. 
Table 8

Summary Table of Analysis of Variance of Simulated Spatial Measure

\begin{tabular}{|c|c|c|c|c|}
\hline ou & $\begin{array}{l}\text { Sum of } \\
\text { Squares }\end{array}$ & $\begin{array}{l}\text { es of } \\
\text { dom }\end{array}$ & $\begin{array}{r}\text { Me } \\
\text { Squ }\end{array}$ & $F$ \\
\hline \multirow{2}{*}{$\begin{array}{l}\text { Sex of Ss (A) } \\
\text { Locus of Control (B) } \\
\text { Sex of } \\
\quad \text { Confederate (C) } \\
\text { AXB } \\
\text { AXC } \\
\text { BXC } \\
\text { AXBXC } \\
\text { Error } 1\end{array}$} & $\begin{array}{r}.010 \\
.527 \\
.015\end{array}$ & $\begin{array}{l}1 \\
1 \\
1\end{array}$ & $\begin{array}{r}.010 \\
.527 \\
.015\end{array}$ & $\begin{array}{r}4.5 \\
.1\end{array}$ \\
\hline & $\begin{array}{r}.017 \\
2.040 \\
.234 \\
.133 \\
8.274\end{array}$ & $\begin{array}{r}1 \\
1 \\
1 \\
1 \\
72\end{array}$ & $\begin{array}{l}.017 \\
2.04 \\
.234 \\
.133 \\
.144\end{array}$ & $\begin{array}{r}17 \\
2 . \\
1 .\end{array}$ \\
\hline $\begin{array}{l}\text { rientation (D) } \\
X D \\
X D \\
X D \\
X B X D \\
X C X D \\
X C X D \\
X B X C X D \\
\text { rror } 2\end{array}$ & $\begin{array}{r}2.573 \\
.006 \\
.036 \\
.044 \\
.028 \\
.001 \\
.068 \\
.034 \\
5.512\end{array}$ & $\begin{array}{r}1 \\
1 \\
1 \\
1 \\
1 \\
1 \\
1 \\
1 \\
72\end{array}$ & $\begin{array}{l}2.573 \\
.006 \\
.036 \\
.044 \\
.028 \\
.001 \\
.068 \\
.034 \\
.076\end{array}$ & $\begin{array}{r}33.6 \\
.0 \\
.4 \\
.5 \\
.3 \\
.0 \\
.8 \\
.4\end{array}$ \\
\hline $\begin{array}{l}p<.05 \\
p<.01\end{array}$ & & & & \\
\hline
\end{tabular}

The interaction of sex of felt figure by sex of the other felt figure pair was found to be statistically significant $(F(1,72)=17.76, \underline{p}<.01)$. The summary of the means comprising this interaction are presented in Table 9.

A simple main effects analysis indicated significant differences across sex of the other felt-figure pair for the male felt figure $(F(1,72)=7.52, \underline{p}<.01)$ and for the female felt figure $(F(1,72)=9.83, \underline{p}<.01)$. It was thus found that mixed sex felt-figure pairs were placed closer together than 
same sex felt-figure pairs.

\section{Table 9}

Summary of the Mean Distance Scores (Transformed)

For Male and Female Felt-Figures With

other Male and Female Felt-Figure Pairs

\begin{tabular}{|c|c|c|c|}
\hline Sex of Felt Figure & $\begin{array}{l}\text { Sex of other } \\
\text { Male }\end{array}$ & $\begin{array}{c}\text { Felt Figure } \\
\text { Female }\end{array}$ & Pair \\
\hline Male & 1.147 & .938 & \\
\hline Female & .935 & 1.180 & \\
\hline
\end{tabular}

Behavioral Interpersonal Distance Scores

The data collected by means of the behavioral measures were analyzed by a $2 \times 2 \times 2 \times 2$ analysis of variance with repeated measures on the last variable. The factors used in the design were sex of subject, locus of control of subjects (internals and externals), sex of confederates and body orientation (side and frontal). An $F \max$ test did not reject the assumptions of homogeneity of variance $(F \max (16,9)=$ 15.5. $p>01$ ). The suminary of the analysis of variance of the behavioral interpersonal distance scores is presented in Table 10.

The analysis of variance yielded a significant main effect for the orientation factor $(F(1,72)=185.08, p<.01)$. The mean distance scores for side and frontal orientations were $174.21 \mathrm{~cm}$ and $88.89 \mathrm{~cm}$ respectively. The interaction of sex of subject by sex of confederate by orientations was found to be significant $(F(1,72)=3.99, \underline{p}<.05)$. However, 
Table 10

Summary Table of Analysis

of Variance of Behavioral Measure

\begin{tabular}{|c|c|c|c|c|}
\hline Source & $\begin{array}{l}\text { Sum of } \\
\text { Squares }\end{array}$ & $\begin{array}{l}\text { Degrees of } \\
\text { Freedom }\end{array}$ & $\begin{array}{c}\text { Mean } \\
\text { Square } \\
\end{array}$ & $\mathrm{F}$ \\
\hline $\begin{array}{l}\text { Sex of Ss (a) } \\
\text { Locus of Control (B) } \\
\text { Sex of Confederate (C } \\
\text { AXB } \\
\text { AXC } \\
\text { BXC } \\
\text { AXBXC } \\
\text { Error } 1\end{array}$ & $\begin{array}{r}1139.56 \\
6237.50 \\
4654.80 \\
1.41 \\
4.55 \\
6312.66 \\
5700.15 \\
117395.20\end{array}$ & $\begin{array}{r}1 \\
1 \\
1 \\
1 \\
1 \\
1 \\
1 \\
72\end{array}$ & $\begin{array}{r}1139.56 \\
6237.50 \\
4654.80 \\
1.41 \\
4.55 \\
6312.66 \\
5700.15 \\
1630.49\end{array}$ & $\begin{array}{r}.69 \\
3.82 \\
2.85 \\
.00 \\
.00 \\
3.87 \\
3.49\end{array}$ \\
\hline $\begin{array}{l}\text { Orientation (D) } \\
\text { AXD } \\
\text { BXD } \\
\text { CXD } \\
\text { AXBXD } \\
\text { AXCXD } \\
\text { BXCXD } \\
\text { AXBXCXD } \\
\text { Error } 2\end{array}$ & $\begin{array}{r}291128 \cdot 80 \\
17 \cdot 69 \\
4654 \cdot 87 \\
41 \cdot 12 \\
18 \cdot 66 \\
6287 \cdot 32 \\
1606 \cdot 22 \\
6388 \cdot 35 \\
113255 \cdot 30\end{array}$ & $\begin{array}{r}1 \\
1 \\
1 \\
1 \\
1 \\
1 \\
1 \\
1 \\
72\end{array}$ & $\begin{array}{r}291128.80 \\
17.69 \\
4654.87 \\
41.12 \\
18.66 \\
6287 \cdot 32 \\
1606.22 \\
6388.35 \\
1572.99\end{array}$ & $\begin{array}{c}185.08^{* *} \\
.01 \\
2.96 \\
.03 \\
.01 \\
3.99^{*} \\
1.02 \\
4.06^{* *}\end{array}$ \\
\hline $\begin{array}{l}{ }^{*} p<.05 \\
{ }^{*} p<.01\end{array}$ & & & & \\
\hline
\end{tabular}

the interaction of sex of subject by locus of control by sex of confederate by orientation was also found to be significant $(F(1,72)=4.06, p<.01)$. Thus, only this fourway interaction was further interpreted statistically by means of a series of simple effects tests and simple, simple effects tests. Figure 3 illustrates the interaction as it occurs for each level of orientation and locus of control. Sex of subject by sex of confederate by orientation examined for internals was significant $(F(1,72)=8.06, p<.05)$, while for externals the interaction did not reach significance $(F(1,72)=.001)$. Sex of subject by sex of confederate 

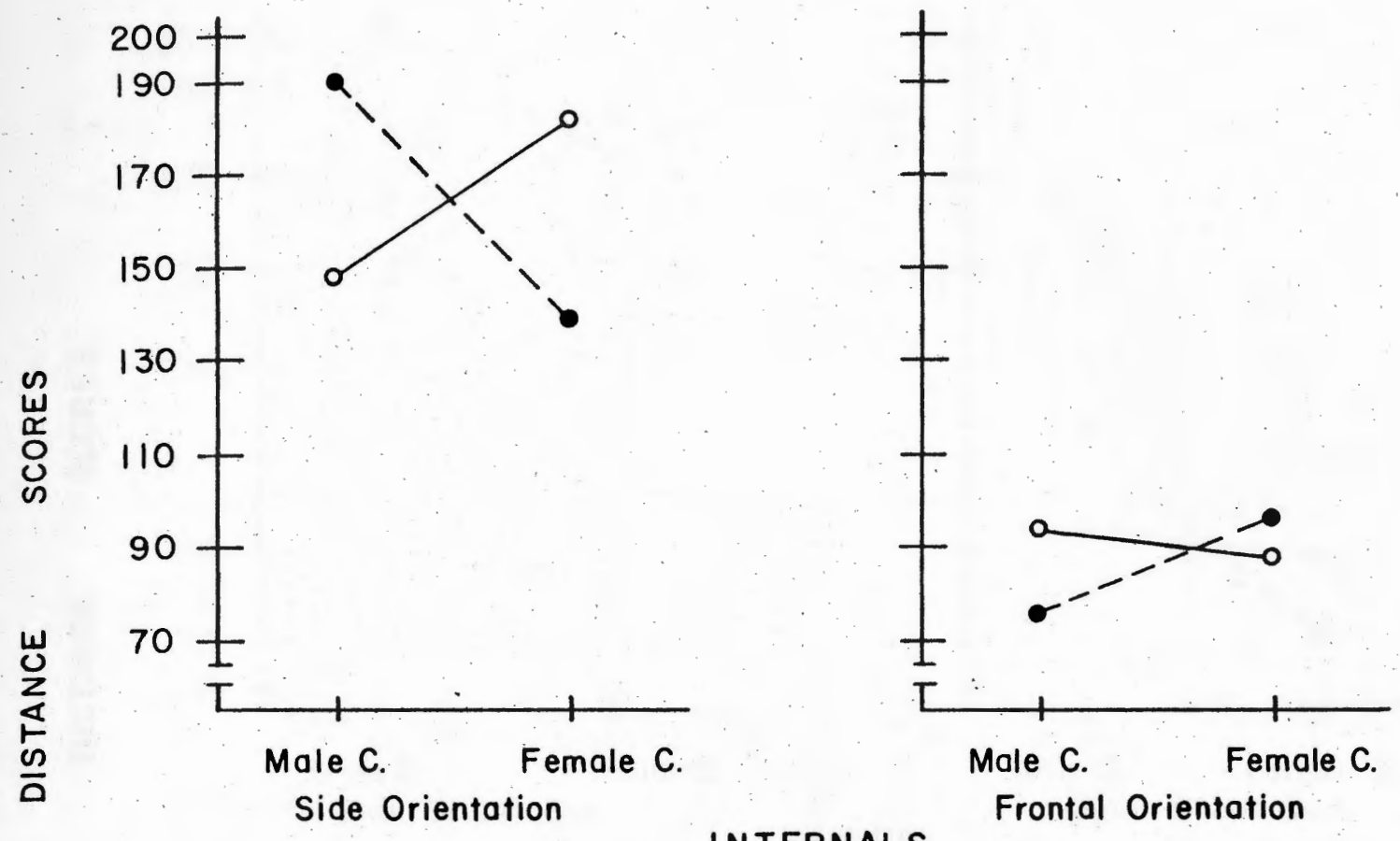

INTERNALS

Frontal Orientation

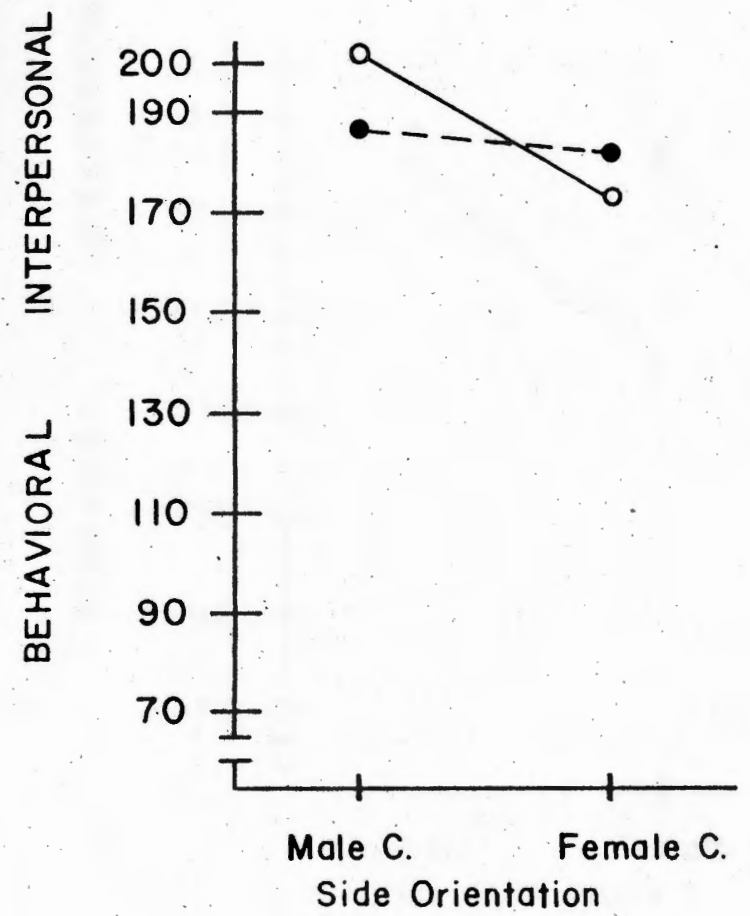

\section{EXTERNALS}

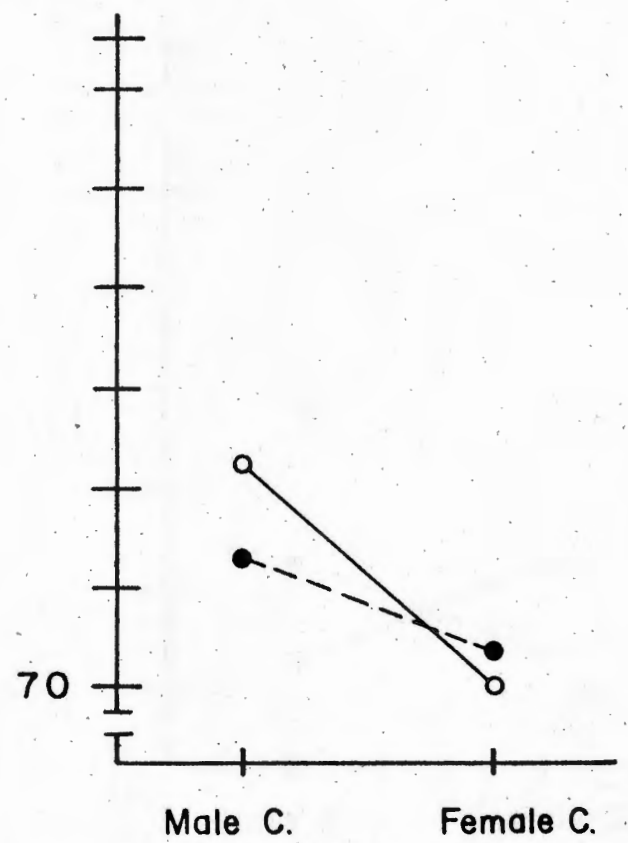

Frontal Orientation

$\bullet--\bullet=$ female subjects

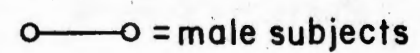

FIGURE 3. Interaction of Sex of Subject by Sex of Confederate at Each Level of Body Orlentation and Locus of control 

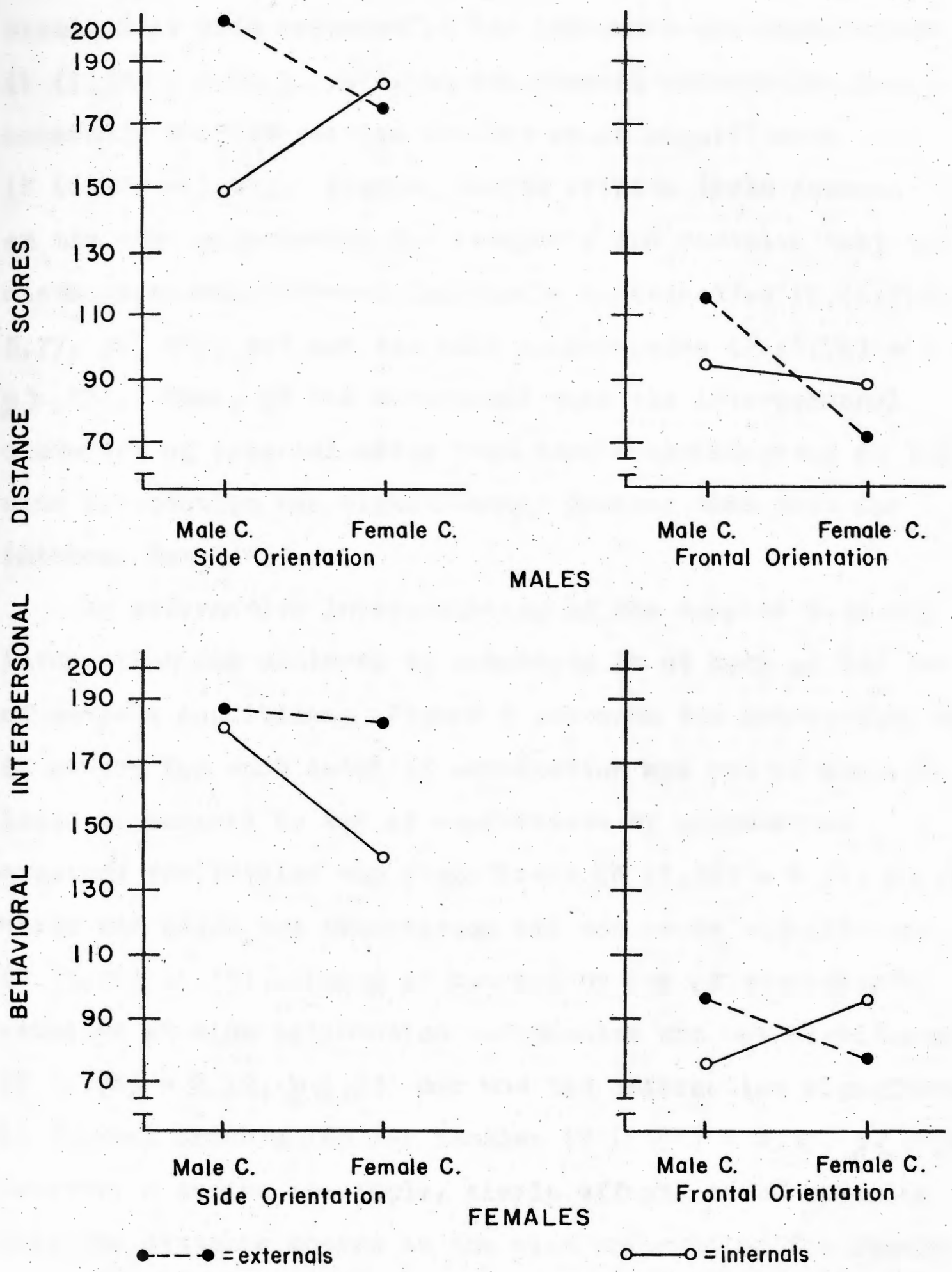

MALES

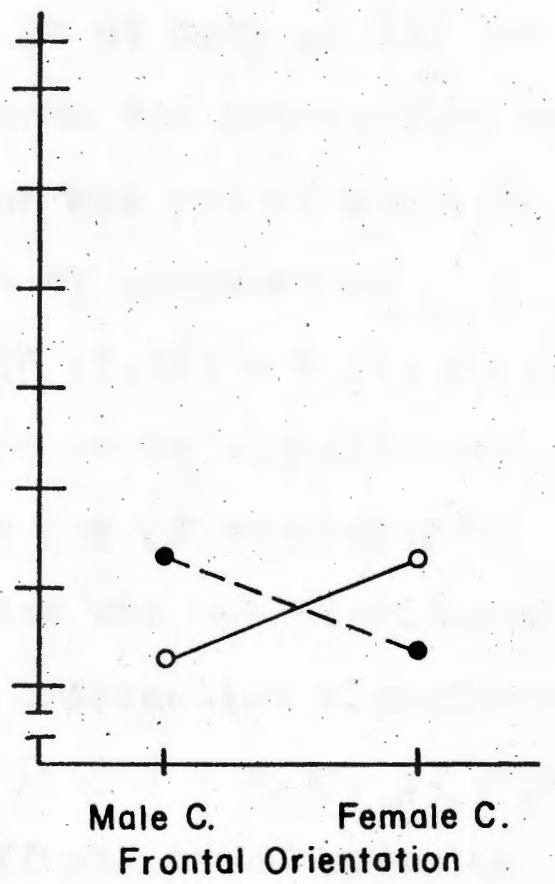

FEMALES

$\stackrel{0}{a}=$ internals

FIGURE 4. Interaction of Locus of Control by Sex of Confederate at Each Level of Body Orlentation and Sex of Subject 
examined at side orientation for internals was significant $(F(1,72)=8.7, \underline{p}<.05)$; at the frontal orientation for internals the interaction did not reach significance $(F(1,72)=1.03)$. Simple, simple effects tests focused on the side orientation for internals and revealed that the distance scores differed for female confederates $(F(1,72)=$ 5.77, $\underline{p}<.05)$, but not for male confederates $(F(1.72)=3.17$. $\underline{p}>$.05). Thus, it was determined that the interpersonal distances of internal males from female confederates at the side orientation was significantly greater than that for internal females.

An alternative interpretation of the complex four-way interaction was achieved by examining it at both of the sex of subject conditions. Figure 4 presents the interaction as it occurs for each level of orientation and sex of subject. Locus of control by sex of confederate by orientation examined for females was significant $(F(1,72)=4.57, p<.05)$, while for males the interaction did not reach significance $(F(1,72)=.50)$. Locus of control by sex of confederate examined at side orientation for females was not significant $(F(1,72)=2.10, \underline{p}<.05)$ nor was the interaction significant at frontal orientation for females $(F(1.72)=2.39, p<.05)$. However, a series of simple, simple effects tests revealed that the distance scores at the side orientation for females differed for female confederates $(F(1,72)=5.63, p<.05)$, but not for male confederates $(F(1,72)=1.35)$ at the frontal orientation. Thus, it was determined that the interpersonal 
distance from female confederates of external females was significantly greater than for internal females at the side orientation. 
Chapter IV

DISCUSSION

The present investigation's major objectives were to determine the following: (a) whether personality variables are related to a simulated spatial measure of interpersonal distancing: (b) whether interpersonal distancing can be understood in terms of a social learning model; (c) the extent to which a simulated spatial measure of interpersonal distancing is related to actual behavior; and (d) the effects of sex differences and body orientation on interpersonal distancing.

The first hypothesis dealt with the relationship between subjects' responses on the simulated spatial measure of interpersonal distancing and personality variables. It was specifically predicted that needs for Affiliation, Autonomy and Dominance would be related to responses on the simulated measure. This hypothesis was only partially supported. Only for subjects with an external locus of control were responses on the simulated measure significantly related to Autonomy. There was no significant correlation between Affiliation and Dominance and responses on the simulated measure.

The second hypothesis was concerned with whether locus of control determines the extent to which personality variables are related to actual interpersonal distance. Specifically, it was predicted that for subjects with an internal locus of control needs for Affiliation. Autonomy and Dominance will be 
more related to the behavioral measure of interpersonal distancing than they will be for subjects with an external locus of control. The results generally supported this hypothesis. Interpersonal distancing on the behavioral measure at the side orientation for internals was positively related to Autonomy, negatively related to Affiliation, and no significant relationship to Dominance. There were no significant relationships between externals ' interpersonal distancing on the behavioral measure and Affiliation, Autonomy and Dominance.

The third hypothesis was concerned with the extent to which a subject's locus of control determines the relationship between a simulated measure and actual interpersonal distancing behavior. It was predicted that the simulated and behavioral measure of interpersonal distancing would be related to a greater extent for subjects with an internal locus of control than subjects with an external locus of control. The results did not support this hypothesis. There were no significant correlations between the simulated and behavioral measures for either internals or externals.

The fourth hypothesis stated that locus of control has a mediational role in interpersonal distancing. It was predicted that subjects with an internal locus of control would demonstrate closer interpersonal distancing behavior on both the simulated and behavioral measures than subjects with an external locus of control. The results partially supported this hypothesis. On the simulated measure, internals placed the felt figures significantly closer together than did the externals. Although there was a trend on the behavioral measure for 
internals to distance themselves closer to others than externals, this finding did not reach statistical significance.

Due to the somewhat exploratory nature of the present study, hypotheses five, six and seven were presented in a nonspecific format. According to hypothesis five, it was predicted that distancing on both the simulated and behavioral measure would differ between side and frontal orientation. The results supported this hypothesis. Distancing at the frontal orientation was significantly closer for both the simulated and behavioral measure than for the side orientation.

Hypothesis six predicted that sex of subject and confederate would differentially affect interpersonal distancing on both the simulated and behavioral measures. There was no support for this hypothesis. On both the simulated and behavioral measures there were no statistically significant differences in interpersonal distancing between male and female subjects nor between male and female confederates.

Hypothesis seven stated that sex of subject would interact with sex of confederate to differentially affect interpersonal distancing on the simulated and behavioral measures. This hypothesis was supported for the simulated but not for the behavioral measures. Mixed sex felt-figure pairs were placed closer together than same sex pairs. There was no significant interaction of sex of subject by sex of confederate in the behavioral measure. 
Overall Implications, Problems and Limitations

The evidence in support of the contention that the simulated measure reflects individuals' personality traits related to need or wish for closeness to others was partially supported only for subjects with an external locus of control. This finding is consistent with previous investigations which have also produced limited and ambiguous results. A major question to be answered is why the personality traits of Autonomy, Impulsivity, Harm Avoidance and Social Recognition are significantly related to externals ' responses on the simulated measure while none of the personality traits measured were related to internals' responses on the simulated measure.

This issue can be brought into a larger context by viewing social learning theory as a framework for understanding interpersonal distancing. A central hypothesis of the present investigation is that locus of control operates as a mediating variable in interpersonal distancing behavior. The findings from the present investigation provide only partial support for this view. On the behavioral measure, subjects with an internal locus of control did reflect needs related to a desire for interpersonal closeness while subjects with an external locus of control did not. Internals did demonstrate closer interpersonal distancing, as demonstrated on the simulated measure than externals did. However, on the behavioral measure, internals did not maintain closer distances to others than externals. Finally, the relationship between the simulated and behavioral measures were not related for either internals 
or externals.

A problem with the conceptual framework of the present investigation may have been its heavy reliance on the concept of locus of control. While it is a major concept, it certainly is not the sole determinant of behavior. Expectancy of reinforcements is only one of three major determinants dealt with in Rotter's Social Learning Theory. "The nature of the reinforcement itself, whether positive or negative, the past history, sequence, and patterning of such reinforcements, and the value attached to the reinforcement are obviously important and probably more crucial determinants of behavior" (Rotter, 1975, p. 57). Thus, focusing only on locus of control may have resulted in an oversimplification of the theory and in limiting its predictive value. For example, on the simulated measure, subjects may have assumed that the figures represented highly attractive individuals and so the reinforcement values were high. Therefore, internals responded as predicted and placed the figures closer together than externals. However, on the behavioral measure approaching the confederate may simply have not been seen as having much reinforcement value.

Another possible problem area may have been that the behavioral situations were overly specific. The importance of a generalized expectancy of reinforcement increases as a situation becomes more unstructured. The lack of explicit situational cues should allow subjects to behave in a characteristically internal or external fashion. The intent of the behavioral measures were to create this sort of ambiguous 
situation, only under these conditions could it be expected that a prediction of behavior be made from a measure of generalized expectancy. However, as will be discussed under methodological issues, the behavioral measure may in fact be viewed as having very specific cues (i.e. explicit instructions given to the subjects).

Another possible limitation was the use of the Rotter I-E Scale. Major reviews of the research literature have indicated that there is support for the view that locus of control needs to be studied at a multi-dimensional rather than unidimensional level (Joe, 1971; Phares, 1975). Factor analysis of the Rotter I-E scale has generally revealed a dimension relating to personal habits, traits and goals and another dimension concerned with social and political events. It would certainly seem that a measure which could differentiate between these two dimensions would increase its predictive power for certain situations. Optimally, the more specific a measure of expectancy for particular type of situation, the greater its potential predictive power. Constructing a separate measure for every specific purpose would be a most difficult task. A measure of generalized expectancy which could distinguish between the two dimensions of personal versus political control would be easier to develop and a decided refinement of the tool. It would seem that factor analysis of the I-E is only a first step in the development of an improved instrument. There is at this time little support for the predictive utility of these separate factors 
and good evidence supporting Rotter's contention that most of the variance is accounted for by one general factor (Rotter, 1975).

It seems clear that a complete test of whether Rotter's social learning theory provides a framework for understanding interpersonal distancing is impractical. For example, it would be required that the entire reinforcement history of individuals in social situations be known. Further indirect and partial tests are the only practical approach. Such assessments would include investigating again how internals and externals vary in their interpersonal distancing among strangers. However, a behavioral measure without as many eliciting cues as that used in this study should be developed. Another possible alternative approach would be to experimentally manipulate subjects' expectancies for reinforcement in the behavioral situation and determine interpersonal distancing.

The preponderance of evidence from previous studies indicates that interpersonal distancing is influenced by sex. The present finding that mixed sex felt-figure pairs are placed significantly closer together than same sex pairs is consistent with studies using simulated measures (e.g. Kuethe, 1962a; Meisels and Guardo, 1969; Tolor and Salfia, 1971). That the results of the behavioral measure did not support the above finding is also consistent with previous investigations (e.g. Dosey and Meisels, 1969; Bailey, Hartnett \& Gibson,1972; Eberts and Lepper, 1975). It would appear that a generally held belief among people in this culture is that a man and a 
woman belong closer together than either two men or two women. This belief is clearly expressed in the simulated measure. There are, however, many factors which would determine whether this cultural view is expressed behaviorally. For instance, the degree of acquaintance between individuals and the setting of their interaction appears to be crucial factors. While the behavioral measures were taken among strangers and in a task-oriented setting, one can only guess as to the assumptions subjects held concerning these factors on the simulated measure.

The present finding that the simulated and behavioral measure of interpersonal distancing were not related has also often been reported in previous investigations (Dosey and Meisels, 1969; Love and Aiello, 1976). One of the major methodological problems with previous studies which have found significant correlations between simulated and behavioral measures has been in their not controlling for subject awareness of the task (e.g. Little, 1965; Haase and Markey, 1973). This problem is clearly demonstrated in Pedersen's (1973b) study in which he reported a moderately high correlation between a simulated and behavioral measure when subjects were aware that their interpersonal distancing was being measured. However, there was no relationship between the simulated and an unobtrusive behavioral measure. Thus, the present finding is consistent with those studies in which subjects were not aware that their interpersonal distancing was being measured. 
Methodological Issues

There are certain problems with the present measure which may have limited the extent to which they were related. While the simulated and behavioral measures were constructed so as to be as comparable as possible, one of the major differences that remained was that the felt figures were in a standing position while the behavioral measures were taken when subjects were seated. It certainly is a reasonable possibility that interpersonal distancing in a sitting position may be quite different from interpersonal distancing in a standing position.

The simulated and behavioral measures may have also lacked comparability in that one was highly ambiguous and unstructured while the other was relatively structured. In the simulated measure subjects were merely handed a pair of felt figures and told to place them anywhere they wished on the felt board. Subjects' assumptions regarding these figures may have added a great deal of error variance to the results. Whether subjects assumed that these figures represented friends, acquaintances or strangers would affect the distance they would place between them (Iittle, 1965). The comparability between the simulated and behavioral measure could have been greatly decreased if subjects perceived the felt figures as representing friends and acquaintances while in the behavioral measure they were faced with strangers.

The behavioral measures may have also been overly affected by the procedures used to prevent subject awareness of the task 
being measured. On the behavioral measure at the side orientation, subjects were simply asked to sit down on a bench, on which a confederate was already seated, to complete a biographical questionnaire. For the frontal orientation, subjects were asked to pull up a chair in front of and facing the confederate and to be seated. The different demands made on the subjects for the side and frontal behavioral measures may account for the lack of a significant relationship between them. In comparison, the response on the side and frontal orientation of the simulated measures were significantly related for all subjects.

Another indication of the lack of comparability between the behavioral measures can be seen through use of Hall's (1966) description of distance zones. The mean behavioral interpersonal distance for all subjects at the side orientation was within what Hall calls the "social-consultative" zone. A feature of this distance is that it allows a person to work in the presence of another without appearing to be rude. This description certainly fits what a subject was required to do in the behavioral measure for side orientation. On the other hand, the frontal behavioral measure was within what Hall calls the "personal" zone. A feature of this zone which seems especially related to what subjects possibly expected would happen, is that topics of personal interest and involvement can be discussed. In sum, the behavioral measure may have so structured subjects' expectations and thus interpersonal distancing, that any relationship to actual interpersonal distancing is certainly suspect. 
It was hoped that improvements in the measurement techniques of interpersonal distancing would provide clarification of some of the inconsistent findings related to sex differences and body orientation. It was clearly found on both simulated and behavioral measures that interpersonal distancing is close at the frontal than the side orientation. The methodological problems with the behavioral measure would tend to suggest that this difference in distancing for the two orientations may be mostly a reflection of the demand characteristics of the task.

Yet for all subjects, distancing on the simulated measure was also closer for the frontal than the side orientation regardless of sex of felt figure. It is probable that on the simulated measure most subjects believed that the figures when facing each other could be assumed to be interacting on some level. Several subjects while placing the figures on the board spontaneously remarked that the figures appeared to be talking to each other. A similar expectation also probably occurred on the frontal behavioral measure. In contrast, felt figures at the side orientation probably were perceived as separate and therefore should be at greater distances from each other.

\section{Future Directions}

The psychological situation, as perceived by the subjects, on both measures needs to be made more equivalent in future research. On the simulated measure, this could be accomplished by clearly stating to the subjects the relationship and action 
the felt figures represent. Unfortunately, decreasing the ambiguousness increases the subject awareness of the task, with all the problems that invokes, and affects the predictive value of locus of control.

Interpersonal distancing is obviously a complex phenomenon which requires continued systematic research. The variables relevant to interpersonal distancing behavior are not clear. The greatest obstacles to progress in this field remains the conceptually and psychometrically inadequate measurement techniques used. The present study highlighted the difficulties involved in constructing such measures. Refinement of the measures developed for this study should provide a firmer base for continued investigations.

It does seem clear that the often held assumptions of the equivalence of simulated and behavioral measures are unwarranted and impede further understanding of interpersonal distancing. The simulated measure may have tapped some cognitive representation of interpersonal distancing. Its relationship with actual behavior has yet to be resolved, but it appears to probably be tangential. Hall (1966) has pointed out that in our distancing behavior we may utilize depth perception, olfaction, heat radiation and audition. These are very different sensory cues then that are available in a simulated measure of interpersonal distancing. This lack of congruence between the simulated and behavioral measure of interpersonal distancing is similar to the often cited problem of traditional personality assessment and behavioral prediction 
(Mischel, 1968). It is generally recognized that projective instruments have so little predictive validity that their sole use in predicting future behavior is completely unjustified (Anastasi, 1961). A similar conclusion regarding interpersonal distancing may also be warranted. The phenomenon of interpersonal distancing may best be investigated by recognizing that there is a cognitive and a behavioral dimension. Each of these dimensions require separate research efforts before they can be adequately defined and integrated into a comprehensive theoretical framework.

\section{Applied Implications}

The practical implications stemming from research in this area must await further findings. However, this is an area that is highly relevant to psychologists involved in therapeutic and diagnostic work. For example, one of the often used projective techniques is that of human figure drawings. What is the clinical significance of a child being asked to draw his family and then placing large spaces between each member of his family? Is this a reflection of the family's actual behavior towards each other or in some way represents a psychological reality for the child? This particular technique suffers from the same lack of proven validity of most projective measures. As the cognitive and behavioral dimensions of interpersonal distancing is further defined and understood, it should provide a clearer understanding of the validity of projective techniques which focus on an individual's use of space. 
The use of space is one way we communicate with each other and thus may provide a vehicle for communication in a therapeutic setting. Certainly, it has often been shown that what a client says verbally may in fact not be congruent with his non-verbal communication. This duplicity of communication thus provides grist for the therapeutic mill. Horowitz et. al (1964) was one of the first to demonstrate that an abnormality in interpersonal distancing is a sign of psychopathology. Kinzel (1972) demonstrated that extremely violent prisoners maintained approximately four times the distance from others than non-violent prisoners. If interpersonal distancing is, as seems reasonable, inextricably intertwined with interpersonal relationships, then it has enormous potential utility in clinical areas. With increased knowledge of the variables affecting interpersonal distancing, its usefulness in understanding and modifying human interactions can only increase. 


\section{BIBLIOGRAPHY}

Anastasi, A. Psychological Testing, 2nd Ed. New York:

Macmillian Company, 1961.

Anastasi, A. Review of D.N. Jackson, Personality Research Form.

In O.K. Buros (Ed.) The Seventh Mental Measurements

Yearbook. Highland Park, N.J.: Gryphon Press, 1972, 297-298. Argyle, M. \& Dean, J. Eye contact, distance and affiliation. Sociometry, 1965, 28, 289-302.

Bailey, K.G., Hartnett, J.J. \& Gibson, F.W., Jr. Implied threat and the territorial factir in personal space.

Psychological Reports, 1972, 30, 263-270.

Barrios, B.A., Corbitt, I.C., Estes, J.P. \& Topping, J.S.

Effect of social stigma on interpersonal distance.

The Psychological Record, 1976, 26, 343-348.

Booraem, C.D. \& Flowers, J.V. Reduction of anxiety and personal

space as a function of assertion training with severely

disturbed neuropsychiatric inpatients. Psychological

Reports, 1972, 20, 923-929.

Brannigan, G.G. \& Tolor, A. Self-parental distance, control of reinforcement, and personal future time perspective. The Journal of Genetic Psychology, 1971, 112, 151-157.

Byrne, D., Baskett, G.D. \& Hodges, I. Behavioral indicators of interpersonal attraction. Journal of Applied Social Psychology, 1971, 1. 137-149.

Church, M.A. A test of four alternative hypotheses of the influences of expressed attitudes, personal evaluations and self-esteem on attraction. Unpublished doctoral 
dissertation, University of Miami, 1975.

Dosey, M.A. \& Meisels, M. Personal space and self-protection. Journal of Personality and Social Psychology, 1969, 11. 293-297.

Duke, M. \& Mullens, M.C. Preferred interpersonal distance as a function of locus of control orientation in chronic schizophrenics, non-schizophrenic patients, and normals. Journal of Consulting and Clinical Psychology, 1973, 41, $230-234$.

Duke, M. \& Nowicki, S. A new measure and social learning model

for interpersonal distance. Journal of Experimental

Research in Personality, 1972, 6, 119-132.

DuHamel, T.R. \& Jarmon, H. Social schemata of emotionally-

disturbed boys and their male siblings. Journal of

Consulting and Clinical Psychology, 1971, 26, 281-285.

Eberts, E.H. Social and personality correlates of personal

space. In W.J. Mitchel (Ed.) Environmental Design:

Research and Practice. Proceedings of the EDRA III/AR

VIII Conference, Los Angeles: University of California

Press, 1972.

Eberts, E.H. \& Lepper, M.R. Individual consistency in proxemic

behavior of preschool children. Journal of Personality

and Social Psychology, 1975, 32, 841-849.

Evans, G.W., Howard, R.G. Personal space. Psychological

Bulletin, 1973, 80, 334-344.

Exline, R. Explorations in the process of person perception

Visual interaction in relation to competition, sex and

need for affiliation. Journal of Personality, 1963, 31, 1-20. 
Fisher, R.I. Social schema of normal and disturbed school children. Journal of Educational Psychology, 1967, 58. 88-92.

Fisher, J.D. \& Byrne, D. Too close for comfort: sex differences in response to invasions of personal space. Journal of Personality and Social Psychology, 1975, 32, 15-21. Frankel, A.S. \& Barrett, J. Variations in personal space as a function of authoritarianism, self-esteem and racial characteristics of a stimulus situation. Journal of Consulting and Clinical Psychology, 1971, 37. 95-98. Gerber, G.I. Psychological distance in the family as schematized by families of normal, disturbed and learning-problem children. Journal of Consulting and Clinical Psychology, 1973, 40, 139-147.

Gerber, G.L. \& Kaswan, J. Expression of emotion through family grouping schemata, distance and interpersonal focus. Journal of Consulting and Clinical Psychology, 1971, 26. $370-377$.

Goldberg, G., Kiesler, C. \& Collins, B. Visual behavior and face-to-face distance during interaction. Sociometry, $1969,32,43-53$.

Gottheil, E., Corey, J. \& Paredes, A, Psychological and physical dimensions of personal space. The Journal of Psychology, 1968, 69, 7-9.

Guardo, C.J. Personal space in children. Child Development, 1969, 40, 143-151. 
Haase, R.F. \& Markey, M.J. A methodological note on the study of personal space. Journal of Consulting and Clinical Psychology, 1973, 40, 122-125.

Hal1, E.T. The Hidden Dimension. New York: Doubleday, 1966. Hartnett, J.J., Bailey, K.G. \& Gibson, F.W., Jr. Personal space as influenced by sex and type of movement. The Journal of Psychology, 1970, 76, 139-144. Horowitz, M.J., Duff, D.F., \& Stratton, L.0. Body buffer zone. Archives of General Psychiatry, 1964, 11, 651-656. Jackson, D.N. Manual for the Personality Research Form. Goshen, New York: Research Psychologists Press, 1967. Joe, V.C. Review of the internal-external control construct as a personality variable. Psychological Reports, 1971. 28, 619-640.

Kinzel, A.F. Syndromes resulting from social isolation. In Cullen, J.H. (Ed.) Experimental Behavior: A Basis for the Study of Mental Disturbance. Irish University Press, 1972. Kuethe, J.I. Social schemas. Journal of Abnormal and Social Psychology, 1962a, 64, 31-38. Kuethe, J.L. Social schemas and the reconstruction of social object displays from memory. Journal of Abnormal and Social Psychology, 1962b, 65, 71-74.

Kuethe, J.I. Pervasive influence of social schemata. Journal of Abnormal and Social Psychology, 1964, 68, 248-254. Kuethe, J.I. Prejudice and aggression: A study of specific social schemata. Perceptual and Motor Skills, 1964b, 18, $107-115$. 
Kuethe, J.L. \& Weingarten, H. Male-female schemata of homosexual and non-homosexual penitentiary inmates. Journal of Personality, 1964, 32, 23-31.

Lefcourt, H.M. Internal versus external control of reinforcement: A review. Psychological Bulletin, 1966, 65, 201-220. Leipold, W.E. Psychological distance in a dyadic interview. Doctoral dissertation, University of North Dakota, 1963. cited by R. Sommer, 1969.

Lett, E., Clark, W. \& Altman, L. A propositional inventory of research on interpersonal distance. Naval Medical Research Institute Research Report, 1969. Levinger, G. \& Gunner, J. The interpersonal grid, I. Felt and tape techniques for the measurement of social relationships. Psychonomic Science, 1967, $8,173-174$.

Little, K.B. Cultural variation in social schemata. Journal of Personality and Social Psychology, 1968, 10, 1-7. Iittle, K.B. Personal space. Journal of Experimental Social Psychology, 1965, 1, 237-247. Lomranz, J., Shapira, A., Choresh, N. \& Gilat, Y. Children's personal space as a function of age and sex. Developmental Psychology, 1975, 11, 541-545.

Love, K.D. \& Aiello, J.R. Relationship between observed interaction distance and projective distance measures. Paper presented at the American Psychological Association Convention, Washington, D.C., 1976. Maccoby, E.E. \& Jacklin, C.N. The Psychology of Sex Differences. Stanford, California: Stanford University Press, 1974. 
Mehrabian, A. Significance of posture and position in the communication of attitude and status relationship. Psychological Bulletin, 1969, 21, 359-372. Meisels, M. \& Canter, F.M. Personal space and personality characteristics: A non-conformation. Psychological Reports, 1970, 27, 287-290.

Meisels, M. \& Guardo, C.J. Development of personal space schemata. Child Development, 1969, 40, 1167-1178. Miller, N.E. Experimental studies in conflict. In J.McV. Hunt (Ed.) Personality and the Behavior Disorders, Vol. 1, New York: Ronald Press, 1944, 431-465. Mischel, W. Personality and Assessment, New Yorks John Wiley \& Sons, Inc.. 1968.

Patterson, M.I., Mullens, S. \& Romano, J. Compensatory reactions to spatial intrusions. Sociometry, 1971, 34, 1, 114-121. Pedersen, D.M. Relations among sensation seeking and simulated and behavioral personal space. Journal of Psychology. $1973 a, 83,79-88$.

Pedersen, D.M. Development of a personal space measure. Psychological Reports, 1973b, 32, 527-535.

Pedersen, D.M. Developmental trends in personal space. Journal of Psychology, 1973c, 83, 3-9.

Pellegrini, R.J. \& Empey. J. Interpersonal spatial orientation in dyads. The Journal of Psychology, 1970, 26, 67-70. Phares, E.J. Internal-external control as a determinant of amount of social influence exerted. Journal of Personality and Social Psychology, 1965, 2., 642-647. 
Phares, E.J. Locus of Control in Personality. New Jersey:

General Learning Press, 1976.

Rotter, J.B. Generalized expectancies for internal versus

external control of reinforcement. Psychological Monographs:

General and Applied, 1966, 80, (1) (Whole No. 609).

Rotter, J., Chance, J.E. \& Phares, E.J. Applications of a

Social Learning Theory of Personality. New York:

Holt, Rinehart \& Winston, 1972.

Seeman, M. \& Evans, J.W. Alienation and learning in a hospital

setting. American Sociological Review, 1962, 27, 772-783.

Sneider, J.M. College students' belief in personal control.

Journal of Individual Psychology, 1971, 27, 188.

Sommer, R. Studies in personal space. Sociometry, 1959, 22 , $247-260$.

Sommer, R. Small group ecology. Psychological Bulletin, 1967. 67. 145-152.

Sommer, R. Personal Space. New Jersey: Prentice Hall, Inc., 1969.

Strickland, B.R. The prediction of social action from a dimension of internal-external control. Journal of Social Psychology, 1965. 353-358.

Tipton, R.M., Bailey, K.G. \& Obenchaim, J.P. Invasion of males personal space by femininists and non-femininists. Psychological Reports, 1975, 32, 99-102.

Tolor, A. Psychological distance in disturbed and normal children. Psychological Reports, 1968, 23, 695-701. 
Tolor, A. Fallacy of schizophrenic deficit in the interpersonal sphere. Journal of Consulting and Clinical Psychology, $1970,35,278-282$.

Tolor, A. Effects of procedural variation in measuring interpersonal distance by means of representational space. Psychological Reports, 1975, 36, 475-491.

Tolor, A., Brannigan, G.G. \& Murphy, V.M. Psychological distance, future time perspective and internal-external expectancy. Journal of Projective Techniques and Personality, 1970, 34, 283-294.

Tolor, A. \& Jalowiec, J.E. Body boundary, parental attitudes and internal-external expectancy. Journal of Consulting and Clinical Psychology, 1968, 32, 206-209.

Tolor, A. \& LeBlanc, R.F. An attempted clarification of the psychological distance construct. The Journal of Social Psychology, 1974, 22, 259-267.

Tolor, A, \& Orange, S. An attempt to measure psychological distance in advantaged and disadvantaged children. Child Development, 1969, 408-420.

Tolor, A., Warren, M. \& Weinick, H.M. Relation between parental interpersonal styles and their children's psychological distance. Psychological Reports, 1971, 29, 1263-1275. Weinstein, L. Social schemata of emotionally-disturbed boys. Journal of Abnormal Psychology, 1965, 20, 457-461. Winer, B.J. Statistical Principles in Experimental Design (2nd ed.). New York: McGraw-Hill, 1971. 
APPENDIX A - TABLES 
Intercorrelations Among the 29 Variables

For All Subjects $(\mathrm{N}=80)$

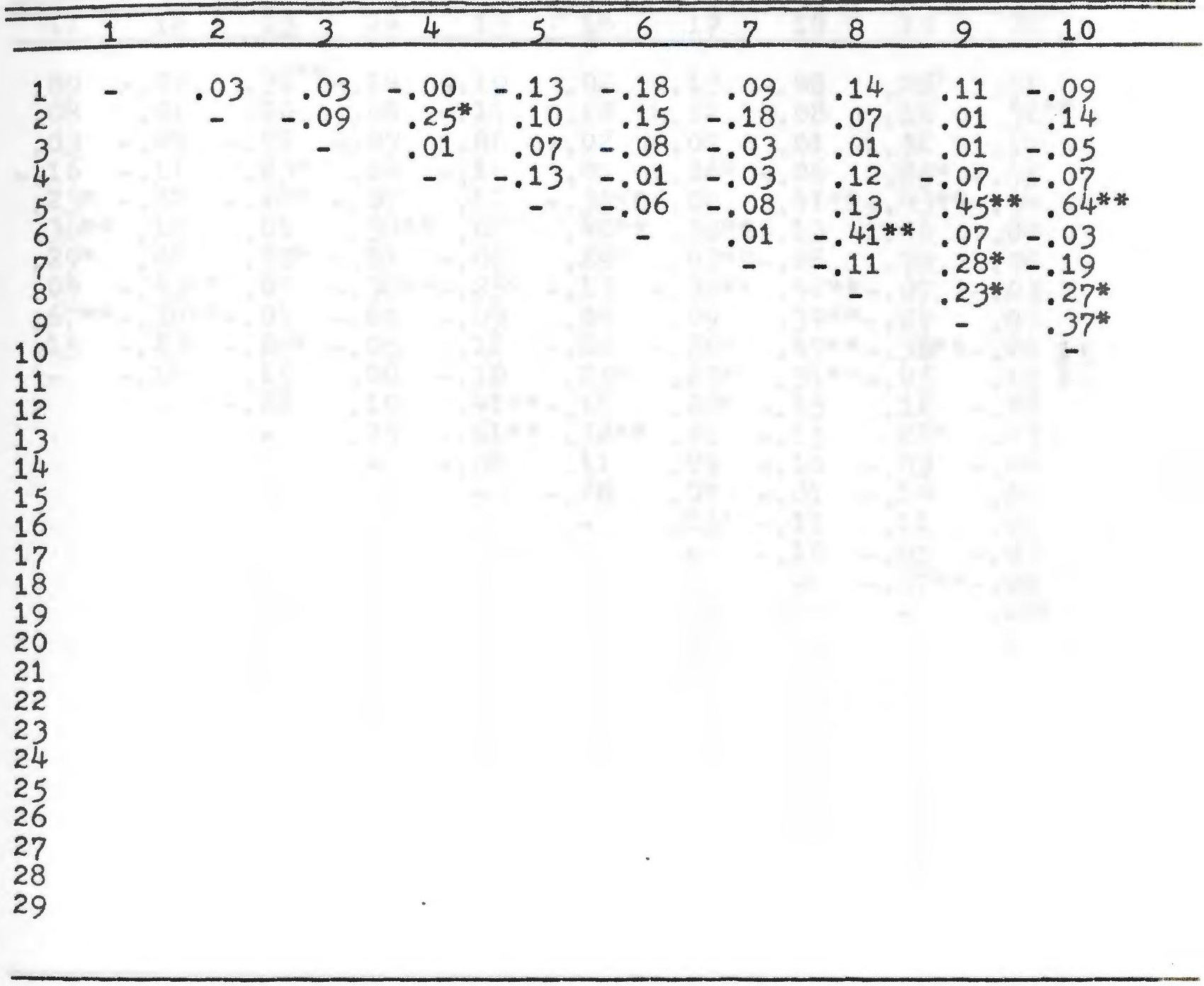

$$
\begin{aligned}
& { }^{*} \mathrm{p} \quad .05 ; \text { ** } \mathrm{p} \quad .01
\end{aligned}
$$


Table 11 (Cont'd.)

\begin{tabular}{|c|c|c|c|c|c|c|c|c|c|}
\hline 11 & 12 & 13 & 14 & 15 & 16 & 17 & 18 & 19 & 20 \\
\hline $\begin{array}{l}.09 \\
.08 \\
.03 \\
.16 \\
.23^{*} \\
.36 * * \\
.29^{*} \\
.04 \\
.67 * * \\
.15 \\
-\end{array}$ & $\begin{array}{r}-.07 \\
.01 \\
-.09 \\
-.11 \\
-.22 \\
.15 \\
.02 \\
-.43^{*} * \\
-.30 * 4 \\
-.23 * \\
-.14 \\
-\end{array}$ & $\begin{array}{l}.36^{* *}-10 \\
-.09 \\
.23 * \\
-.24 * \\
.01 \\
.23^{*} \\
.09 \\
-.01 \\
-.26 * \\
.15 \\
-22\end{array}$ & $\begin{array}{r}-.14 \\
.04 \\
-.09 \\
.04 \\
-.07 \\
.38 * 0 \\
-.01 \\
-.038 * \\
-.09 \\
-.05 \\
.00 \\
.10 \\
.04 \\
-\end{array}$ & $\begin{array}{r}-.19 \\
-.11 \\
.06 \\
-.16 \\
.12 \\
.07 \\
-.09 \\
-.25 \% \\
-.09 \\
.12 \\
-.10 \\
.41 * \\
-.01 * \\
-.00 \\
-\end{array}$ & $\begin{aligned} .02 \\
.12 \\
-.02 \\
.07 \\
-.035^{*} * \\
.40 * * \\
.29 * \\
-.13 \\
.04 \\
-.22 \\
.25^{*} \\
-.18 \\
.32 * * \\
.11 \\
-.20 \\
-\end{aligned}$ & $\begin{array}{l}-.13 \\
-.12 \\
-.07 \\
-.26 * \\
-.09 \\
.38 * * \\
.43 * * \\
-.37 * \\
.09 \\
-.26 * \\
.23^{*} \\
.27 * \\
.01 \\
.09 \\
.07 \\
.25 * \\
-\end{array}$ & $\begin{array}{r}-.08 \\
.08 \\
.01 \\
-.06 \\
.41 * *-1\end{array}$ & $\begin{array}{l}.26^{*} \\
.12 \\
.02 \\
.25^{*} \\
-.43^{*}\end{array}$ & $\begin{array}{r}.01 \\
-.32^{*} \\
.10 \\
-.05 \\
-.04 \\
.00 \\
.08 \\
-.03 \\
.09 \\
-.20 \\
.15 \\
-.07 \\
.03 \\
-.06 \\
.00 \\
.05 \\
-.03 \\
-.06 \\
.27 *\end{array}$ \\
\hline
\end{tabular}


Table 11 (Cont'd.)

\begin{tabular}{|c|c|c|c|c|c|c|c|c|}
\hline 21 & 22 & 23 & 24 & 25 & 26 & 27 & 28 & 29 \\
\hline $\begin{array}{r}.00 \\
-.01 \\
.020 \\
-.07 \\
-.09 \\
.06 \\
.11 \\
.02 \\
.10 \\
.08 \\
.08 \\
.11 \\
-.10 \\
-.04 \\
.00 \\
.02 \\
.14 \\
-.12 \\
.10 \\
.06 \\
-\end{array}$ & $\begin{array}{r}-.31 * \\
-.02 \\
.03 \\
.06 \\
-.05 \\
.20 \\
.01 \\
.03 \\
-.01 \\
.13 \\
.08 \\
.15 \\
-.02 \\
.00 \\
-.00 \\
-.00 \\
.06 \\
.00 \\
.10 \\
.02 \\
.47 * \\
-\end{array}$ & $\begin{array}{r}-.17 \\
.11 \\
.05 \\
-.06 \\
.10 \\
-.04 \\
.10 \\
-.10 \\
.05 \\
.00 \\
.12 \\
-.09 \\
.09 \\
-.111 \\
.06 \\
-.02 \\
-.00 \\
.01 \\
-.06 \\
-.08 \\
-.012 \\
.21 \\
-10\end{array}$ & $\begin{array}{r}.03 \\
-.06 \\
-.08 \\
.03 \\
-.05 \\
-.15 \\
.02 \\
.29 * \\
.08 \\
-.09 \\
.04 \\
-.06 \\
.12 \\
-.01 \\
-.10 \\
-.07 \\
-.04 \\
.14 \\
-.03 \\
.30 \% \\
-.01 \\
-.12 \\
-.25 \% \\
-\end{array}$ & $\begin{array}{r}-.02 \\
.07 \\
.08 \\
-.00 \\
-.14 \\
.04 \\
.06 \\
-.10 \\
.09 \\
-.31 * * \\
.06 \\
.12 \\
-.03 \\
-.03 \\
.14 \\
.17 \\
.30 * * \\
-.02 \\
.06 \\
.06 \\
.03 \\
-.10 \\
-.05 \\
-19 \\
-05\end{array}$ & $\begin{array}{r}-.02 \\
.06 \\
.024 \\
. .05 \\
.15 \\
-.01 \\
-.06 \\
-.12 \\
-.07 \\
.04 \\
-.11 \\
.13 \\
-.26 * \\
-.16 \\
.28 * \\
-.12 \\
-.07 \\
-.04 \\
.00 \\
.28 * \\
.20 \\
.04 \\
-.03 \\
-.03 \\
.13 \\
-0\end{array}$ & $\begin{array}{r}-.17 \\
-.03 \\
.17 \\
-.00 \\
.24 \\
.10 \\
-.04 \\
-.07 \\
-.04 \\
.21 \\
.03 \\
.04 \\
-.17 \\
-.05 \\
.26 * \\
-.14 \\
-.01 \\
-.01 \\
.05 \\
.27 * \\
.07 \\
.22 \\
-.03 \\
-.04 \\
-.21 \\
.53 * * \\
-.0\end{array}$ & $\begin{array}{r}-.00 \\
.00 \\
.01 \\
-.01 \\
-.11 \\
.08 \\
.08 \\
-.15 \\
-.15 \\
-.13 \\
-.01 \\
-.06 \\
.11 \\
-.16 \\
-.01 \\
.021 \\
.10 \\
-.05 \\
.02 \\
.09 \\
-.02 \\
.03 \\
.04 \\
.11 \\
-.06 \\
.10 \\
.16 \\
-.0\end{array}$ & $\begin{array}{r}-.03 \\
-.05 \\
-.09 \\
-.07 \\
-.10 \\
-.16 \\
.12 \\
-.15 \\
-.16 \\
-.13 \\
-.11 \\
.03 \\
.10 \\
-.10 \\
.05 \\
.00 \\
.01 \\
-.18 \\
.12 \\
.17 \\
-.01 \\
-.07 \\
.11 \\
.10 \\
.28 \\
.08 \\
-.09 \\
.21\end{array}$ \\
\hline
\end{tabular}


Intercorrelations Among the 29 Variables For Male Subjects $(N=40)$

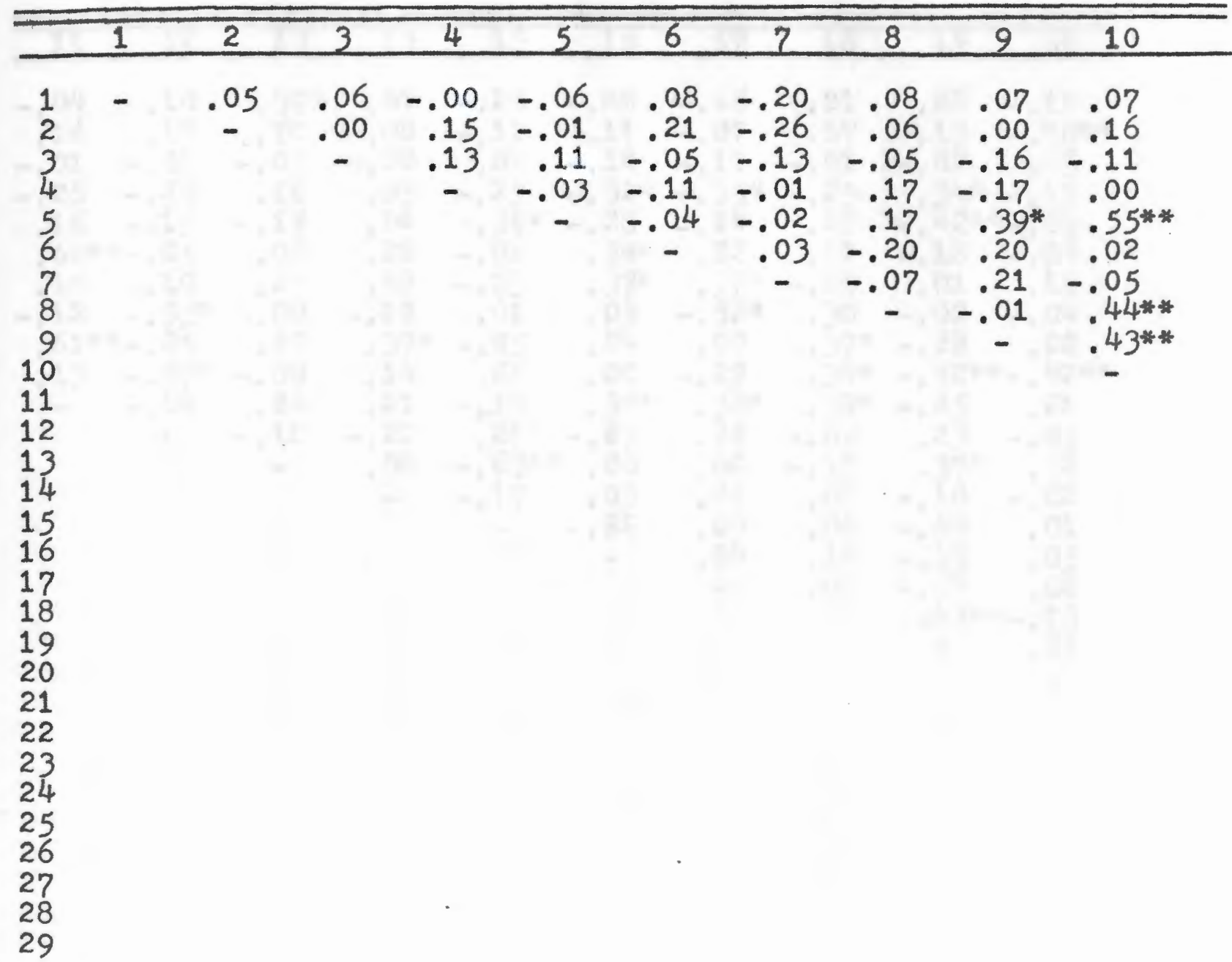

${ }^{*} \mathrm{p} \quad .05 i^{* *} \mathrm{p} \quad .01$

Code: 1. Behavioral Side Distance; 2. Simulated Side Distance; 3. Behavioral Frontal Distance; 4. Simulated Frontal Distance; 5. Achievement; 6. Affiliation; 7. Aggression; 8. Autonomy; 9. Dominance; 10. Endurance; 11. Exhibition; 12. Harm Avoidance; 13. Impulsivity; 14. Nurturance; 15. Order; 16. Play; 17. Social Recognition; 18. Understanding; 19. Locus of Control; 20. Side Confederate Attractiveness; 21. Side Confederate Size; 22. Side Confederate Strength; 23. Side Confederate Aggressiveness; 24. Side Confederate Bearing; 25. Frontal Confederate Attractiveness; 26. Frontal Confederate Size; 27. Frontal Confederate Strength; 28. Frontal Confederate Aggressiveness; 29. Frontal Confederate Bearing. 
Table 12 (Cont'd.)

\begin{tabular}{|c|c|c|c|c|c|c|c|c|c|}
\hline 11 & 12 & 13 & 4 & 15 & 16 & 17 & 18 & 19 & 20 \\
\hline $\begin{array}{l}.04 \\
16 \\
.01 \\
.26 \\
16 \\
.60 \% . \\
16 \\
12 \\
.61 \% \\
13\end{array}$ & $\begin{array}{r}.10 \\
.12 \\
-.01 \\
-.20 \\
-.15 \\
-.05 \\
-.10 \\
-.33^{*} \\
-.25 \\
-.37 * \\
-.14 \\
-\end{array}$ & $\begin{array}{r}.39 * \\
.10 \\
-.05 \\
.16 \\
-.15 \\
.06 \\
.27 \\
-.00 \\
.15 \\
-.09 \\
.24 \\
-.12 \\
-\end{array}$ & $\begin{array}{r}.07 \\
.00 \\
-.20 \\
.05 \\
.04 \\
.28 \\
.02 \\
-.18 \\
.37 \% \\
.14 \\
.21 \\
-.22 \\
.08 \\
-\end{array}$ & $\begin{array}{r}-.20 \\
-.11 \\
.00 \\
-.23 \\
.39 \% \\
-.08 \\
-.23 \\
.01 \\
-.05 \\
.21 \\
-.19 \\
.21 \\
-.63 * \% \\
-.17 \\
-\end{array}$ & $\begin{array}{r}-.00 \\
.11 \\
-.14 \\
-.32 * \\
-.28 \\
.34 * \\
.37 * \\
.03 \\
.24 \\
.00 \\
.38 * \\
-.27 \\
.20 \\
.03 \\
-.22\end{array}$ & $\begin{array}{l}-.16 \\
-.07 \\
-.11 \\
-.35^{*} \\
-.14 \\
.22 \\
.37^{*} \\
-.32 \\
.07 \\
-.27 \\
.34 * \\
.22 \\
.00 \\
.01 \\
.04 \\
.24 \\
-\end{array}$ & $\begin{array}{r}.01 \\
.07 \\
-.01 \\
-.25 \\
.29 \\
.17 \\
-.09 \\
.30 \\
.37 \\
.34 \% \\
.39 * \\
-.09 \\
-.17 \\
.05 \\
.06 \\
.14 \\
.09\end{array}$ & $\begin{array}{l}.26 \\
.13 \\
-.02 \\
.34 \% \\
-.42 * \\
-.18 \\
.01 \\
-.02 \\
-.28 \\
-.42 * \\
-.25 \\
.23 \\
.37 * \\
-.18 \\
-.27 \\
-.13 \\
-.117 \\
-.44 * \\
-\end{array}$ & $\begin{array}{r}-.05 \\
.12 \\
-.22 \\
.01 \\
.05 \\
.02 \\
-.13\end{array}$ \\
\hline
\end{tabular}


Table 12 (Cont'd.)

\begin{tabular}{|c|c|c|c|c|c|c|c|c|}
\hline 21 & 22 & 23 & 24 & 25 & 26 & 27 & 28 & 29 \\
\hline $\begin{array}{r}.07 \\
.00 \\
.09 \\
.02 \\
.19 \\
.14 \\
.08 \\
.13 \\
.02 \\
.36 * \\
.18 \\
.19 \\
.06 \\
.00 \\
.18 \\
.09 \\
.26 \\
.10 \\
.04 \\
.02 \\
-\end{array}$ & $\begin{array}{r}-.29 \\
.17 \\
-.20 \\
.26 \\
-.16 \\
.19 \\
.18 \\
.08 \\
-.15 \\
-.04 \\
.04 \\
.13 \\
.09 \\
-.01 \\
-.23 \\
.00 \\
.15 \\
.04 \\
.15 \\
-.06 \\
.35 \\
-.0\end{array}$ & $\begin{array}{r}-.38 * \\
.038 \\
-.09 \\
-.06 \\
.18 \\
-.03 \\
-.07 \\
.07 \\
-.08 \\
-.01 \\
.05 \\
.05 \\
.08 \\
-.18 \\
-.00 \\
-.03 \\
-.12 \\
.14 \\
-.08 \\
-.13 \\
-.20 \\
.37 * \\
-.0\end{array}$ & $\begin{array}{r}.01 \\
-.23 \\
-.22 \\
-.08 \\
.06 \\
-.14 \\
.00 \\
-.07 \\
.025 \\
-.13 \\
.18 \\
-.01 \\
.26 \\
.21 \\
-.19 \\
-.12 \\
-.00 \\
-.03 \\
.03 \\
.44 \\
-.08 \\
-.06 \\
.01 \\
-\end{array}$ & $\begin{array}{r}-.06 \\
.09 \\
-.00 \\
-.31 \\
-.08 \\
.06 \\
.01 \\
-.13 \\
.15 \\
-.29 \\
.31 \\
.33 \\
-.08 \\
-.06 \\
.20 \\
.09 \\
.50 \% \\
.20 \\
.00 \\
.23 \\
.11 \\
-.01 \\
.08 \\
.22 \\
-\end{array}$ & $\begin{array}{r}.00 \\
-.05 \\
.022 \\
-.02 \\
.17 \\
-.12 \\
.08 \\
.02 \\
-.04 \\
-.02 \\
.09 \\
.26 \\
-.06 \\
-.37 * \\
.227 \\
-.14 \\
-.02 \\
.04 \\
.09 \\
.32 * \\
. .34 * \\
-.06 \\
-.06 \\
-.01 \\
.10 \\
-0\end{array}$ & $\begin{array}{r}-.24 \\
-.02 \\
.23 \\
.02 \\
.23 \\
.00 \\
.18 \\
-.04 \\
-.07 \\
.12 \\
.14 \\
.03 \\
-.12 \\
-.15 \\
.39 * \\
-.07 \\
-.00 \\
-.05 \\
.10 \\
.22 \\
-.09 \\
-.01 \\
.14 \\
-.17 \\
-.01 \\
. .49 * \\
-.0\end{array}$ & $\begin{array}{r}-.03 \\
-.10 \\
.04 \\
-.06 \\
-.12 \\
.09 \\
.09 \\
-.25 \\
-.11 \\
-.11 \\
.06 \\
.00 \\
.05 \\
-.14 \\
-.02 \\
.16 \\
.10 \\
-.04 \\
.00 \\
.09 \\
.11 \\
.18 \\
.05 \\
-.02 \\
-.08 \\
.14 \\
.22 \\
-.04\end{array}$ & $\begin{array}{r}-.17 \\
-.11 \\
-.28 \\
-.15 \\
-.03 \\
-.34 \\
.20 \\
-.11 \\
-.10 \\
-.05 \\
-.16 \\
.12 \\
.07 \\
-.09 \\
-.06 \\
-.11 \\
-.12 \\
-.27 \\
.14 \\
.28 \\
.10 \\
.01 \\
.14 \\
.22 \\
.20 \\
.116 \\
-.04 \\
-.06\end{array}$ \\
\hline
\end{tabular}


Table 13

Intercorrelations Among the 29 Variables

For Female Subjects $(\mathrm{N}=40)$

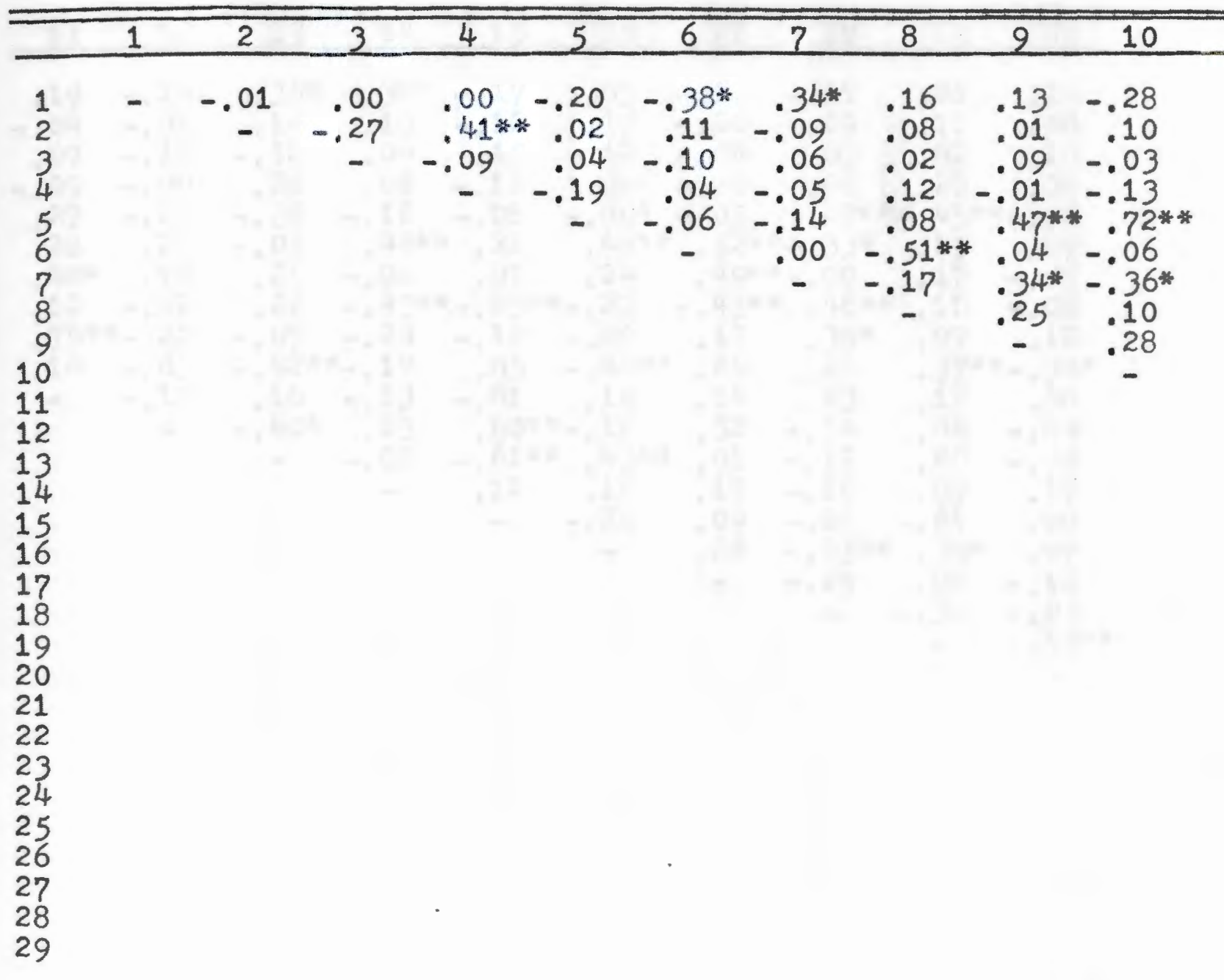

${ }^{*} \mathrm{p} \quad .05 ; *{ }^{*} \mathrm{p} \quad .01$

Code: 1. Behavioral Side Distance; 2. Simulated Side Distance; 3. Behavioral Frontal Distance; 4. Simulated Frontal Distance; 5. Achievement; 6. Affiliation; 7. Aggression; 8. Autonomy; 9. Dominance; 10. Endurance; 11. Exhibition; 12. Harm Avoidance; 13. Impulsivity; 14. Nurturance; 15. Order; 16. Play; 17. Social Recognition; 18. Understanding; 19. Locus of Control; 20. Side Confederate Attractiveness; 21. Side Confederate Size; 22. Side Confederate Strength; 23. Side Confederate Aggressiveness; 24. Side Confederate Bearing; 25. Frontal Confederate Attractiveness; 26. Frontal Confederate Size; 27. Frontal Confederate Strength; 28. Frontal Confederate Aggressiveness; 29. Frontal Confederate Bearing. 
Table 13 (Cont'd.)

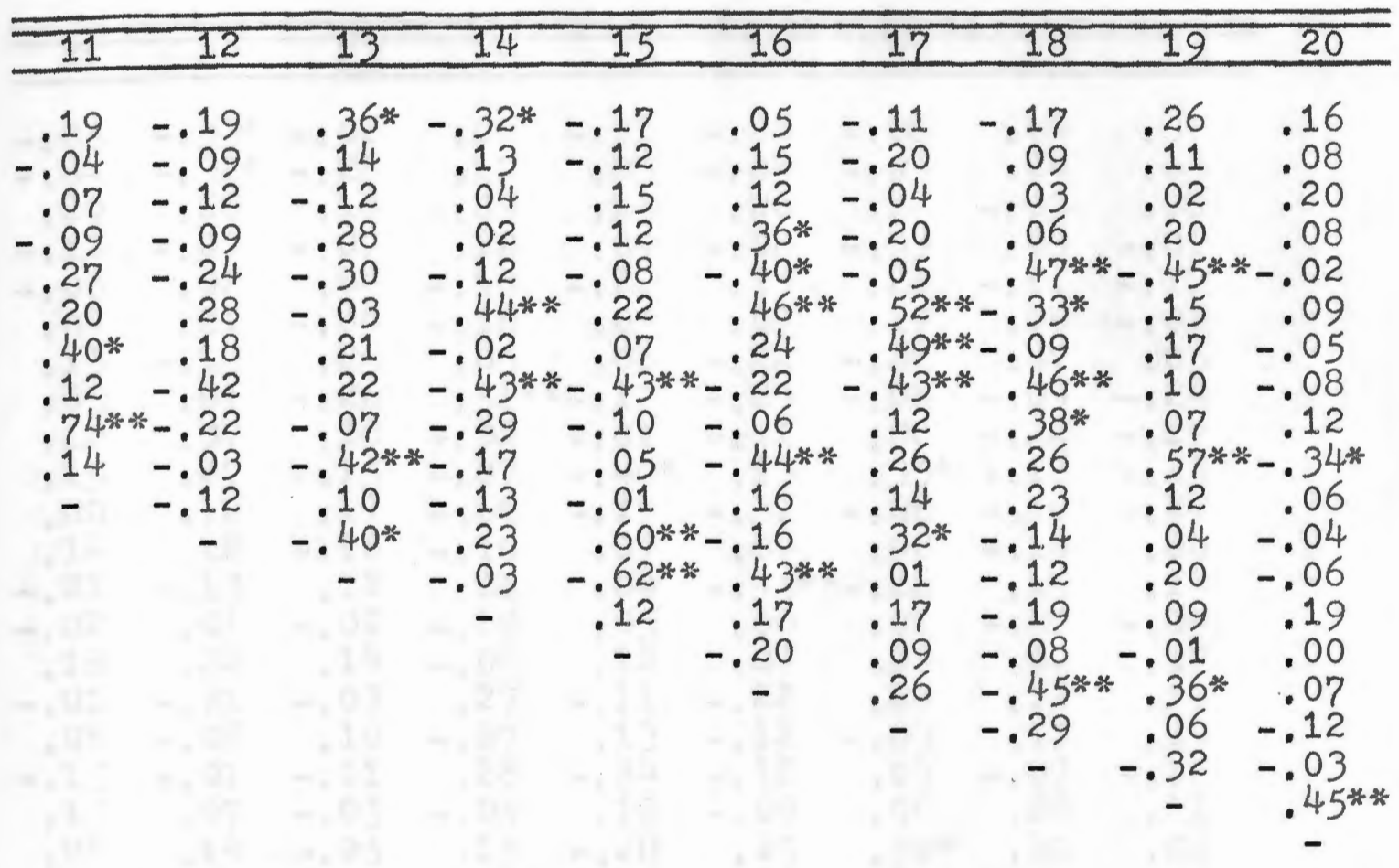


Table 13 (Cont'd.)

\begin{tabular}{|c|c|c|c|c|c|c|c|c|}
\hline 21 & 22 & 23 & 24 & 25 & 26 & 27 & 28 & 29 \\
\hline $\begin{array}{r}-.05 \\
-.04 \\
.029 \\
-.12 \\
-.06 \\
.04 \\
.13 \\
.05 \\
.12 \\
.15 \\
.00 \\
.14 \\
-.21 \\
-.02 \\
.18 \\
-.01 \\
.06 \\
-.15 \\
.15 \\
.08 \\
-\end{array}$ & $\begin{array}{c}-.33 * \\
-.32 * \\
.28 \\
-.07 \\
.02 \\
.21 \\
-.13 \\
.01 \\
.07 \\
.27 \\
.12 \\
.18 \\
-.13 \\
.01 \\
.22 \\
-.01 \\
-.02 \\
-.01 \\
.07 \\
.14 \\
.57 * 0 \\
-\end{array}$ & $\begin{array}{r}-.02 \\
-.02 \\
.18 \\
-.07 \\
.04 \\
-.04 \\
.25 \\
-.26 \\
.10 \\
-.15 \\
.117 \\
-.16 \\
.12 \\
-.02 \\
.14 \\
-.03 \\
.10 \\
-.11 \\
-.05 \\
-.05 \\
-.09 \\
.09 \\
-\end{array}$ & $\begin{array}{c}.04 \\
.17 \\
.04 \\
.12 \\
-.14 \\
-.16 \\
.05 \\
.01 \% \\
-.02 \\
-.07 \\
-.06 \\
-.10 \\
.01 \\
-.19 \\
-.02 \\
. .27 \\
-.07 \\
.028 \\
-.04 \\
.15 \\
.03 \\
-.17 \\
-.47 * \\
-\end{array}$ & $\begin{array}{r}-.01 \\
.03 \\
.15 \\
.09 \\
-.22 \\
.05 \\
.08 \\
-.17 \\
-.01 \\
-.40 * \\
-.17 \\
.07 \\
.04 \\
.05 \\
.12 \\
-.11 \\
.13 \\
-.24 \\
.12 \\
-.20 \\
-.06 \\
-.19 \\
-.26 \\
-.28 \\
-.0\end{array}$ & $\begin{array}{r}-.06 \\
-.08 \\
.26 \\
-.08 \\
.15 \\
.07 \\
-.22 \\
-.24 \\
-.11 \\
.13 \\
-.31 \\
.04 \\
-.45 \\
.00 \\
.29 \\
-.22 \\
-.12 \\
-.12 \\
-.09 \\
.25 \\
.11 \\
.14 \\
-.01 \\
-.06 \\
.11 \\
-.01\end{array}$ & $\begin{array}{c}-.08 \\
-.05 \\
.12 \\
-.03 \\
.28 \\
.19 \\
-.28 \\
-.08 \\
.00 \\
.35 \% \\
-.08 \\
.02 \\
-.26 \\
.01 \\
.08 \\
.28 \\
-.03 \\
.03 \\
.00 \\
.38 * \\
.23 \\
.48 * \\
-.20 \\
.08 \\
-.42 * \\
.58 * \\
-\end{array}$ & $\begin{array}{r}.04 \\
. .24 \\
-.03 \\
.03 \\
-.11 \\
.08 \\
.07 \\
-.09 \\
-.22 \\
-.16 \\
-.10 \\
-.14 \\
.119 \\
-.20 \\
.00 \\
.12 \\
.11 \\
-.07 \\
.06 \\
.10 \\
-.15 \\
-.14 \\
.05 \\
.27 \\
-.05 \\
.06 \\
.09 \\
-\end{array}$ & 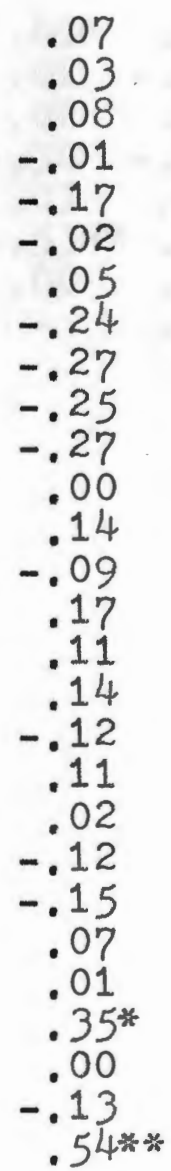 \\
\hline
\end{tabular}


Table 14

Intercorrelations Among 28 Variables

For Internal Subjects $(\mathrm{N}=40)$

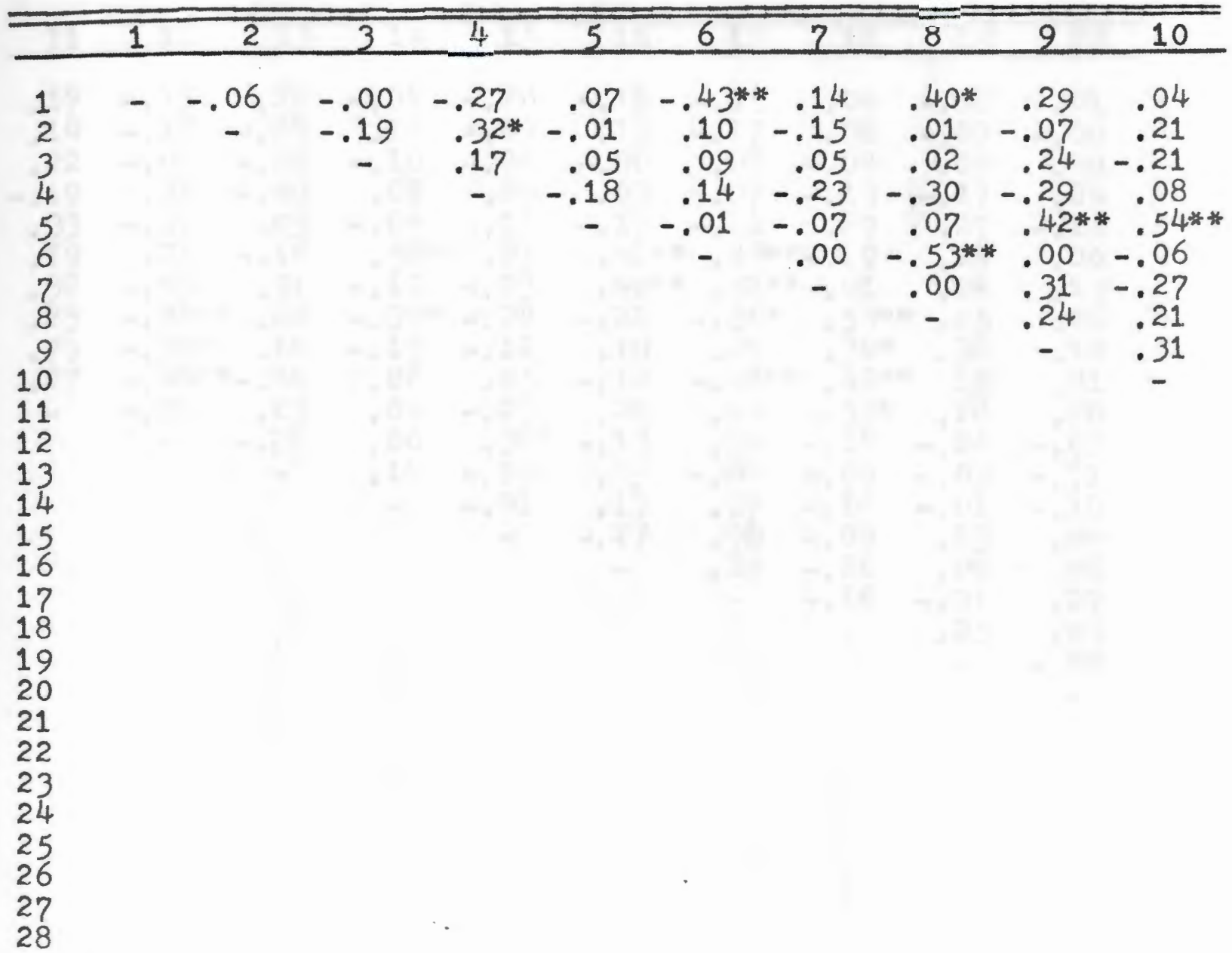

${ }^{*} \mathrm{p}<.05 ; * \mathrm{p}<.01$

Code: 1. Behavioral Side Distance; 2. Simulated Side Distance; 3. Behavioral Frontal Distance; 4. Simulated Frontal Distance; 5. Achievement; 6. Affiliation; 7. Aggression; 8. Autonomy; 9. Dominance; 10. Endurance; 11. Exhibition; 12. Harm Avoidance; 13. Impulsivity; 14. Nurturance; 15. Order; 16. Play; 17. Social Recognition; 18. Understanding; 19. Side Confederate Attractiveness 20. Side Confederate Size; 21. Side Confederate Strength; 22. Side Confederate Aggressiveness; 23. Side Confederate Bearing; 24. Frontal Confederate Attractiveness; 25. Frontal Confederate Size; 26. Frontal Confederate Strength; 27. Frontal Confederate Aggressiveness; 28. Frontal Confederate Bearing. 
Table 14 (Cont'd.)

\begin{tabular}{|c|c|c|c|c|c|c|c|c|c|}
\hline 11 & 12 & 13 & 14 & 15 & 16 & 17 & 18 & 19 & 20 \\
\hline $\begin{array}{l}.17 \\
.14 \\
.22 \\
.19 \\
.33 \\
.19 \\
.32 \\
.25 \\
.79 \\
.27\end{array}$ & $\begin{array}{r}-.15 \\
-.10 \\
-.00 \\
. .22 \\
-.31 \\
. .25 \\
-.04 \\
-.44 * \% \\
-.39 * \\
-.46 \% \\
-.27 \\
-\end{array}$ & $\begin{array}{r}.26 \\
-.08 \\
-.08 \\
-.08 \\
.03 \\
-.16 \\
.31 \\
.22 \\
.10 \\
-.00 \\
.23 \\
-.28 \\
-\end{array}$ & $\begin{array}{r}-.31 \\
.16 \\
-.10 \\
.08 \\
-.04 \\
.58 * \% \\
-.12 \\
-.34 \% \\
-.13 \\
.06 \\
.04 \\
.06 \\
.10 \\
-\end{array}$ & $\begin{array}{r}-.20 \\
-.09 \\
-.08 \\
.04 \\
.11 \\
.25 \\
-.23 \\
-.24 \\
-.12 \\
.05 \\
-.23 \\
.38 \% \\
-.73 \% \\
-.01 \\
-\end{array}$ & $\begin{array}{r}-.18 \\
.15 \\
-.00 \\
.03 \\
-.17 \\
.41 \% * \\
.40 * * \\
-.22 \\
.10 \\
-.12 \\
.20 \\
-.13 \\
.29 \\
.13 \\
-.27 \\
-\end{array}$ & $\begin{array}{c}-.15 \\
-.27 \\
.08 \\
.07 \\
-.11 \\
.43 * * \\
.52 * * \\
-.36 * \\
.09 \\
-.42 * * \\
.14 \\
.30 \\
-.06 \\
.09 \\
.08 \\
.29 \\
-\end{array}$ & $\begin{array}{r}.04 \\
.08 \\
-.04 \\
-.13 \\
.29 \\
-.19 \\
-.01 \\
.50 * \\
.34 * \\
.42 * \\
.35 * \\
-.12 \\
-.00 \\
-.16 \\
-.09 \\
-. .26 \\
-.16 \\
-\end{array}$ & $\begin{array}{r}-.00 \\
-.07 \\
.09 \\
-.17 \\
.27 \\
.24 \\
.04 \\
.05 \\
.30 \\
.19 \\
.28 \\
-.06 \\
-.05 \\
-.01 \\
.13 \\
.06 \\
-.01 \\
.25 \\
-\end{array}$ & $\begin{array}{r}.01 \\
-.06 \\
.30 \\
.24 \\
-.12 \\
.00 \\
.15 \\
.06 \\
.18 \\
.01 \\
.20 \\
-.03 \\
-.11 \\
-.104 \\
.04 \\
.08 \\
.27 \\
.03 \\
-.09 \\
-\end{array}$ \\
\hline
\end{tabular}


Table 14 (Cont'd.)

\begin{tabular}{|c|c|c|c|c|c|c|c|}
\hline 21 & 22 & 23 & 24 & 25 & 26 & 27 & 28 \\
\hline $\begin{array}{c}-.32 * \\
-.11 \\
.11 \\
.21 \\
.01 \\
.23 \\
.06 \\
.10 \\
.01 \\
.18 \\
.16 \\
-.02 \\
.00 \\
.08 \\
-.04 \\
.15 \\
.06 \\
.19 \\
-.00 \\
.50 * \\
-\end{array}$ & $\begin{array}{r}-.22 \\
.14 \\
-.01 \\
.00 \\
.19 \\
-.02 \\
.09 \\
-.04 \\
.16 \\
.00 \\
.07 \\
-.07 \\
.13 \\
.03 \\
-.07 \\
.10 \\
-.11 \\
-.01 \\
-.07 \\
.10 \\
.21 \\
-\end{array}$ & $\begin{array}{r}.10 \\
.04 \\
-.04 \\
-.23 \\
-.08 \\
-.06 \\
.02 \\
.39 * \\
.19 \\
.10 \\
.25 \\
.08 \\
.09 \\
-.00 \\
-.04 \\
-.09 \\
-.06 \\
.039 * \\
. .31 \\
-.03 \\
.01 \\
-.26 \\
-\end{array}$ & $\begin{array}{r}-.04 \\
-.11 \\
.11 \\
.02 \\
-.06 \\
.25 \\
.25 \\
-.22 \\
.20 \\
-.28 \\
.15 \\
.05 \\
-.07 \\
-.01 \\
.14 \\
.22 \\
. .48 \\
-.10 \\
-.09 \\
.117 \\
-.08 \\
.25 \\
-.22 \\
-.\end{array}$ & $\begin{array}{r}.00 \\
-.05 \\
.02 \\
.03 \\
.00 \\
.25 \\
-.05 \\
-.26 \\
-.14 \\
-.06 \\
-.08 \\
.25 \\
-.27 \\
-.13 \\
.44 * * \\
-.06 \\
.00 \\
-.23 \\
.18 \\
.23 \\
.07 \\
-.14 \\
-.12 \\
.08 \\
-\end{array}$ & $\begin{array}{r}-.24 \\
.04 \\
-.09 \\
.05 \\
.25 \\
.28 \\
-.08 \\
-.11 \\
-.04 \\
.31 \\
.16 \\
.07 \\
-.24 \\
.09 \\
.43 * \\
-.09 \\
-.03 \\
-.05 \\
.43 * \\
.07 \\
.25 \\
-.12 \\
.15 \\
-.19 \\
.49 \\
-1\end{array}$ & $\begin{array}{r}.18 \\
.13 \\
-.31 \\
-.13 \\
.11 \\
.04 \\
.12 \\
-.07 \\
.00 \\
.11 \\
-.00 \\
.01 \\
.10 \\
-.16 \\
-.10 \\
.26 \\
.18 \\
.13 \\
.11 \\
.13 \\
-.04 \\
-.15 \\
.14 \\
-.02 \\
.24 \\
.08 \\
-\end{array}$ & $\begin{array}{r}-.09 \\
-.08 \\
-.19 \\
-.04 \\
.011 \\
-.07 \\
.15 \\
-.21 \\
-.12 \\
.18 \\
-.27 \\
.00 \\
-.10 \\
-.14 \\
.13 \\
.00 \\
-.01 \\
-.05 \\
-.01 \\
-.09 \\
-.11 \\
.18 \\
-.28 \\
.25 \\
.18 \\
.222 \\
.24 \\
-\end{array}$ \\
\hline
\end{tabular}


Table 15

Intercorrelations Among 28 Variables

For External Subjects $(\mathrm{N}=40)$

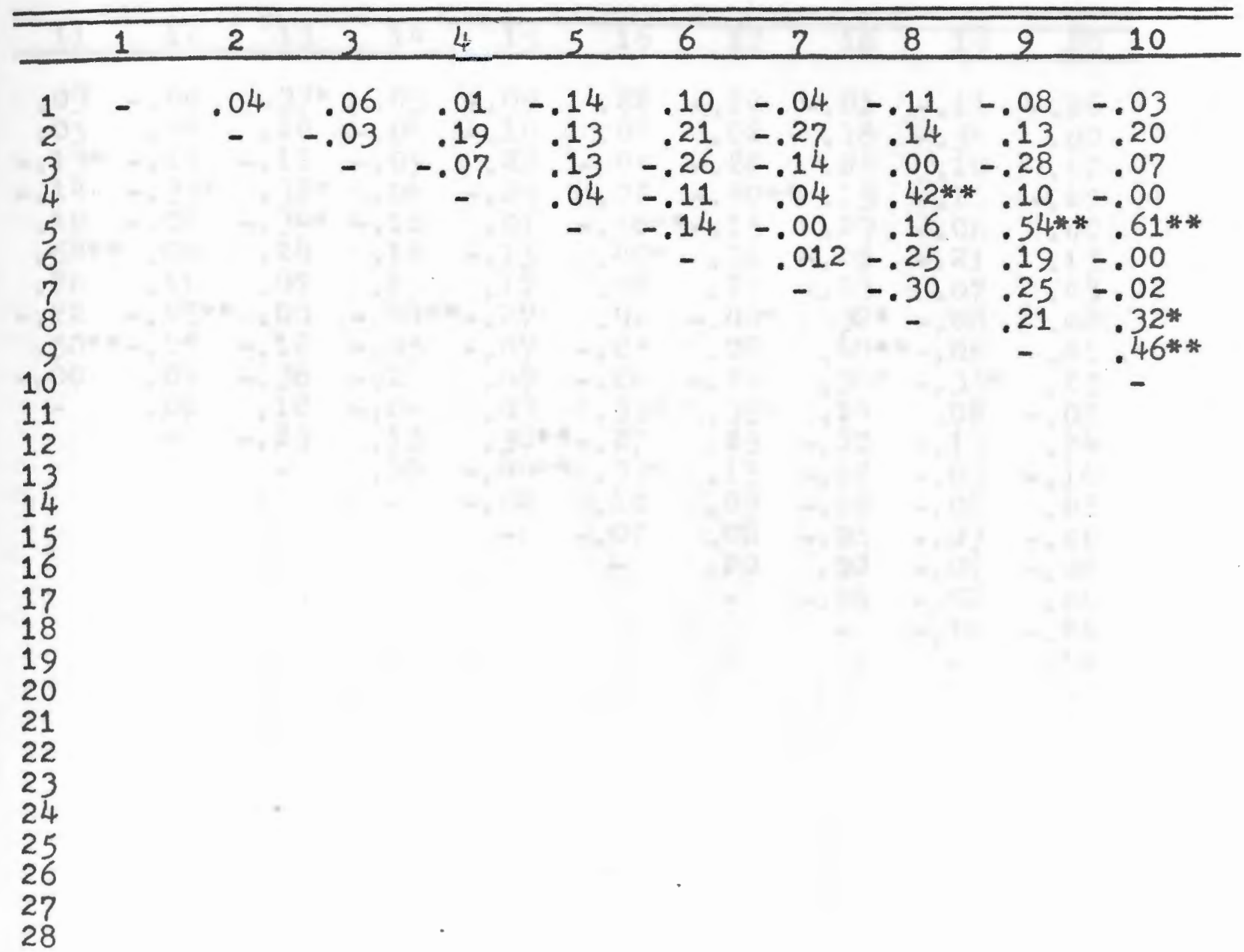

${ }^{*} \mathrm{p}<.05 ;{ }^{* *} \mathrm{p}<.01$

Code: 1. Behavioral Side Distance; 2. Simulated Side Distance; 3. Behavioral Frontal Distance; 4. Simulated Frontal Distance; 5. Achievement; 6. Affiliation; 7. Aggression; 8. Autonomy; 9. Dominance; 10. Endurance; 11. Exhibition; 12. Harm Avoidance; 13. Impulsivity; 14. Nurturance; 15. Order; 16. Play; 17. Social Recognition; 18. Understanding; 19. Side Confederate Attractivenes: 20. Side Confederate Size; 21. Side Confederate Strength; 22. Side Confederate Aggressiveness; 23. Side Confederate Bearing; 24. Frontal Confederate Attractiveness; 25. Frontal Confederate Size; 26. Frontal Confederate Strength; 27. Frontal Confederate Aggressiveness; 28. Frontal Confederate Bearing. 
Table 15 (Cont'd.)

\begin{tabular}{|c|c|c|c|c|c|c|c|c|c|}
\hline 11 & 12 & 13 & 14 & 15 & 16 & 17 & 18 & 19 & 20 \\
\hline $\begin{array}{r}.03 \\
.05 \\
-.13^{*} \\
-.14 \\
.10 \\
.58^{* * *} \\
.26 \\
-.22 \\
.50 * \\
-.00 \\
-\end{array}$ & $\begin{array}{c}-.06 \\
.08 \\
-.16 \\
-.35 * \\
-.06 \\
.04 \\
.11 \\
-.43 * * \\
-.15 \\
.04 \\
.00 \\
-\end{array}$ & $\begin{array}{r}.37^{*} \\
.20 \\
-.12 \\
.32 * \\
-.34 * \\
.24 \\
.07 \\
-.00 \\
-.12 \\
-.36 \\
.12 \\
-.25 \\
-\end{array}$ & $\begin{array}{r}.03 \\
-.04 \\
-.09 \\
.04 \\
-.16 \\
.16 \\
.15 \\
-.44 \\
-.05 \\
-.21 \\
-.04 \\
.15 \\
.00 \\
-\end{array}$ & $\begin{array}{r}-.09 \\
-.10 \\
.22 \\
-.25 \\
.01 \\
-.15 \\
.17 \\
-.27 \\
-.07 \\
.09 \\
.03 \\
.50 * \\
-.44 * \\
-.02 \\
-\end{array}$ & $\begin{array}{r}.22 \\
.07 \\
-.04 \\
.07 \\
-.56 * \\
.40 * \\
.08 \\
.01 \\
-.03 \\
-.28 \\
.35^{*} \\
-.27 \\
.33^{*} \\
.10 \\
-.07 \\
-\end{array}$ & $\begin{array}{l}-.10 \\
.02 \\
-.24 \\
-.50 * * \\
-.15 \\
.31 \\
.29 \\
-.40 * \\
.08 \\
-.17 \\
.35 * \\
.25 \\
.15 \\
.09 \\
.02 \\
.20 \\
-\end{array}$ & $\begin{array}{r}-.01 \\
.18 \\
.09 \\
.13 \\
.29 \\
-.06 \\
-.13 \\
.32 * \\
.47 * \\
.34 * \\
.24 \\
-.10 \\
-.12 \\
-.09 \\
-.06 \\
.02 \\
-.09 \\
-\end{array}$ & $\begin{array}{r}-.11 \\
-.54 \\
.10 \\
-.11 \\
-.08 \\
-.21 \\
.07 \\
-.08 \\
-.08 \\
-.35 * \\
.08 \\
-.15 \\
-.03 \\
-.08 \\
-.03 \\
-.01 \\
-.02 \\
-.16 \\
-\end{array}$ & $\begin{array}{r}-.06 \\
.00 \\
.12 \\
-.27 \\
.00 \\
.13 \\
.03 \\
.00 \\
.01 \\
.25 \\
-.02 \\
.24 \\
-.16 \\
.02 \\
-.01 \\
-.06 \\
.01 \\
-.24 \\
.14 \\
-\end{array}$ \\
\hline
\end{tabular}


Table 15 (Cont'd.)

\begin{tabular}{|c|c|c|c|c|c|c|c|}
\hline$\overline{21}$ & 22 & 23 & 24 & 25 & 26 & 27 & 28 \\
\hline $\begin{array}{r}-.40 * \\
.02 \\
-.04 \\
-.07 \\
.05 \\
.15 \\
.13 \\
-.04 \\
-.04 \\
.18 \\
.00 \\
.37 * \\
-.14 \\
-.09 \\
.09 \\
-.27 \\
.07 \\
-.15 \\
.00 \\
.44 * \\
-\end{array}$ & $\begin{array}{r}-.10 \\
.10 \\
.11 \\
-.08 \\
-.04 \\
-.07 \\
.14 \\
-.18 \\
-.12 \\
-.05 \\
.16 \\
.12 \\
.09 \\
-.26 \\
.20 \\
-.16 \\
.12 \\
-.01 \\
-.07 \\
-.035 \\
.24 \\
-\end{array}$ & $\begin{array}{r}-.02 \\
-.14 \\
-.11 \\
.20 \\
-.06 \\
-.26 \\
.04 \\
.15 \\
-.08 \\
-.36 * \\
-.20 \\
-.23 \\
.18 \\
-.03 \\
-.18 \\
-.04 \\
-.02 \\
-.15 \\
.35 * \\
.02 \\
-.31 \\
-.25 \\
-\end{array}$ & $\begin{array}{r}-.04 \\
.20 \\
.02 \\
-.16 \\
-.20 \\
-.20 \\
-.23 \\
.04 \\
-.04 \\
-.33^{*} \\
-.03 \\
.17 \\
-.03 \\
-.06 \\
.17 \\
.10 \\
.08 \\
.12 \\
.16 \\
-.11 \\
-.15 \\
.13 \\
.13 \\
-\end{array}$ & $\begin{array}{c}-.06 \\
-.07 \\
. .45^{*} \\
-.11 \\
. .38 * \\
-.37 * \\
-.09 \\
.05 \\
.02 \\
.18 \\
-.14 \\
.00 \\
-.26 \\
-.21 \\
.07 \\
-.22 \\
-.17 \\
.20 \\
.41 * \\
.18 \\
.00 \\
.09 \\
.07 \\
.20 \\
-\end{array}$ & $\begin{array}{c}-.14 \\
-.10 \\
-.40 * \\
-.05 \\
. .35 \\
-.11 \\
.00 \\
-.02 \\
-.03 \\
.119 \\
-.10 \\
-.00 \\
-.16 \\
-.20 \\
.07 \\
-.21 \\
.01 \\
.07 \\
.14 \\
.05 \\
.18 \\
.07 \\
-.25 \\
-.25 \\
.59 * \\
-0\end{array}$ & $\begin{array}{r}-.20 \\
-.08 \\
.26 \\
.02 \\
-. .34 * \\
.12 \\
.02 \\
-.23 \\
-. .38 * \\
-.36 * \\
-.02 \\
-.14 \\
.11 \\
-.17 \\
.09 \\
.15 \\
.01 \\
-.25 \\
.06 \\
-.17 \\
.11 \\
.25 \\
.09 \\
-.10 \\
-.03 \\
.23\end{array}$ & $\begin{array}{c}-.05 \\
-.05 \\
-.04 \\
-.13 \\
-.21 \\
-.26 \\
.08 \\
-.08 \\
-.21 \\
-.35 * \\
-.14 \\
.02 \\
.22 \\
-.06 \\
.00 \\
-.03 \\
.05 \\
-.24 \\
.25 \\
.02 \\
-.06 \\
.06 \\
.48 * 4 \\
.30 \\
-.02 \\
-.38 * \\
.17\end{array}$ \\
\hline
\end{tabular}




\section{APPENDIX B - RAW DATA}


Subject Sex ${ }^{*}$ Locus of Control ${ }^{*}$ Confederate Sex* Subject
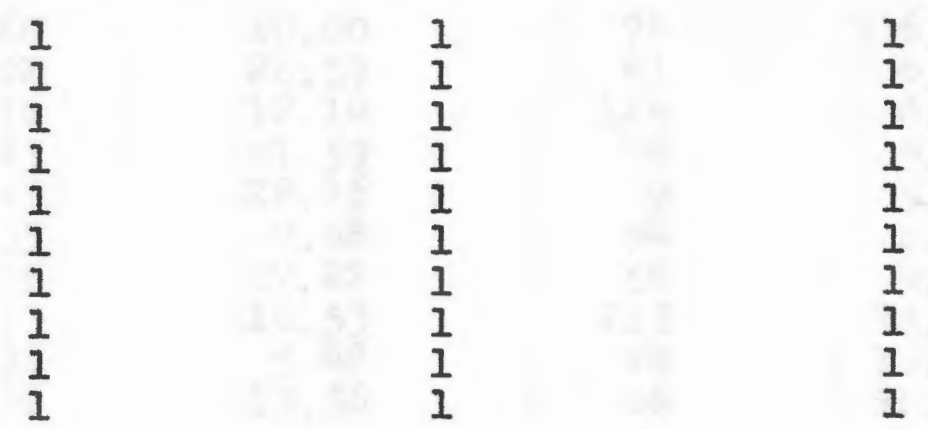

01

02

1

1

09
10
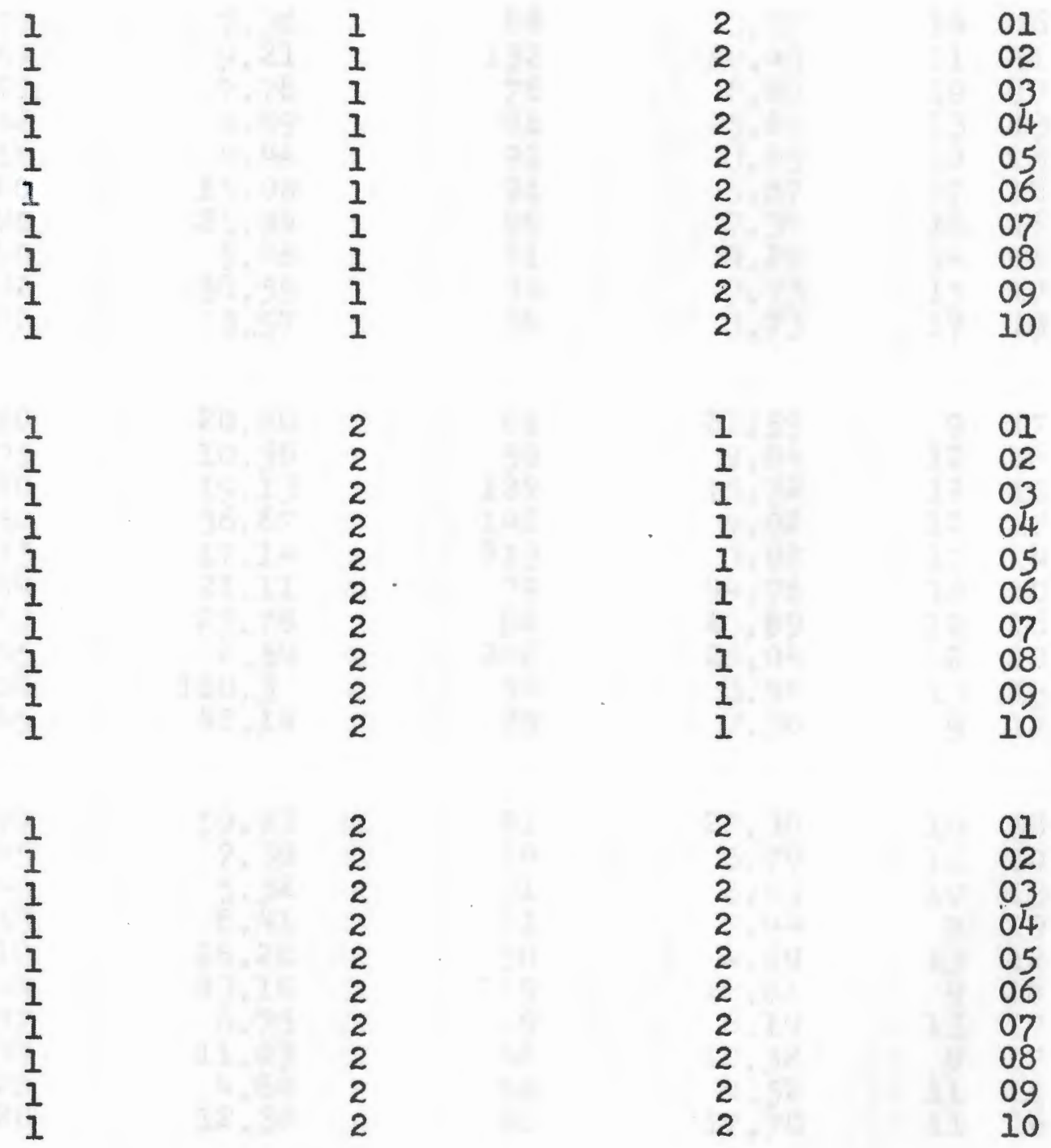

* subject sex: $M=1 ; \quad F=2$ locus of control: Internals $=1$; Externals $=2$ confederate sex: $M=1 ; F=2 \quad 112$ 
Raw Data (Cont'd.)

Side Orientation Behavioral Simulated

160

102

216

165

145

155

115

153

135

138

271

167

121

142

218

180

170

190

182

182

220

195

220

250

185

184

162

155

200

245
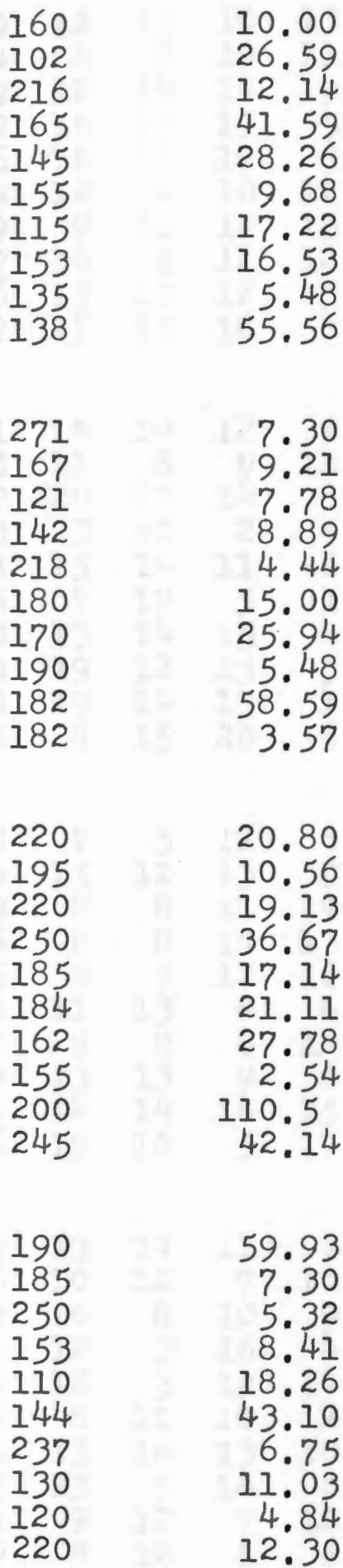

3.57

20.80

10.56

19.13

17.14

21.11

27.78

2.54

110.5

42.14
Frontal Orientation Behavioral Simulated

74
61
124
86
69
94
56
213
94
66
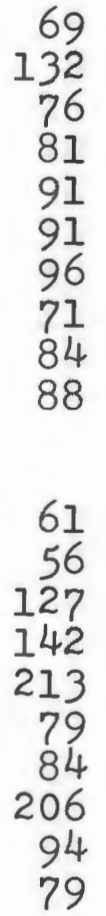

91
64

51

58

119

69

66
60

80
6.82

6.35

8.10

9.68

5.32

6.90

4.44

11.27

10.24

26.91

3.57
14.45

6.83

5.64

3.65

5.87

7.38

4.29

3.73
3.73

21.59
9.84
15.72
9.92
3.02
44.76
23.89
26.04
3.96
7.30

Ac Af Ag

$\begin{array}{lll}14 & 17 & 4\end{array}$

$\begin{array}{lll}16 & 20 & 3\end{array}$

$\begin{array}{lll}17 & 19 & 8\end{array}$

$\begin{array}{lll}12 & 16 & 9\end{array}$

$\begin{array}{lll}16 & 15 & 5\end{array}$

$\begin{array}{lll}15 & 15 & 3\end{array}$

11178

$\begin{array}{lll}15 & 16 & 6\end{array}$

$\begin{array}{lll}11 & 17 & 3\end{array}$

$\begin{array}{lll}14 & 16 & 3\end{array}$

11 11 8

$\begin{array}{lll}19 & 17\end{array}$

$13 \quad 136$

$\begin{array}{lll}12 & 15 & 8\end{array}$

$17 \quad 127$

$\begin{array}{lll}16 & 16 & 10\end{array}$

$\begin{array}{lll}14 & 16 & 12\end{array}$

$\begin{array}{rrr}15 & 17 & 3 \\ 17 & 19 & 18\end{array}$

$\begin{array}{rrr}9 & 17 & 6 \\ 12 & 18 & 8 \\ 12 & 18 & 4 \\ 12 & 17 & 6 \\ 17 & 14 & 5 \\ 18 & 10 & 11 \\ 12 & 16 & 9 \\ 12 & 12 & 8 \\ 13 & 15 & 6 \\ 9 & 17 & 5\end{array}$

27.30

5.79

5.63

7.94

4.60
18.81

6.19

10.32

4.52

17.70 $\begin{array}{lll}16 & 18 \quad 5\end{array}$

$1110 ?$

$10 \quad 136$

$\begin{array}{lll}9 & 19 & 9\end{array}$

13128

$\begin{array}{lll}9 & 18 & 6\end{array}$

$\begin{array}{lll}13 & 17 & 12\end{array}$

$\begin{array}{lll}9 & 17 & 9\end{array}$

111110 
Au Do En Ex Ha Im Nu or PI Sr Un Score

$\begin{array}{llllllllllll}9 & 12 & 15 & 10 & 13 & 7 & 17 & 17 & 9 & 7 & 16 & 4\end{array}$

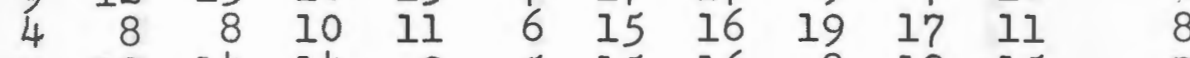

$\begin{array}{lllllllllll}9 & 12 & 14 & 14 & 9 & 5 & 15 & 16 & 8 & 12 & 15\end{array}$

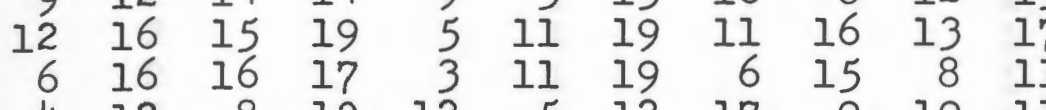

$\begin{array}{lllllllllll}4 & 12 & 8 & 10 & 12 & 5 & 12 & 17 & 9 & 19 & 11\end{array}$

$\begin{array}{rrrrrrrrrrr}9 & 9 & 11 & 12 & 13 & 8 & 10 & 17 & 16 & 10 & 15 \\ 7 & 10 & 5 & 12 & 12 & 7 & 14 & 7 & 13 & 12 & 14\end{array}$

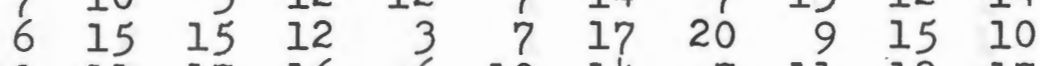

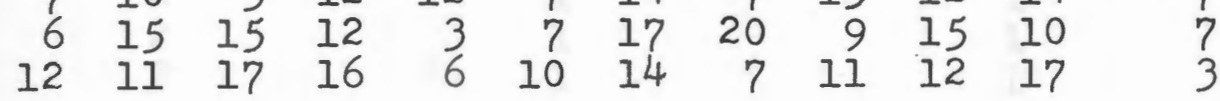

$\begin{array}{llllllllllll}11 & 14 & 14 & 12 & 9 & 13 & 18 & 14 & 12 & 9 & 12 & 4\end{array}$

$\begin{array}{llllllllllll}8 & 11 & 8 & 9 & 12 & 12 & 14 & 5 & 13 & 10 & 10 & 6\end{array}$

$\begin{array}{rrrrrrrrrrrr}7 & 20 & 17 & 14 & 8 & 8 & 16 & 15 & 11 & 10 & 14 & 7 \\ 13 & 3 & 10 & 2 & 5 & 8 & 14 & 10 & 9 & 9 & 14 & 6\end{array}$

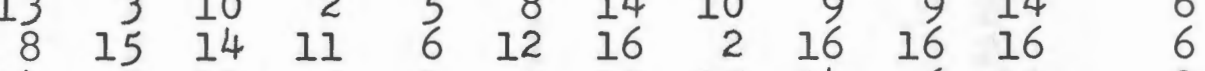

$\begin{array}{llllllllllll}14 & 7 & 17 & 5 & 1 & 9 & 13 & 15 & 14 & 6 & 10 & 8\end{array}$

$\begin{array}{lllllrrrrrrr}10 & 13 & 14 & 15 & 4 & 6 & 15 & 13 & 15 & 15 & 16 & 3 \\ 10 & 19 & 12 & 15 & 5 & 13 & 13 & 11 & 17 & 16 & 17 & 6\end{array}$

$\begin{array}{rrrrrrrrrrrr}8 & 19 & 14 & 13 & 1 & 10 & 16 & 8 & 16 & 3 & 13 & 5 \\ 8 & 8 & 15 & 20 & 6 & 19 & 15 & 4 & 14 & 15 & 16 & 1\end{array}$

$\begin{array}{rrrrrrrrrrrr}8 & 7 & 5 & 11 & 6 & 15 & 17 & 7 & 15 & 14 & 11 & 14 \\ 14 & 15 & 12 & 13 & 9 & 9 & 15 & 12 & 14 & 8 & 15 & 15\end{array}$

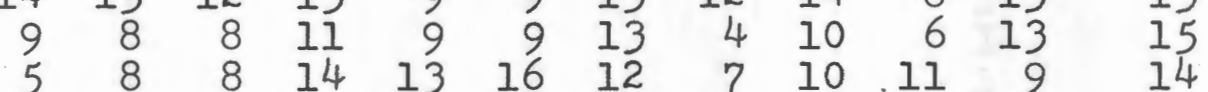

$\begin{array}{rrrrrrrrrrrr}5 & 8 & 8 & 14 & 13 & 16 & 12 & 7 & 10 & 11 & 9 & 14 \\ 5 & 9 & 9 & 12 & 12 & 10 & 14 & 17 & 11 & 10 & 13 & 18\end{array}$

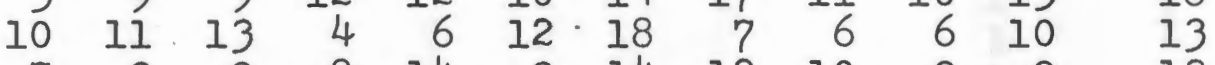

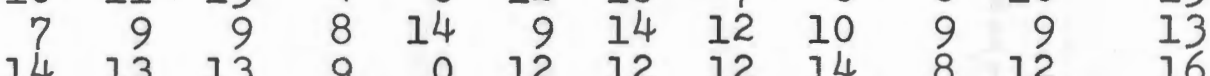

$\begin{array}{rrrrrrrrrrrr}14 & 13 & 13 & 9 & 0 & 12 & 12 & 12 & 14 & 8 & 12 & 16 \\ 11 & 14 & 14 & 14 & 15 & 12 & 12 & 11 & 15 & 16 & 15 & 14\end{array}$

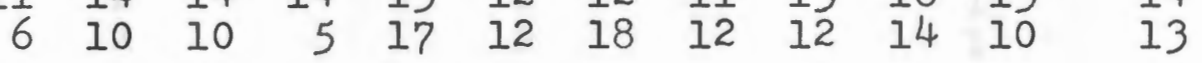

$\begin{array}{rrrrrrrrrrrr}9 & 13 & 14 & 11 & 7 & 14 & 15 & 7 & 11 & 3 & 12 & 14 \\ 6 & 10 & 12 & 7 & 10 & 12 & 15 & 7 & 10 & 9 & 14 & 18\end{array}$

$\begin{array}{llllllllllll}8 & 16 & 8 & 10 & 9 & 8 & 14 & 12 & 14 & 7 & 15 & 13\end{array}$

$\begin{array}{llllllllllll}6 & 12 & 3 & 16 & 4 & 15 & 17 & 2 & 16 & 17 & 14 & 14\end{array}$

$\begin{array}{llllllllllll}9 & 10 & 3 & 12 & 14 & 13 & 12 & 10 & 8 & 14 & 10 & 21\end{array}$

$\begin{array}{llllllllllll}9 & 8 & 11 & 10 & 2 & 11 & 14 & 4 & 14 & 8 & 10 & 15\end{array}$

$\begin{array}{llllllllllll}11 & 13 & 14 & 13 & 10 & 14 & 14 & 3 & 16 & 13 & 9 & 14\end{array}$

$\begin{array}{llllllllllll}5 & 13 & 5 & 14 & 8 & 12 & 18 & 6 & 15 & 14 & 5 & 15\end{array}$

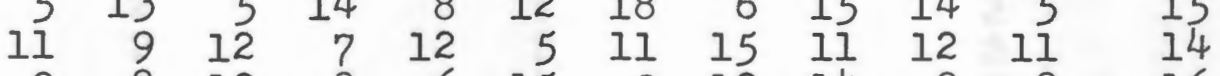

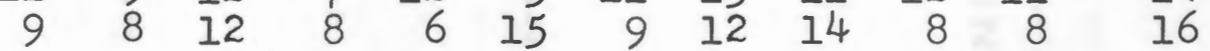




\section{RAW DATA (Cont'd.)}

Subject Sex ${ }^{*}$ Locus of Control ${ }^{*}$ Confederate Sex ${ }^{*}$ Subject
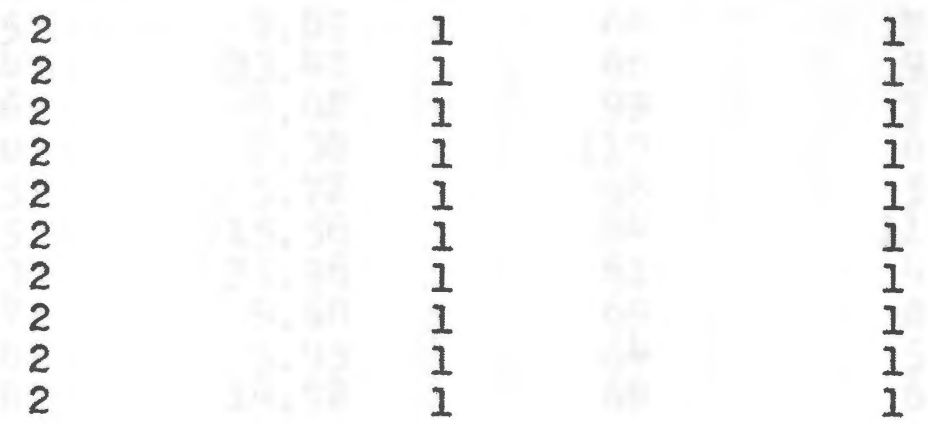

01

1

1

02

1

$\frac{1}{1}$

03

1

1

05

1

1

07

$\frac{1}{1}$

$\frac{1}{1}$

08

09

$\begin{array}{ll}2 & 1 \\ 2 & 1 \\ 2 & 1 \\ 2 & 1 \\ 2 & 1 \\ 2 & 1 \\ 2 & 1 \\ 2 & 1 \\ 2 & 1 \\ 2 & 1\end{array}$

2
2
2
2
2
2
2
2
2
2

01

02

2
2
2
2
2
2
2
2
2
2

2
2
2
2
2
2
2
2
2
2

1
1
1
$\frac{1}{1}$
$\frac{1}{1}$
$\frac{1}{1}$
1

01

02

03
04

05
06

07

08

09

10

2
2
2
2
2
2
2
2
2
2

2
2
2
2
2
2
2
2
2
2

2
2
2
2
2
2
2
2
2
2

01

02

03
04

05
06

0?

08

09
10 
Side Orientation Frontal Orientation Behavioral Simulated Behavioral Simulated

$\begin{array}{rr}255 & 8.89 \\ 244 & 33.42 \\ 176 & 8.02 \\ 180 & 7.38 \\ 95 & 5.72 \\ 115 & 15.56 \\ 193 & 35.96 \\ 147 & 9.68 \\ 220 & 5.95 \\ 178 & 14.92\end{array}$
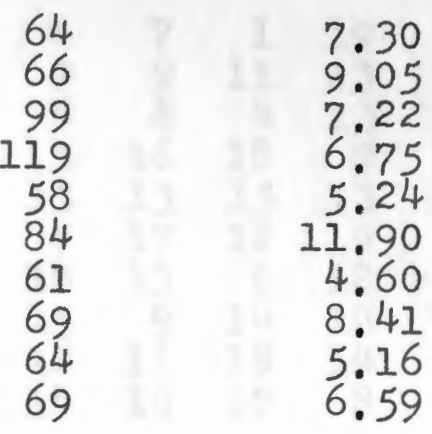

Ac Af Ag

128

8.81

220

118

124

110

122

162

194

98

117

110

155

195

205

176

190

213

172

182

263

170

145

183

163

150

265

122

220

183

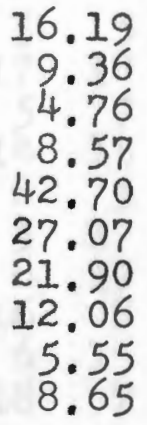

89

6.19

11.67

7.30

43.52

38.10

3.88

36.35

33.10

12.38

24.29

198

86

64

64

61

61

53
135

2.62

32.54

4.05

4.84

5.72

8.57

28.89

1846

$\begin{array}{lll}18 & 911\end{array}$

$\begin{array}{rrr}9 & 10 & 1 \\ 11 & 16 & 12\end{array}$

1217 ?

$\begin{array}{lll}17 & 17 & 9\end{array}$

$\begin{array}{lll}8 & 15 & 9 \\ 17 & 17 & 6\end{array}$

$\begin{array}{lll}10 & 14 & 14\end{array}$

$\begin{array}{lll}10 & 18 & 10\end{array}$

69

61
241

3.81
6.67

3.97
6.03

84

79

69

84

66

119

6.03

11.43

4.53

5.80

89

4.84

$11 \quad 16 \quad 4$

$\begin{array}{lll}18 & 20 & 5 \\ 18 & 17 & 7\end{array}$

$\begin{array}{lll}18 & 14 & 6\end{array}$

$11 \quad 180$

$\begin{array}{lll}15 & 20 & 2\end{array}$

$17 \quad 18 \quad 5$

$\begin{array}{lll}14 & 16 & 5 \\ 15 & 19 & 2\end{array}$

$\begin{array}{lll}13 & 19 & 8\end{array}$

34.37
17.38

86

58

6.51

34.05

86

89

17.46

20.08

29.21

30.80

28.97

84

64

86

84

48

19.20

8.41

6.03

56.83

26.27

24.95

$\begin{array}{llr}13 & 15 & ? \\ 17 & 18 & 11\end{array}$

$\begin{array}{lll}9 & 11 & 8\end{array}$

$\begin{array}{lll}10 & 18 & 14\end{array}$

$\begin{array}{lll}17 & 19 & 2\end{array}$

$\begin{array}{lll}6 & 16 & 10\end{array}$

$\begin{array}{lll}7 & 15 & 4\end{array}$

$\begin{array}{lll}13 & 17 & 5 \\ 13 & 12 & 5\end{array}$

$\begin{array}{lll}12 & 19 & 12\end{array}$

9.84

12.30

53.10

$\begin{array}{rrr}10 & 19 & 11 \\ 9 & 18 & 3 \\ 8 & 18 & 6 \\ 10 & 15 & 5 \\ 11 & 17 & 8 \\ 9 & 20 & 7 \\ 10 & 15 & 6 \\ 13 & 18 & 9 \\ 10 & 19 & 10 \\ 10 & 15 & 9\end{array}$


Raw Data (Cont'd.)

PRF Scores

$\mathrm{Au}$ Do En Ex $\mathrm{Ha}$ Im Nu Or PI Sr Un Score

$\begin{array}{lllllllllll}14 & 17 & 18 & 11 & 1 & 12 & 6 & 6 & 7 & 1 & 19\end{array}$

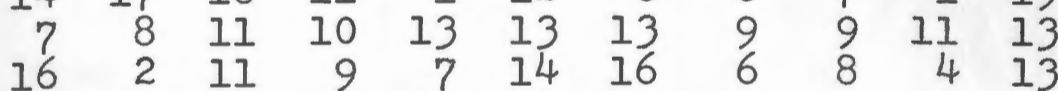

$\begin{array}{lllllllllll}7 & 20 & 4 & 14 & 7 & 13 & 15 & 5 & 16 & 18 & 9\end{array}$

$\begin{array}{lllllllllll}1 & 8 & 13 & 10 & 18 & 5 & 17 & 15 & 13 & 15 & 13\end{array}$

$\begin{array}{rrrrrrrrrrr}4 & 5 & 11 & 10 & 1 & 16 & 19 & 7 & 17 & 12 & 13 \\ 8 & 6 & 7 & 11 & 13 & 12 & 16 & 10 & 13 & 6 & 12\end{array}$

$\begin{array}{rrrrrrrrrrrr}5 & 11 & 13 & 10 & 16 & 8 & 18 & 15 & 13 & 14 & 12 & 8 \\ 14 & 11 & 5 & 13 & 17 & 11 & 15 & 12 & 11 & 18 & 14 & 2 \\ 7 & 4 & 8 & 6 & 16 & 10 & 12 & 14 & 16 & 17 & 8 & 8\end{array}$

$\begin{array}{llllllllllll}6 & 6 & 12 & 4 & 9 & 7 & 15 & 18 & 10 & 6 & 15 & 6\end{array}$

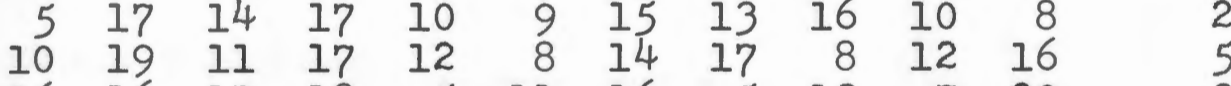

$\begin{array}{rrrrrrrrrrrr}16 & 16 & 17 & 18 & 5 & 11 & 16 & 5 & 13 & 7 & 20 & 3 \\ 1 & 2 & 13 & 4 & 18 & 5 & 17 & 20 & 12 & 9 & 11 & 7\end{array}$

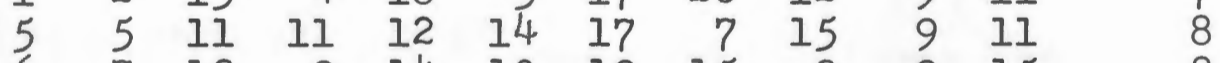

$\begin{array}{llllllllllll}6 & 7 & 13 & 9 & 14 & 10 & 19 & 15 & 9 & 9 & 15 & 8\end{array}$

$\begin{array}{rrrrrrrrrrrr}4 & 5 & 11 & 8 & 10 & 7 & 16 & 11 & 8 & 11 & 9 & 7 \\ 5 & 4 & 9 & 6 & 8 & 12 & 19 & 7 & 12 & 14 & 12 & 7\end{array}$

$\begin{array}{llllllllllll}5 & 4 & 9 & 6 & 8 & 12 & 19 & 7 & 12 & 14 & 12 & ? \\ & 4 & 13 & 7 & 14 & 14 & 17 & 7 & 17 & 15 & 12 & 5\end{array}$

$\begin{array}{rrrrrrrrrrrr}7 & 9 & 8 & 5 & 15 & 6 & 20 & 7 & 11 & 9 & 8 & 17 \\ 2 & 16 & 16 & 17 & 18 & 9 & 15 & 11 & 9 & 16 & 15 & 17 \\ 6 & 1 & 7 & 5 & 7 & 9 & 17 & 13 & 15 & 8 & 12 & 14\end{array}$

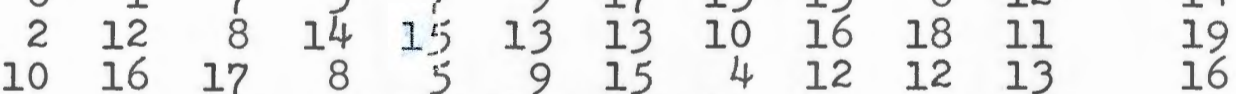

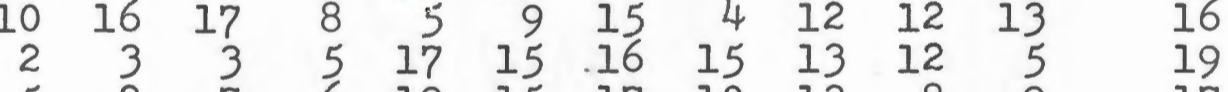

$\begin{array}{rrrrrrrrrrrr}5 & 2 & 7 & 6 & 19 & 15 & 17 & 10 & 13 & 8 & 9 & 17\end{array}$

$\begin{array}{rrrrrrrrrrrr}5 & 10 & 8 & 16 & 8 & 7 & 11 & 15 & 15 & 9 & 7 & 15 \\ 6 & 7 & 10 & 6 & 15 & 6 & 17 & 17 & 11 & 12 & 10 & 14\end{array}$

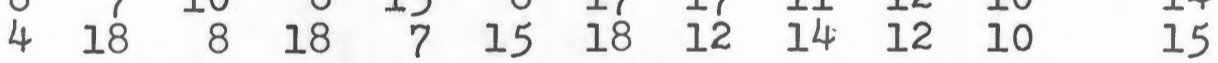

$\begin{array}{llllllllllll}6 & 10 & 8 & 13 & 14 & 11 & 17 & 16 & 16 & 10 & 10 & 19\end{array}$

$\begin{array}{llllllllllll}12 & 8 & 8 & 9 & 8 & 15 & 11 & 8 & 14 & 15 & 10 & 19\end{array}$

$\begin{array}{llllllllllll}4 & 6 & 7 & 15 & 12 & 12 & 18 & 9 & 16 & 10 & 11 & 17\end{array}$

$\begin{array}{llllllllllll}16 & 12 & 10 & 11 & 11 & 14 & 13 & 7 & 17 & 4 & 15 & 14\end{array}$

$\begin{array}{rrrrrrrrrrrr}6 & 12 & 4 & 12 & 2 & 17 & 17 & 5 & 18 & 13 & 14 & 15 \\ 6 & 7 & 11 & 11 & 15 & 13 & 18 & 12 & 13 & 14 & 10 & 15\end{array}$

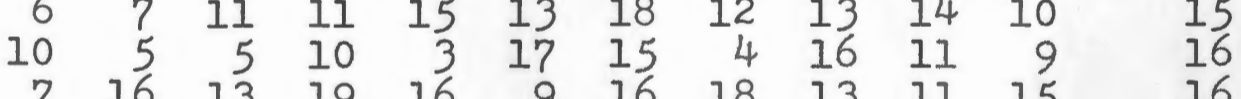

$\begin{array}{llllllllllll}7 & 16 & 13 & 19 & 16 & 9 & 16 & 18 & 13 & 11 & 15 & 16\end{array}$

$\begin{array}{rrrrrrrrrrrr}2 & 9 & 10 & 15 & 13 & 11 & 20 & 15 & 17 & 15 & 9 & 19 \\ 8 & 12 & 7 & 10 & 9 & 14 & 18 & 9 & 14 & 8 & 13 & 14\end{array}$ 
APPENDIX C - SUBJECT BIOGRAPHICAL DATA SHEET 
Code

Name

Age

Height

Weight

Class Standing

Where were you born?

Where were your parents born?

Please list the number and ages of siblings in your family. 
APPENDIX D - POST-EXPERIMENTAL QUESTIONNAIRE 
Post-Experimental Questionnaire

What did you think this experiment was all about?

Please rate the person you met in the waiting room and the one you worked with on the learning task on the following dimensions. These ratings are strictly confidential and will not be seen by the persons you are rating.

\section{Waiting Room Person}

ATTRACTIVENESS

$\begin{array}{lllllll}\text { attractive } & 1 & 2 & 3 & 4 & 5 & \text { unattractive }\end{array}$

SIZE

small

12

34

5

large

STRENGTH

weak

12

34

5

strong

AGGRESSIVITY

passive

1

2

34

5

aggressive

BEARING

$$
\text { friendly }
$$

1

2

3

4

5

unfriendly

\section{Learning Task Person}

ATTRACTIVENESS

attractive $1120 \quad 3 \quad 4 \quad 5$ unattractive

SIZE

small

12

$3 \cdot 4$

5

large

STRENGTH weak

12

34

5

strong

AGGRESSIVITY passive

12

3

4

5

aggressive

BEARING

1

2

3

4

5

unfriendly 
APPENDIX E - WORD LIST 


\section{WORD LIST}

$$
\begin{aligned}
& \text { Blue - House } \\
& \text { White - Yard } \\
& \text { Black - Boat } \\
& \text { Brown - Car } \\
& \text { Pink - Bike }
\end{aligned}
$$

